UNIVERSIDADE DE SÃO PAULO

INSTITUTO DE QUÍMICA

DEPARTAMENTO DE QUÍMICA FUNDAMENTAL

\author{
DETERMINAÇÃO DAS CONSTANTES DE \\ DISSOCIAÇÃO/IONIZAÇÃO DA DI-2-PIRIDIL CETONA \\ BENZOILHIDRAZONA (DPKBH) EM DIFERENTES \\ PORCENTAGENS DE ETANOL
}

\author{
Ivanise Gaubeur \\ Dissertação de Mestrado
}

Profa. Dra. Maria Encarnación Vázquez Suárez Iha

Orientadora

São Paulo

1997 


\section{"Determinação das Constantes de Dissociação/Ionização da Di-2-Piridil Cetona Benzoilhidrazona (DPKBH) em Diferentes Porcentagens de Etanol"}

\section{IVANISE GAUBEUR}

Dissertação de Mestrado submetida ao Instituto de Química da Universidade de São Paulo como parte dos requisitos necessários à obtenção do grau de Mestre em Ciências - Área:Química Analítica.

Aprovado por:

Profa. Dra. MARIA ENCARNACION VAZQUEZ SUAREZ IHA IQ - USP

(Orientadora e Presidente)

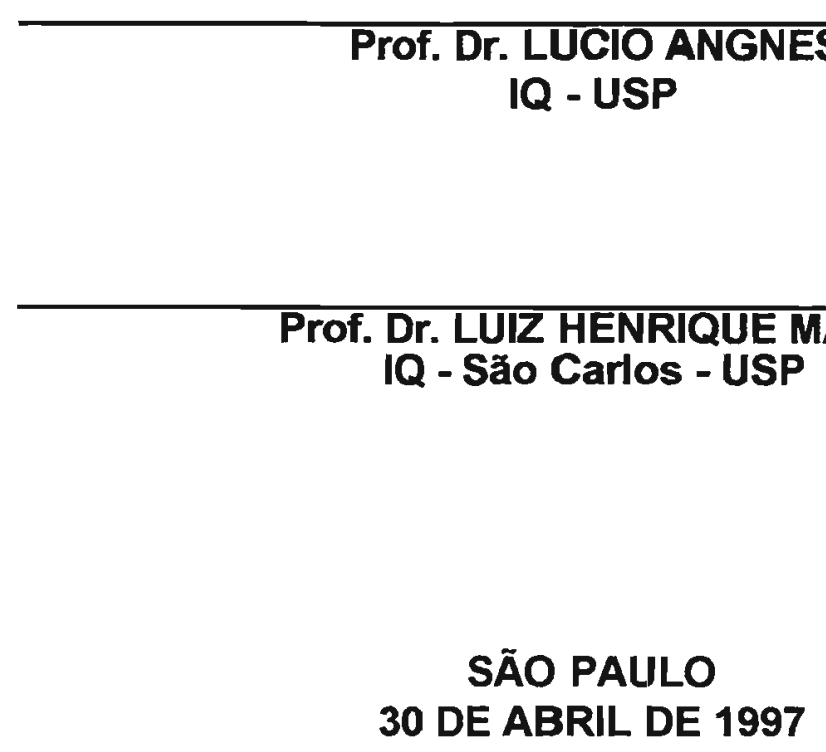


À minha mãe ERINA

$"(\ldots)$

De forçar coração, nervos,

músculos, tudo, a dar, seja o que

for, que neles ainda existe, e a

persistir assim quando, exaustos,

contudo resta a vontade em $t i$, que

ainda ordena: persiste!

$(\ldots) "$

(Rudyard Kipling) 
Aos meus irmãos que sempre estiveram presentes dando apoio, carinho...

Aos meus queridos sobrinhos por alegres convívios e inesquecíveis recordações da infância. 
À Profa. Dra Maria Encarnación V. Suárez Iha, toda a minha gratidão pela orientação sábia e humana, pela confiança, amizade, apoio e infindáveis ensinamentos registrados nessa dissertação e na minha vida. 
À Profa. Dra. Márcia Guekezian, dedicada amiga, pelo incentivo diário e inestimável apoio durante o desenvolvimento dessa dissertação. 


\section{AGRADECIMENTOS}

À Profa. Dra Maura V. Rossi, pela co-orientação e por todo apoio na minha iniciação científica.

Ao Prof. Dr Koshun Iha pela descoberta de artigos muito interessantes que trouxeram valiosas informações.

À Cristiane F. Fernandes Lopes por toda ajuda durante o meu mestrado e pela alegre convivência.

À Madalena C. Areias por ter me ajudado a fazer o glossário e pela alegre convivência.

À Lúcia Helena de Ávila Terra por ser uma grande amiga do dia a dia.

Ao grupo LABEQ: Cristiane, Lúcia, Madalena, Márcia, Milton e Sílvio pelas valiosas discussões e colaboração recíproca.

À Margareth por ter sido solidária me emprestando o peagômetro.

À Kathy Cazeli Arenas por ter me incentivado a procura de mais conhecimentos no mundo da Química.

À Dora e a Marlene pela ajuda e colaboração.

Aos demais Professores, Pós-Graduandos e Funcionários da Química Analítica que de alguma forma contribuíram para a realização deste trabalho.

Ao CNPQ e FAPESP, pelo apoio financeiro 


\section{SUMÁRIO}

PÁGINA

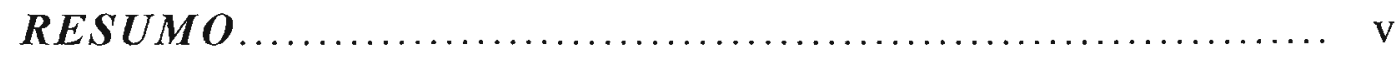

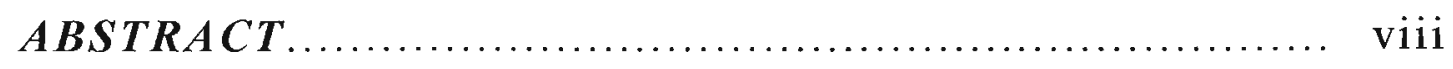

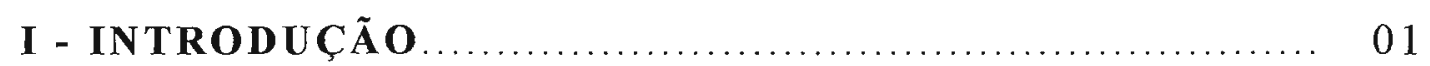

II - ALGUNS ASPECTOS DAS HIDRAZONAS E SUAS

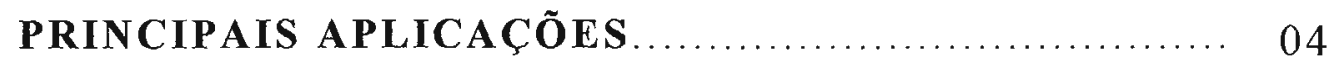

II. 1 - Aspectos Gerais................................. 05

II.2 - Nomenclatura..................................... 06

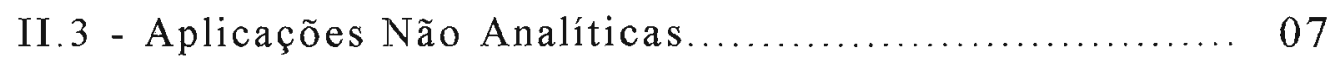

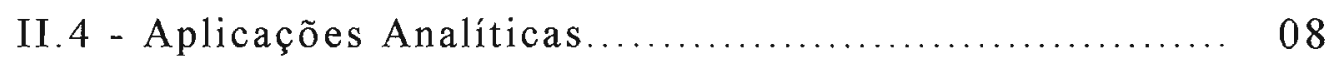

\section{III- DI-2-PIRIDIL CETONA BENZOILHIDRAZONA}

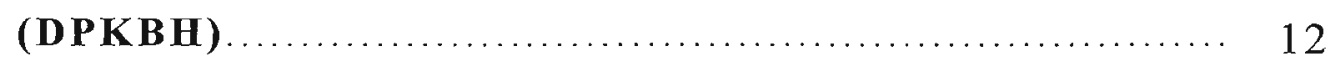

III. 1 - Di-2-Piridil Cetona Benzoilhidrazona (DPKBH).... 13

III.2 - Algumas Aplicações Analíticas do DPKBH.......... 15

III.3 - Equilíbrios Químicos Envolvendo DPKBH.......... 19 


\section{IV - ALGUNS ASPECTOS SOBRE O ESTUDO DE}

CONSTA NTES DE DISSOCIAÇÃO/IONIZAÇÃO.

IV. 1 - Aspectos Gerais.

IV.2 - Métodos Utilizados para Determinação das

Constantes

IV.2.1 - Método Condutométrico 28

IV.2.2 - Método Potenciométrico.

IV.2.3 - Método Espectrofotométrico

V-ASPECTOS DAS MEDIDAS POTENCIOMÉTRICAS (pH) 40

V.1 - Eletrodo de Vidro. 41

V.2 - Calibração do Sistema de Medida. 45

V.3 - Fatores de Correção Utilizados nas Medidas de pH em Meio Não Aquoso e na Mistura de Solventes...

VI-PARTE EXPERIMENTAL E TRATAMENTO DE DADOS 58

VI.1 - Reagentes, Equipamentos e Acessórios. 59

VI.2 - Limpeza da Vidraria............................. 60

VI.3 - Síntese do DPKBH, ................................. 62

VI.4 - Determinação do Fator de Resposta ("Slope") do Eletrodo de Vidro 
VI.5 - Determinação das Constantes de Dissociação/ Ionização em 10, 19, 29 e $48 \%$ de Etanol pelo 64 Método Potenciométrico

VI.6 - Determinação das Constantes de Dissociação/ Ionização em 10 e $48 \%$ de Etanol pelo Método Espectrofotométrico

VII - RESULTADOS EXPERIMENTAIS 76

VII. 1 "Slope" do Eletrodo de Vidro em 10, 19, 29 e $48 \%$ de Etanol

VII.2- Determinação Potenciométrica das Constantes de Dissociação/Ionização.

VII.2.1 - Obtenção da constante de dissociação $\left(\mathrm{K}_{1}\right)$ em $10,19,29$ e $48 \%$ de Etanol.

VII.2.2 - Obtenção da constante de ionização $\left(\mathrm{K}_{2}\right)$ em 10,19,29 e $48 \%$ de Etanol

VII. 3 - Determinação Espectrofotométrica das Constantes de Dissociação/Ionização

VII.3.1-Determinação das Constantes de Dissociação/Ionização do DPKBH em 10 e $48 \%$ de de Etanol 
VII.3.1.1-Determinação dos Espectros de Absorbância do DPKBH nas Formas Envolvidas nos Equilíbrios

VII.3.1.2-Determinação do "Slope" em 10 e $48 \%$ de Etanol

VII.3.2 - Obtenção do $K_{2}$ em 10 e $48 \%$ de Etanol. 102

VII.3.3 - Obtenção do $K_{1}$ em 10 e $48 \%$ de Etanol. 109

VII.4 - Estudos Referentes à Protonação do DPKBH

VIII - DISCUSSÕES E CONCLUSÕES

IX - PERSPECTIVAS FUTURAS

GLOSSÁRIO 
RESUMO 
A di-2-piridil cetona benzoilhidrazona (DPKBH) é um reagente solúvel em uma série de solventes orgânicos mas pouco solúvel em água. Vem sendo utilizado para a determinação de metais, (principalmente do grupo de transição) como Fe(II), Fe(III), Ni(II), $\mathrm{Cu}(\mathrm{II})$, entre outros e como ligante de referência para estudar o comportamento dos íons $\mathrm{Fe}(\mathrm{II})$ e $\mathrm{Fe}(\mathrm{III})$ em presença de espécies orgânicos encontrados em águas naturais.

Com o objetivo de entender melhor as propriedades do DPKBH em meio de etanol, foi necessário determinar as constantes de dissociação/ionização em diferentes porcentagens desse solvente orgânico $(10,19,29$ e $48 \%)$. Nestas porcentagens de etanol, através de medidas absolutas de $\mathrm{pH}$ determinaram-se os $\mathrm{pKs}$ do DPKBH utilizando-se a técnica potenciométrica e em 10 e $48 \%$ de etanol através de medidas absolutas de $\mathrm{pH}$ associadas às absorbâncias das espécies presentes nos equilíbrios, utilizando-se a técnica espectrofotométrica. Nas devidas porcentagens de etanol, o comportamento do eletrodo foi previamente determinado.

Os valores de $\mathrm{pK}_{1} 3,210 ; 3,342 ; 3,398$ e 3,360 e de $\mathrm{pK}_{2}$ 10,$834 ; 11,013 ; 11,793$ e 11,382 foram obtidos respectivamente 
para $10,19,29$ e $48 \%$ de etanol, utilizando-se a técnica potenciométrica. Através da técnica espectrofotométrica os valores de $\mathrm{pK}_{1}$ foram 3,257 e 3,322 e $\mathrm{pK}_{2} 10,880$ e 11,820 , em 10 e $48 \%$ de etanol, respectivamente. 
ABSTRACT 
The di-2-pyridyl ketone benzoylhydrazone (DPKBH) is a soluble reagent in different organic solvents but slightly soluble in water. It has been used for metal determinations, (mainly transition metals) such as for $\mathrm{Fe}$ (II), $\mathrm{Fe}(\mathrm{III}), \mathrm{Ni}(\mathrm{II}), \mathrm{Cu}(\mathrm{II})$ and also like a reference ligand to study the behavior of $\mathrm{Fe}(\mathrm{II})$ and $\mathrm{Fe}$ (III) ions in the presence of organic species found in natural waters.

So as to better understand the DPKBH properties in ethanol, it was necessary to determine the dissociation/ionization constant in different percentages of ethanol $(10,19,29$ and $48 \%)$. In these ethanol percentages, through absolute $\mathrm{pH}$ measurements, $\mathrm{pKs}$ of DPKBH could be the found by using the potentiometric technique, and in 10 and $48 \%$ of ethanol the pKs of DPKBH were determined with $\mathrm{pH}$ measurements associated to absorbance of the species present in the equilibria by using the spectrophotometric technique. In appropiate percentage of ethanol the behavior of the glass electrode was previously determined.

The $\mathrm{pK}_{1}$ values $3.210 ; 3.342 ; 3.398$ and 3.362 , and $\mathrm{pK}_{2}$ $10.834 ; 11.013 ; 11.793$ and 11.382 were found for $10,19,29,48 \%$ 
of ethanol, by using the potentiometric technique. The spectrophotometric technique led to $\mathrm{pK}_{1}$ values 3.257 and 3.322 , and the $\mathrm{pK}_{2}$ ones 10.880 and 11.820 in 10 and $48 \%$ of ethanol respectively. 


\section{I - INTRODUÇÃO}




\section{I - INTRODUÇÃO}

A di-2-piridil cetona benzoilhidrazona (DPKBH) foi inicialmente sintetizada por Nakanishi e Otomo ${ }^{(1)}$ e Garcia-Vargas et $\mathrm{al}^{(2)}$. Este reagente pertence ao grupo das aroilhidrazonas que são caracterizadas pelo grupo triatômico $\mathrm{C}=\mathrm{N}-\mathrm{N}$, e pode ser facilmente preparado a partir da aroilhidrazona e o derivado carbonílico (benzoilhidrazina e di-2-piridil cetona) em um solvente adequado. É solúvel em uma série de solventes orgânicos mas pouco solúvel em água(2).

DPKBH foi utilizado pelo grupo de Hoffmann na determinação simultânea de $\mathrm{Fe}(\mathrm{II})$ e $\mathrm{Fe}(\mathrm{III})$ em amostras de água de chuva ${ }^{(3,4)}$. Este mesmo reagente vem sendo utilizado como ligante de referência para estudar o comportamento dos íons $\mathrm{Fe}$ (II) e Fe(III) em presença de ligantes orgânicos, como acetato e formiato, além de oxalato, sulfato e S(IV).

Para complementação de alguns estudos sobre o DPKBH, este trabalho tratou da determinação das constantes de dissociação/ionização do DPKBH em diferentes porcentagens de etanol $(10,19,29$ e $48 \% \mathrm{~V} / \mathrm{V})$, em condições semelhantes às utilizadas na determinação das constantes de estabilidade dos complexos de $\mathrm{Fe}(\mathrm{II})$ e Fe(III) com DPKBH${ }^{(5)}$. 
As constantes de dissociação ácida, $\mathrm{K}_{1}$, e ionização, $\mathrm{K}_{2}$, em $10,19,29$ e $48 \%$ de etanol foram determinadas utilizandose a técnica potenciométrica, fazendo-se titulações de DPKBH com $\mathrm{HClO}_{4}$ e $\mathrm{NaOH}$, e em 10 e $48 \%$ de etanol por espectrofotometria, medindo-se a absorbância de soluções de DPKBH em diversos valores de pH. A utilização das técnicas potenciométrica e espectrofotométrica, neste trabalho, permite tanto a comparação dos valores das constantes quanto a avaliação da eficiência de cada técnica e, assim, a obtenção de resultados mais precisos e confiáveis.

Com o intuito de estudar a interação existente entre a molécula de $\mathrm{DPKBH}$ e o $\mathrm{HClO}_{4}$ no processo de protonação do DPKBH, titulações condutométricas foram efetuadas em $10 \%$ de etanol. 
II - ALGUNS ASPECTOS DAS HIDRAZONAS E SUAS PRINCIPAIS APLICAÇÕES 


\section{II.1 - Aspectos Gerais}

Hidrazonas são azometinas caracterizadas pela presença do grupo triatômico $=\mathrm{C}=\mathrm{N}-\mathrm{N}^{(6)}$. São diferenciadas dos outros membros desta classe (iminas, oximas e outras) devido à presença de dois átomos de nitrogênio interligados. O grupo hidrazona ocorre em compostos orgânicos do tipo:<smiles>[X]C([R])=NN([R])[Y]</smiles>

onde $R, R^{\prime}, X$ e $Y$ podem ser iguais a $H$, alcanos, $R C O$, grupos heterocíclicos. O nome geral "hidrazonas" é usado para todos os compostos que apresentam a estrutura geral (I) ${ }^{(7)}$.

As hidrazonas podem ser consideradas azometinas carbonílicas e, em geral, são sintetizadas fazendo-se refluxo de quantidades estequiométricas da hidrazina apropriada misturada a um aldeído ou cetona, dissolvido em um solvente adequado. O composto é cristalizado em soluções resfriadas e recristalizado a 
partir de solvente adequado. Muitas hidrazonas são comercialmente disponíveis ${ }^{(6)}$.

Podem apresentar-se em equilíbrio tautomérico envolvendo as formas enólica e cetônica, conforme observa-se a seguir:<smiles>[R]C(=O)NN=C([R])[R]</smiles>

Estes ligantes formam compostos de coordenação através do átomo de oxigênio do grupo carbonila ou na maioria das vezes do grupo enólico. Complexos neutros de metais são formados em muitos casos, quando o ligante se coordena na forma de ânion. Aroilhidrazonas podem ainda atuar como ligantes tri, tetra ou pentadentados quando $R_{1}, R_{2}$ e/ou $R_{3}$ apresentam um átomo doador em posição apropriada ${ }^{(2)}$.

\section{II.2 - Nomenclatura}

Hidrazonas são usualmente nomeadas a partir do composto carbonila do qual são derivadas. Por exemplo, o 
composto sintetizado a partir da reação de benzaldeído com fenilhidrazina é denominado benzaldeído fenilhidrazona ${ }^{(7)}$. O ligante, objeto deste trabalho, sintetizado a partir da di-2-piridil cetona e da benzoilhidrazina é denominado di-2-piridil cetona benzoilhidrazona.

\section{II.3 - Aplicações Não Analíticas}

Algumas hidrazonas têm sido aplicadas no tratamento de várias doenças como tuberculose, leprose, leucemia, sarcomas e outros neoplasmas malignos, apresentando assim muitas atividades terapêuticas. Isto é atribuído ao fato de formarem complexos estáveis com metais de transição presentes na célula e assim inviabilizar algumas reações enzimáticas vitais catalisadas por estes metais ${ }^{(6-8)}$.

Atuam também como herbicidas, inseticidas, nematocidas, rodenticidas e reguladoras do crescimento de plantas. Hidrazonas de 2-metilftalazona são eficientes esterelizantes para uso doméstico ${ }^{(9)}$. São usadas como plastificantes e estabilizantes para polímeros, iniciantes da polimerização, antioxidantes entre outros ${ }^{(7)}$. 


\section{II.4 - Aplicações Analíticas}

Diversas são as aplicações analíticas das hidrazonas. Além de um "review" datado de $1975^{(6)}$ contendo 82 citações, tem-se disponível um "review" mais completo de $1982^{(7)}$, contendo 198 referências. Para as décadas de 60 e 70 são citadas 62 e 103 referências, respectivamente, o que demonstra a crescente utilização das hidrazonas em relação à década de 50 , com apenas 8 citações. Na década de 80 são 277 citações e nos anos de 1991 a 1996 têm-se 103 citações.

Em Química Analítica hidrazonas encontram aplicação na deteç̧ão, determinação e isolamento de compostos contendo o grupo carbonila ${ }^{(10,11)}$. Terent'ev e Andreeva(11) utilizaram a 2,4dinitro fenilhidrazina em meio aquoso e não aquoso em soluções ácidas, alcalinas e neutras para determinação total dos compostos carbonilas. Relacionaram a quantidade do composto carbonila com a diminuição de absorbância em um comprimento de onda de 320 $\mathrm{nm}$, onde a hidrazona apresenta um máximo.

As hidrazonas têm sido extensamente utilizadas na detecção e determinação de muitos metais (principalmente do grupo de transição) formando complexos coloridos ${ }^{(6,7)}$ e entre os métodos utilizados destacam-se os colorimétricos ou 
fluorimétricos. A potencialidade das aroilhidrazonas como agentes de pré-concentração em processos de extração líquido-líquido para vários íons metálicos a nível de traços tem sido estudada ${ }^{(2)}$.

Algumas hidrazonas, bem como suas principais aplicações ${ }^{(12-24)}$ estão apresentadas na Tabela I, onde a maioria das interações metal/ligante é estudada pelo método espectrofotométrico.

Entre outras potencialidades das hidrazonas tem-se a utilização destas como indicadores ácido-base. Hirsch ${ }^{(25)}$, baseando-se na reação entre a ditizona e o chumbo, utilizou como indicador o complexo vermelho formado. O ponto final foi então determinado em titulações ácido-base. Cameron e Gibson ${ }^{(18,19)}$ propuseram a utilização de certos complexos entre ligantes tridentados como o piridina-2-aldeído 2-piridilhidrazona (PAPHY) e íons metálicos como $\mathrm{Cu}(\mathrm{II}), \mathrm{Fe}(\mathrm{II}), \mathrm{Ni}(\mathrm{II}), \mathrm{Cd}(\mathrm{II})$ e $\mathrm{Zn}$ (II) como indicadores em titulações ácido-base, como por exemplo ácido clorídrico com hidróxido de sódio. Compostos cationnicos, tais como $\left[\mathrm{Ni}(\mathrm{PAPHY})_{2}\right]^{2+}$, podem ser desprotonados no grupo imino com adição de álcalis provocando o aparecimento de intensa coloração pela formação de complexos neutros [Ni(PAPY) 2 ]. As faixas de transição dos indicadores variam de acordo com o metal, sendo 4,4-6,8 para o $\mathrm{Cu}(\mathrm{II})$ (amarelo pálido para amarelo), 5, 6-8,2 
para o $\mathrm{Fe}(\mathrm{II})$ (rosa para amarelo), 6,4-9,5 para o $\mathrm{Ni}(\mathrm{II})$ (incolor para amarelo), 6,7-9,8 para o $\mathrm{Zn}(\mathrm{II})$ (incolor para amarelo) e 7,810,4 para o $\mathrm{Cd}(\mathrm{II})$ (incolor para amarelo) ${ }^{(6,7)}$.

Tabela I - Principais aplicações analíticas de algumas hidrazonas ${ }^{(6,7)}$

\begin{tabular}{|c|c|}
\hline Aroilhidrazonas & Aplicações \\
\hline bisciclohexanona oxalilhidrazona & $\begin{array}{l}\text { Cu(II) em polpa de papel, } \\
\text { soro humano, plantas, } \\
\text { metais, ligas não ferrosas } \\
\text { e sulfeto de cádmio }\end{array}$ \\
\hline $\begin{array}{c}\text { piridina-2-aldeído 2-piridilhidrazona } \\
\text { (PAPHY) }\end{array}$ & $\begin{array}{l}\text { indicador ácido-base } \\
\mathrm{Cu}(\mathrm{II}) \text { em alimentos } \\
(20)\end{array}$ \\
\hline $\begin{array}{c}\text { 2,2'-bipiridil 2-piridilhidrazona } \\
(\mathrm{BPPH})\end{array}$ & $\begin{array}{l}\text { Co (II) em água do mar e } \\
\text { salmoura }\end{array}$ \\
\hline 2-benzoilpiridina 2-piridilhidrazona & $\begin{array}{lll}\mathrm{Fe}(\mathrm{II}), \quad \mathrm{Co}(\mathrm{II}), & \mathrm{Ni}(\mathrm{II}) & \mathrm{e} \\
\mathrm{Zn}(\mathrm{II}) & \end{array}$ \\
\hline $2,2^{\prime}$-dipiridil cetona hidrazona & $\mathrm{Hg}(\mathrm{II})$ e $\mathrm{Cu}(\mathrm{II})^{(23)}$ \\
\hline di-2-piridil cetona 2-tiofenoilhidrazona & $\operatorname{Co}(\mathrm{II})^{(24)}$ \\
\hline
\end{tabular}


Libergott et $\mathrm{al}^{(26)}$ exploraram a utilização das hidrazonas como reagentes de "spot-test", utilizando a piruvilidina-2-hidrazina-benzotiazol, para a determinação de cádmio em ligas metálicas. Em meio alcalino na presença de cádmio desenvolve-se um precipitado laranja, com alta sensibilidade e seletividade, pois metais como $\mathrm{Al}, \mathrm{Sb}$ e $\mathrm{Cr}$ entre outros não interferem.

Devido ao grande número de complexos formados entre as hidrazonas e os metais, as constantes de estabilidade de alguns destes tem sido determinadas, como é o caso dos complexos formados por piridina-2-aldeído-2-piridilhidrazona (PAPHY) com cobre(II), zinco(II), cádmio(II), manganês(II), ferro(II) e níquel(II) ${ }^{(27,28)}$.

Há publicações também sobre análises gravimétricas envolvendo hidrazonas, por exemplo uma solução etanólica de resacetofenona fenilhidrazona precipita cobre(II) quantitativamente a partir de soluções amoniacais, sem rígido controle das condições experimentais; além disso, acima de $32 \mathrm{mg}$ o cobre(II) pode ser determinado na presença de cádmio(II) ${ }^{(29)}$, frequente interferente em amostras de cobre. 


\section{III - DI-2-PIRIDIL CETONA}

\section{BENZOILHIDRAZONA (DPKBH)}


III.1 - Di-2-piridil cetona benzoilhidrazona (DPKBH)

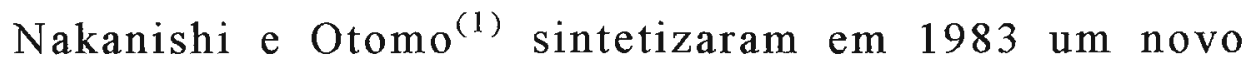
ligante hidrazona, di-2-piridil cetona benzoilhidrazona (DPKBH), através da interação entre a di-2-piridil cetona e a benzoilhidrazina.

Este composto sintetisado apresenta fórmula molecular $\mathrm{C}_{18} \mathrm{H}_{14} \mathrm{~N}_{4} \mathrm{O}$, massa molar igual a 304,32 g. mol $^{-1}$ e ponto de fusão entre $130-132^{\circ} \mathrm{C}$. Sua fórmula estrutural é apresentada na Figura 1.

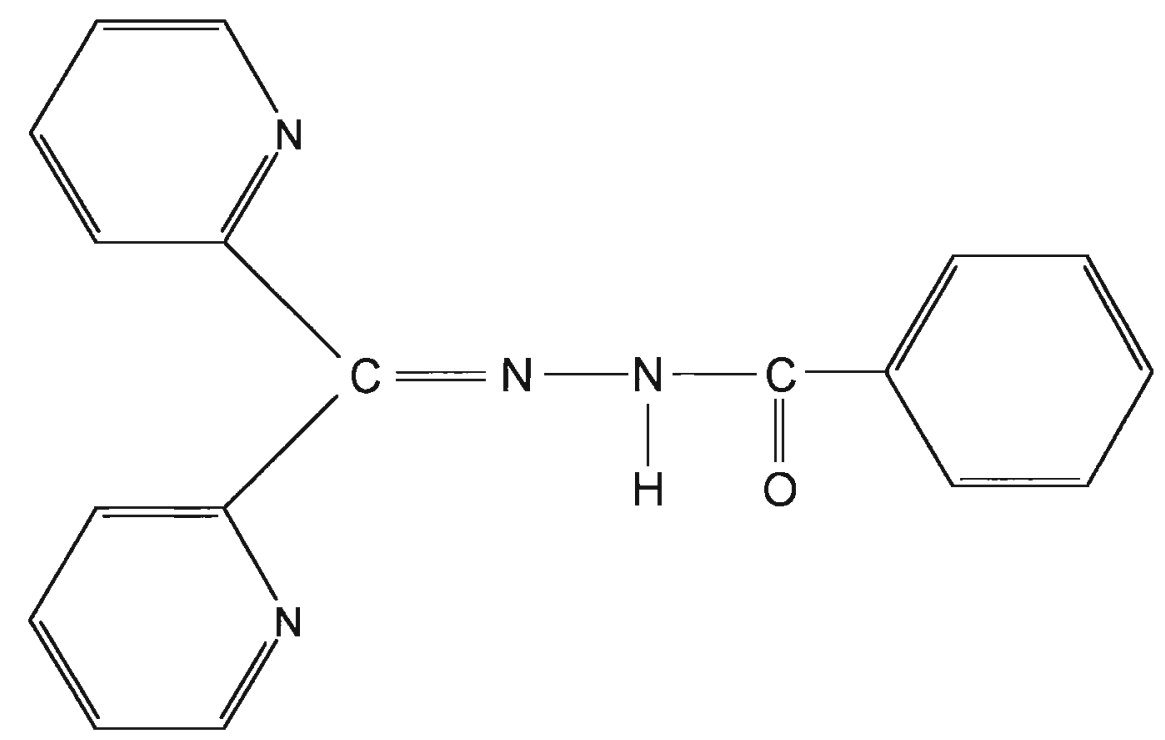

Figura 1 - Fórmula estrutural do DPKBH. 
Garcia-Vargas et $a l^{(2)}$ caracterizaram este ligante e obtiveram o espectro de infravermelho, que apresentou bandas em $3.000,1.684,1.500,1.325$ e $1.267 \mathrm{~cm}^{-1}$ características dos grupos $\mathrm{N}-\mathrm{H}, \mathrm{C}=\mathrm{O}, \mathrm{C}=\mathrm{N}$ e dos anéis aromáticos ${ }^{(5)}$. A solubilidade em diferentes solventes e a reatividade desta aroilhidrazona com íons metálicos em diversos valores de $\mathrm{pH}$ foram também apresentadas.

DPKBH é um material cristalino solúvel em vários solventes orgânicos, mas pouco solúvel em água. A Tabela II apresenta sua solubilidade em diversos solventes. É estavel em etanol por no mínimo 30 dias e outros solventes orgânicos por no mínimo duas semanas.

Tabela II - Valores de solubilidade do DPKBH em diferentes solventes ${ }^{(2)}$

SOLVENTE SOLUBILIDADE $(\mathrm{g} / \mathrm{L})$

Água 0,20

Dimetilformamida 87,6

Etanol 15,2

Clorofórmio 50,0

Benzeno 15,6 
Agentes redutores (sulfato de hidrazina, ácido ascórbico) presentes em concentração $0,1 \% \mathrm{~m} / \mathrm{v}$ tem pouco efeito sobre a estabilidade do reagente, no entanto, peróxido de hidrogênio em concentrações análogas causa mudanças no espectro destes compostos. Este efeito é maior na presença da solução tampão de borato, ou seja valor de pH próximo a 9,0 .

\section{III.2 - Algumas Aplicações Analíticas do DPKBH}

O DPKBH assim como outras hidrazonas substituídas apresentam grandes potencialidades para determinar traços de íons metálicos, principalmente os de transição. Pode comportar-se como um ligante bi ou tri-dentado e foi já utilizado na determinação de metais, como ferro ${ }^{(1,3-5,30)}$, paládio ${ }^{(31)}$, cobalto ${ }^{(24,32,33)}$, níquel $^{(34)}$ e cobre(II) ${ }^{(35)}$.

O DPKBH foi utilizado para a determinação espectrofotométrica de traços de ferro(II) fazendo-se uma préconcentração através da extração dos complexos com benzeno. Tem-se formação de complexo verde, Ferro(II)/DPKBH, que apresenta dois máximos de absorbância em 379 e 686 nm. A lei de Beer é obedecida na faixa de 0-30 $\mu \mathrm{g}$ de ferro em $10 \mathrm{~mL}$ de benzeno em $686 \mathrm{~nm}$. Neste comprimento de onda, a absortividade 
molar do complexo é $1,59 \cdot 10^{4} \mathrm{~L} \cdot \mathrm{mol}^{-1} \cdot \mathrm{cm}^{-1}$. O desvio padrão relativo nas determinações a nível de $16,8 \mu \mathrm{g}$ de ferro foi de 0,40 $\%$, com medidas de absorbância em $686 \mathrm{~nm}$. O método proposto é relativamente seletivo para ferro(II) e é satisfatoriamente aplicado para a determinação de ferro total em águas naturais ${ }^{(1)}$.

Zatar et al ${ }^{(30)}$ desenvolveram um método espectrofotométrico para a determinação simultânea de ferro total, ferro(II) e ferro(III) em misturas contendo outros íons metálicos em $50 \%(\mathrm{~V} / \mathrm{V})$ de solução etanólica. O complexo ferro (II) com DPKBH apresenta dois máximos de absorbância em 360 e $650 \mathrm{~nm}$, enquanto o complexo de ferro(III) apresenta somente um máximo em $360 \mathrm{~nm}$. As leis de Beer são obedecidas na faixa de 0,1$2 \mu \mathrm{g} \cdot \mathrm{mL}^{-1}$ e $0,4-5 \mu \mathrm{g} \cdot \mathrm{mL}^{-1}$ para complexos de ferro (II) e ferro(III) em $360 \mathrm{~nm}$ e $650 \mathrm{~nm}$, respectivamente. Complexos com o Fe(III) apresentaram resultados similares aos obtidos para complexos com Fe(II) em $360 \mathrm{~nm}$.

A determinação colorimétrica simultânea de ferro(II) e ferro(III) em águas de nuvens, utilizando DPKBH, foi desenvolvida por Pehkonen et $\mathrm{al}^{(3)}$. Estabeleceu-se o limite de deteç̧ão espectrofotométrica de $4 \mathrm{nM}$ para ambos, ferro(II) e ferro(III), com uma resposta linear na faixa entre $4 \mathrm{nM}$ e $0,1 \mu \mathrm{M}$. Este limite foi determinado para amostras extraídas com 
clorofórmio. O complexo formado em etanol-água, sem o processo de extração portanto, apresentou resposta linear de 0,1 até $30 \mu \mathrm{M}$. O coeficiente de absortividade molar dos complexos

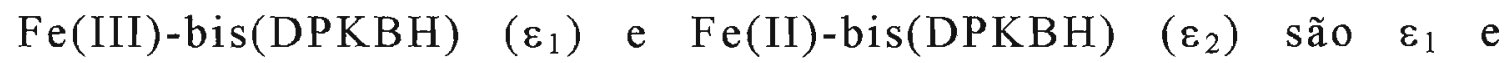
$\varepsilon_{2}=3,6 \cdot 10^{4} \mathrm{~L} \cdot \mathrm{mol}^{-1} \cdot \mathrm{cm}^{-1}$ em $370 \mathrm{~nm}$ e $\varepsilon_{2}=1,1 \cdot 10^{4} \mathrm{~L} \cdot \mathrm{mol}^{-1} \cdot \mathrm{cm}^{-1}$ em $660 \mathrm{~nm}$.

Devido à grande importância da determinação de ferro com DPKBH e a fim de complementar estes estudos, Suárez-Iha et al ${ }^{(5)}$ estudaram a estequiometria e a estrutura dos complexos de $\mathrm{Fe}$ (II) e Fe(III) com DPKBH em soluções áquo-etanólicas $50 \%$ em pH 5,3 e $25^{\circ} \mathrm{C}$. Utilizando o método espectrofotométrico obtiveram as constantes de formação dos complexos $\beta_{1}$ e $\beta_{2}$ para as espécies $1: 1$ e $1: 2$, respectivamente, dos complexos $\mathrm{Fe}^{\mathrm{n}+} / \mathrm{DPKBH}$ :

$\mathrm{Fe}(\mathrm{III}) / \mathrm{DPKBH} \quad \mathrm{Fe}(\mathrm{II}) / \mathrm{DPKBH}$
$\beta_{1}\left(\mathrm{~L} \cdot \mathrm{mol}^{-1}\right)$
$4,693 \cdot 10^{6}$
$1,217.10^{5}$
$\beta_{2}\left(\mathrm{~L} \cdot \mathrm{mol}^{-1}\right)$
$2,195 \cdot 10^{10}$
$7,814 \cdot 10^{9}$

Titulações conduto e potenciométricas indicaram que DPKBH coordena preferencialmente como um ânion, enquanto análise por infravermelho mostrou que DPKBH existe na forma 
enólica e encontra-se provavelmente coordenado como ligante tridentado.

A determinação espectrofotométrica do paládio(II) com DPKBH foi estudada por Nakanishi e Otomo ${ }^{(31)}$. Este método é baseado na formação de um complexo paládio(II)-DPKBH que é extraído com benzeno a partir de soluções de ácido sulfúrico na presença de íons cloreto. As espécies extraídas tem máximos de absorção em 455 e $481 \mathrm{~nm}$ com absortividade molar de $9,38 \cdot 10^{3} \mathrm{~L} \cdot \mathrm{mol}^{-1} \cdot \mathrm{cm}^{-1}$ em $455 \mathrm{~nm}$. A lei de Beer é obedecida na faixa de 0-10 $\mu \mathrm{g} \cdot \mathrm{mL}^{-1}$ de paládio em $455 \mu \mathrm{nm}$. Este método é seletivo na presença de ácido tartárico ou cítrico e tem sido satisfatoriamente aplicado à determinação de paládio em ligas metálicas e em amostras catalisadas por paládio.

Em ligas contendo cobalto(II) e outros íons metálicos aquele foi determinado espectrofotometricamente por complexação com DPKBH em soluções $50 \%(\mathrm{~V} / \mathrm{V})$ de etanol. Cobalto(II) forma um complexo 1:2 com DPKBH, que apresenta o máximo de absorbância em $370 \mathrm{~nm}$. A lei de Beer é obedecida na faixa de $0,1-2,8 \mu \mathrm{g} \cdot \mathrm{mL}^{-1(24)}$.

Rossi et $\mathrm{al}^{(33)}$, a fim de obter maiores informações sobre as propriedades termodinâmicas dos complexos de cobalto (II) e DPKBH e para o desenvolvimento de métodos de especiação 
para o cobalto, determinaram através de método espectrofotométrico as constantes de formação dos complexos em solução de etanol $50 \%$ (V/V), pH 5,3 e a $25^{\circ} \mathrm{C} . \quad$ Os valores de $\beta_{1}$ e $\beta_{2}$ são $5,305.10^{6} \quad \mathrm{M}^{-1}$ e $8,476.10^{10} \quad \mathrm{M}^{-2}$, respectivamente. A absortividade molar para o complexo $1: 1$ é de $4,475 \cdot 10^{3} \mathrm{~L} \cdot \mathrm{mol}^{-1} \cdot \mathrm{cm}^{-1}$ e para a espécie $1: 2$ é de $2,994 \cdot 10^{4} \mathrm{~L} \cdot \mathrm{mol}^{-1} \cdot \mathrm{cm}^{-1}$.

Um método espectrofotométrico para a determinação de Ni(II) em amostras de várias fontes foi desenvolvido por Terra et $\mathrm{al}^{(34)}$. DPKBH foi usado em excesso para coordenar o Ni(II) e uma sensibilidade maior foi obtida em soluções de etanol $50 \%(\mathrm{~V} / \mathrm{V})$, quando tampão de acetato de amônio foi adicionado para manter $\mathrm{pH}=6,0$. Uma relação linear foi observada entre absorbância e concentração de níquel com coeficiente de correlação de 0,997. A faixa favorável para determinação de níquel é de $8,50 \cdot 10^{-7}$ até $1,72 \cdot 10^{-5}$ mol. $L^{-1}$.

\section{III.3 - Equilíbrios Químicos Envolvendo o DPKBH}

Para melhor visualização dos equilíbrios envolvendo o DPKBH, a fórmula estrutural apresentada anteriormente na Figura 1 pode ser escrita como: 


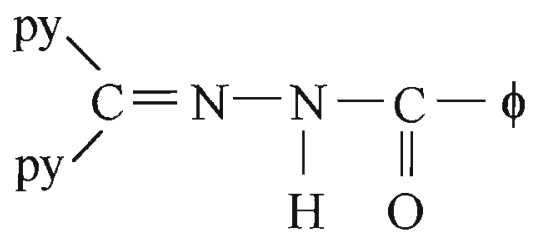

Um equilíbrio de dissociação, representado a seguir, pode ser considerado a partir da protonação de uma das piridinas da molécula:

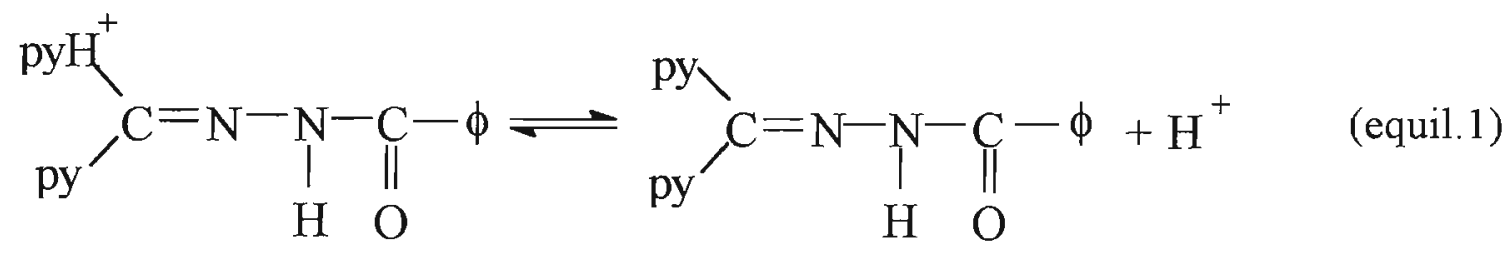

Ao equilíbrio 1 atribui-se então uma constante de dissociação, aqui representada por $\mathrm{K}_{1}$.

Em solução, DPKBH apresenta equilíbrio tautomérico $^{(2)}$ entre as formas cetônica e enólica, conforme representado abaixo:

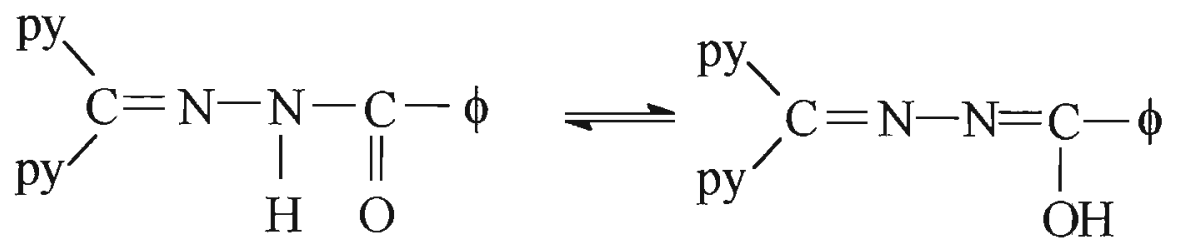


A partir da forma enólica pode-se, então, considerar um segundo equilíbrio:
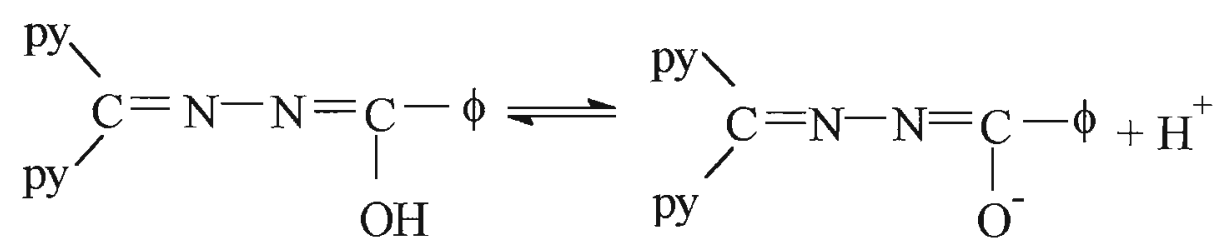

(equil.3)

cuja distribuição é determinada pela constante de ionização do $\operatorname{DPKBH}\left(\mathrm{K}_{2}\right)$.

Na literatura encontra-se que o DPKBH apresenta

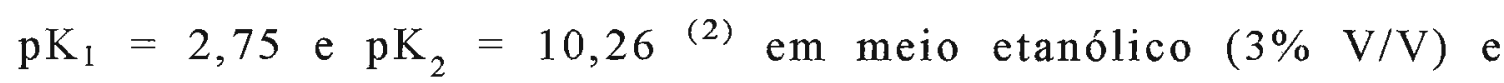
$\mathrm{pK}_{1}=3,25$ e $\mathrm{pK}_{2}=10,51^{(1)} \mathrm{em}$ meio de etanol $10 \% \mathrm{~V} / \mathrm{V}$. Nos artigos citados, os valores de $\mathrm{pK}$ foram determinados através de medidas espectrofotométricas a $25^{\circ} \mathrm{C}$ e em força iônica $0,1 \mathrm{~mol} . \mathrm{L}^{-1}$. 


\section{IV- ALGUNS APECTOS SOBRE O ESTUDO DE CONSTANTES DE DISSOCIAÇÃO / IONIZAÇÃO}




\section{IV.1 - Aspectos Gerais}

As constantes de dissociação/ionização representam a força de um ácido ou de uma base, além disso expressam as diferentes proporções de espécies iônicas que uma substância pode apresentar em um determinado valor de $\mathrm{pH}$.

A amônia, por exemplo, pode complexar-se com vários metais, porém em determinados valores de $\mathrm{pH}$ pode ser preferencialmente protonada diminuindo assim a probabilidade de formação de complexo. O comportamento da amônia pode ser exemplificado conforme o equilíbrio (4):

$$
\mathrm{NH}_{3}+\mathrm{H}^{+} \rightleftharpoons \mathrm{NH}_{4}{ }^{+}
$$

No equilíbrio acima representado, o ligante atua como uma base e os íons amônio como um ácido de Brönsted; este equilíbrio é chamado de protonação. A reação inversa é chamada de reação de desprotonação ou dissociação e sua extensão é representada pela equação:

$$
K_{d}=\frac{\left[N H_{3}\right]\left[H^{+}\right]}{\left[N H_{4}^{+}\right]}
$$


Quando o $\quad \mathrm{pH}$, a concentração de $\begin{array}{lllll}\mathrm{NH}_{3} & \text { e } & \mathrm{NH}_{4}{ }^{+} & \text {e }\end{array}$ consequentemente a razão entre elas são conhecidos, a constante de dissociação pode ser calculada a partir da equação 1. Através do logarítmo desta equação chega-se à conhecida equação de Henderson-Hasselbalch ${ }^{(36)}$ que possibilita o cálculo dos valores de pK a partir do $\mathrm{pH}$ e do logarítmo da razão das espécies envolvidas no equilíbrio.

$$
p H=p K+\log \frac{\left[\mathrm{NH}_{3}\right]}{\left[\mathrm{NH}_{4}^{+}\right]}
$$

Devido ao fato de a constante de dissociação normalmente apresentar um valor pequeno torna-se muito mais conveniente escrevê-la como o negativo do seu logarítmo.

As equações 1 e 2 representam a constante de dissociação condicional, onde admite-se que as concentrações efetivas, ou as massas ativas, dos componentes são expressas pelas concentrações estequiométricas, porém segundo a termodinâmica esta relação não é verdadeira. A equação exata para representar o equilíbrio acima envolve a atividade das espécies, sendo assim a equação 1 deve ser escrita como: 


$$
K_{d, T}=\frac{\left\{a_{N H_{3}}\right\}\left\{a_{H^{+}}\right\}}{\left\{a_{N H_{4}^{+}}\right\}}
$$

onde $\{a\}$ representa a atividade das espécies e $K_{\mathrm{T}}$ é a constante de dissociação termodinâmica. A atividade representa a tendência de um íon participar de uma reação ou de determinar a posição de um equilíbrio, sendo que esta é afetada pela presença de outros íons em solução. Em condições de diluição infinita, a atração interiônica é minimizada e a atividade se aproxima da concentração.

Como a atividade é o produto da concentração pelo coeficiente de atividade $(\gamma)$ e representa a diferença entre as soluções reais e ideais, a equação 3 pode ser escrita como:

$$
K_{d_{3} T}=\frac{\left[\mathrm{NH}_{3}\right]\left[\mathrm{H}^{+}\right]}{\left[\mathrm{NH}_{4}^{+}\right]} \frac{\gamma_{N H_{3}} \gamma_{H^{+}}}{\gamma_{N H_{4}^{+}}}
$$

Quando o valor da concentração se aproxima da atividade a interação entre os íons tende a zero e a solução adquire as propriedades de uma solução ideal, sendo assim, o coeficiente de atividade tende à unidade.

No caso de íons, o coeficiente de atividade varia com a carga total iônica que é representada pela força iônica (I), que é 
a medida do campo elétrico existente na solução. O conceito de força iônica foi introduzido por Lewis e Randall ${ }^{(37)}$, como sendo :

$$
I=\frac{1}{2} \sum_{i=1}^{n} C_{i} Z_{i}^{2}
$$

onde $C_{i}$ representa a concentração do íon, em mols por litro da solução, e $Z_{i}$ é a carga do íon i.

A teoria de Debye-Hückel ${ }^{(38)}$ expressa a relação entre coeficiente de atividade e força iônica como:

$$
-\log \gamma_{ \pm}=A Z_{+} Z_{-} \sqrt{I}
$$

onde $\gamma_{ \pm}$é o coeficiente de atividade iônico médio, A é uma constante que em solução aquosa e a $25^{\circ} \mathrm{C}$ é igual a 0,509 e $Z_{+} / Z$. são as cargas dos íons positivos e negativos, respectivamente. Esta teoria não considera o "diâmetro efetivo" de cada íon, além disso considera que a constante dielétrica da solução é igual à do solvente, porém a constante diminui pois os dipolos do solvente sofrem orientação no sentido do campo formado pelos íons. Somente em soluções muito diluídas este efeito pode ser desprezado pois a parte do solvente ligada aos íons é pequena em comparação a seu total de solvente ${ }^{(39,40)}$. Algumas aproximações da teoria de Debye-Hückel foram realizadas a fim de aumentar a 
faixa de aplicação em termos de concentração ${ }^{(41)}$ e são apresentadas na Tabela III.

Tabela III - Equações para o cálculo do coeficiente de atividade iônico médio ${ }^{(41)}$.

\begin{tabular}{|c|c|c|}
\hline Equações & $\begin{array}{l}\text { Faixa de } \\
\text { validade }\end{array}$ & Autor \\
\hline$-\log \gamma \pm=A Z_{+} Z_{-} \sqrt{I}$ & $<10^{-3} \mathrm{M}$ & $\begin{array}{l}\text { Debye e } \\
\text { Hückel }\end{array}$ \\
\hline$-\log \gamma \pm=\mathrm{AZ}_{+} Z_{-} \frac{\sqrt{\mathrm{I}}}{1+\mathrm{Ba} \sqrt{\mathrm{I}}}$ & $<10^{-2} \mathrm{M}$ & $\begin{array}{l}\text { Debye e } \\
\text { Hückel }^{*}\end{array}$ \\
\hline$-\log \gamma \pm=\mathrm{AZ}_{+} Z_{-} \frac{\sqrt{\mathrm{I}}}{1+\mathrm{Ba} \sqrt{\mathrm{I}}}+\mathrm{B}^{\prime} \mathrm{I}$ & & Hückel ${ }^{\#}$ \\
\hline$-\log \gamma \pm=\mathrm{AZ}_{+} \mathrm{Z}_{-} \frac{\sqrt{\mathrm{I}}}{1+\sqrt{\mathrm{I}}}$ & $<0,1 \mathrm{M}$ & Güntelberg \\
\hline$-\log \gamma \pm=\mathrm{AZ}_{+} Z_{-} \frac{\sqrt{\mathrm{I}}}{1+\sqrt{\mathrm{I}}}+\mathrm{B}^{\prime} \mathrm{I}$ & $<0,5 \mathrm{M}$ & Guggenheim \\
\hline$-\log \gamma \pm=\mathrm{AZ}_{+} \mathrm{Z}_{-} \frac{\sqrt{\mathrm{I}}}{1+\sqrt{\mathrm{I}}}-0,2 \mathrm{I}$ & $<0,2 \mathrm{M}$ & Davies \\
\hline$-\log \gamma \pm=\mathrm{AZ}_{+} Z_{-} \frac{\sqrt{\mathrm{I}}}{1+1,5 \sqrt{\mathrm{I}}}$ & $<0,2 \mathrm{M}$ & Scatchard \\
\hline$-\log \gamma \pm=A Z_{+} Z_{-} \frac{\sqrt{\mathrm{I}}}{1+\sqrt{\mathrm{I}}}+\mathrm{B}^{\prime} \mathrm{I}+\mathrm{C}^{\prime} \mathrm{I}^{3 / 2}$ & $<0,2 \mathrm{M}$ & $\begin{array}{c}\text { Datta e } \\
\text { Grzybowski }\end{array}$ \\
\hline \multicolumn{3}{|c|}{$\begin{array}{l}\text { "B é uma constante que depende da constante dielétrica do solvente e da } \\
\text { temperatura. Em solução aquosa e a } 25^{\circ} \mathrm{C} \text {, é igual a } 0,328 \text {. a é a distância } \\
(\AA) \text { média de menor aproximação dos íons. } \\
{ }^{\#} \mathrm{~B}^{\prime} \text { e C' são parâmetros empíricos e apresentam valores diferentes nas } \\
\text { diferentes equações. }\end{array}$} \\
\hline
\end{tabular}




\section{IV.2 - Métodos Utilizados para a Determinação das Constantes}

Os métodos condutométricos foram os mais utilizados até 1932 quando foram substituídos pelos métodos potenciométricos pois estes apresentam resultados mais precisos. Os métodos espectrofotométricos, por sua vez, são adequados para substâncias muito pouco solúveis e também quando é necessário trabalhar-se com valores de $\mathrm{pH}$ muito altos ou baixos, evitando as faixas de erro significativo devido ao uso do eletrodo de vidro. Podem ser utilizados somente quando a substância absorve na região do ultravioleta ou visível, sendo imprescindível que as espécies envolvidas no equilíbrio apresentem um máximo de absorbância em comprimentos de onda diferentes ${ }^{(42)}$.

Espectro de Raman e ressonância magnética nuclear permitem a determinação das constantes de ionização de ácidos fortes como $\mathrm{HNO}_{3}, \mathrm{HClO}_{4}$ e $\mathrm{H}_{2} \mathrm{SO}_{4}$, para isso os espectros de Raman e a ressonância magnética dos núcleos de $\mathrm{H}, \mathrm{N}, \mathrm{Cl}, \mathrm{F}$ são obtidos $^{(43)}$.

\section{IV.2.1 - Método Condutométrico}

As primeiras determinações de constantes de ionização 
aplicando método condutométrico foram realizadas por Ostwald que utilizou procedimentos experimentais já estabelecidos por Kohlrausch ${ }^{(44)}$.

Ostwald estudou a condutividade de soluções como as de ácidos clorídrico, acético, dicloroacético, entre outros e, em um curto espaço de tempo, aproximadamente outros duzentos e quarenta ácidos orgânicos em solução aquosa.

A base deste método está relacionada com a obtenção dos valores de condutância $\left(\mathrm{ohm}^{-1}\right)$ que é o inverso da resistência (ohm). Este método relaciona valores de condutância equivalente, $\Lambda_{c}$, a qual representa a condutividade por equivalência de cada ion (por carga iônica). A condutância equivalente aumenta com a diluição para um valor limite, a condutância limite ou a condutância em diluição infinita, $\Lambda_{0}$, que representa o valor limite da condutância equivalente quando a concentração tende a zero com o aumento da diluição. No caso de eletrólitos fracos, $\Lambda_{0}$ é determinado a partir da lei de Kohlrausch da migração independente, segundo a qual, em diluição infinita, os íons apresentam comportamento independente, logo:

$$
\Lambda_{\mathrm{o}}=\lambda_{\mathrm{o}(\text { cátion })}+\lambda_{\mathrm{o}(\text { ânion })}
$$


onde $\lambda_{o}$ representa a condutância equivalente dos íons, calculada a partir de suas mobilidades iônicas à diluição infinita ${ }^{(45-47)}$.

Através da teoria de Arrhenius, da ionização completa, o grau de ionização $(\alpha)$ pode ser calculado a partir da expressão:

$$
\alpha=\frac{\Lambda_{\mathrm{c}}}{\Lambda_{\mathrm{o}}}
$$

Cálculos mais apurados, não aprofundados aqui por não serem objeto deste trabalho, podem ser feitos considerando a teoria de Debye-Hückel e a expressão de Osanger ${ }^{(44)}$.

Substituindo-se, então, $\alpha$ na equação da lei da ação das massas pode-se obter a constante de ionização a partir da expressão:

$$
\mathrm{K}_{\mathrm{a}}=\frac{\alpha^{2} \mathrm{c}}{1-\alpha}
$$

A resistência das soluções é medida utilizando-se célula de condutividade. Vários modelos desta já foram propostos, provavelmente as mais conhecidas sejam as células desenvolvidas por Washburn e Hartley. Uma célula adequada é formada por 
eletrodos de platina, que a fim de diminuir a capacitância da célula são recobertos com uma fina camada de negro de platina depositada por eletrólise de uma solução aquosa que contém $3 \%$ de cloreto de platina e $0,025 \%$ de acetato de chumbo ${ }^{(44)}$.

Como o volume entre os eletrodos varia de célula para célula deve-se inicialmente efetuar a calibração desta utilizandose a solução padrão de um eletrólito forte, convencionalmente cloreto de potássio.

Para a obtenção da constante de ionização prepara-se inicialmente a solução de estudo, por exemplo ácido acético, e mede-se a resistência específica, na temperatura adequada. Prepara-se novas soluções deste ácido em concentrações diferentes, mede-se a resistência correspondente a cada uma delas e converte-se cada valor condutância específica $(\Lambda)$. A seguir, todos os valores de condutância específica são convertidos em condutância equivalente através da equação:

$$
\Lambda_{\mathrm{c}}=\frac{1000 \Lambda}{\mathrm{C}}
$$

onde C representa a concentração em mol. $\mathrm{L}^{-1}$.

Considerando-se que o cálculo de $\alpha$, equação 8 , exige o conhecimento de $\Lambda_{0}$, neste exemplo do ácido acético, este valor 
pode ser obtido preparando-se soluções do sal correspondente em diferentes concentrações. Para esta finalidade parte-se do ácido acético e faz-se a neutralização quase total pela adição de hidróxido de sódio (livre de carbonato). A resistência específica de cada solução é medida e convertida para $\Lambda$.

A partir dos dados encontrados constrói-se um gráfico de $1 / \Lambda$ versus $\sqrt{ } \mathrm{C}$ e $\Lambda_{0}$ do sal é obtido por extrapolação. Tendo-se a $\Lambda_{\mathrm{o}}$ do sal, subtraindo a $\Lambda_{\mathrm{o}}$ do íon sódio e somando-se a do íon hidrogênio que são 50 e $350\left(\mathrm{ohm}^{-1}\right)$, respectivamente a $25^{\circ} \mathrm{C}$, obtem-se a $\Lambda_{0}$ do ácido. Substituindo-se os valores de $\Lambda_{0}$ e $\Lambda_{c}$ na equação (8) obtém-se $\alpha$ e consequentemente a constante de dissociação a partir da equação $(9)^{(42)}$.

A temperatura durante a obtenção dos valores acima mencionados deve ser controlada, pois a condutividade de uma solução aquosa aumenta aproximadamente $2 \%$ com o aumento de um grau da temperatura. Em função disto e considerando a dependência das constantes de equilíbrio com a temperatura, devese utilizar um sistema termostatizado.

Uma especial vantagem da condutometria frente aos outros métodos é que resultados significativos podem ser obtidos na determinação de constantes de ionização de ácidos muito fracos, ou seja, com $\mathrm{pK}_{a} 11$ a 14 . No entanto não é adequado 
para bases fortes onde os métodos potenciométricos e espectrofotométricos são mais apropriados.

Este método não é facilmente adaptado para a determinação da constante de ionização de substâncias que apresentam dois grupos ionizáveis. Devido à alta condutividade de eletrólitos fortes, a condutometria não é adequada à determinação de constantes em força iônica ajustada.

\section{IV.2.2 Método Potenciométrico}

Até 1932 a condutometria foi o método mais utilizado para a obtenção das constantes de ionização. Naquele ano alguns trabalhos mostraram que a potenciometria ${ }^{(48)}$ poderia apresentar resultados mais precisos. O método potenciométrico mostrou-se também mais fácil e rápido, além de requerer poucos cálculos.

O princípio deste método envolve a titulação de uma solução de concentração conhecida com ácido forte (ou base forte) e o pH da solução é medido utilizando-se uma célula formada por um eletrodo de referência e um indicador, este último apresentando um potencial que varia de acordo com a composição da solução de estudo. Vários eletrodos indicadores podem ser utilizados com este propósito, como o de hidrogênio, vidro, e 
quinidrona. Quanto aos eletrodos de referência utiliza-se o de calomelano e prata/cloreto de prata. Um dos passos mais importantes na investigação de constantes de dissociação torna-se, então, a escolha destes eletrodos.

No eletrodo o de vidro o potencial através da membrana de vidro é proporcional ao $\mathrm{pH}$ da solução. No entanto, quando existe uma alta razão de íons sódio para íons hidrogênio, ocorre a interferência daquele e tem-se uma leitura falsa.

A diferença de potencial gerada pelos íons hidrogênio da solução e os íons hidrogênio do eletrodo indicador é medida por um potenciômetro. A relação entre o potencial do eletrodo de vidro e o $\mathrm{pH}$ da solução segue geralmente a equação:

$$
-\log \left[\mathrm{H}^{+}\right]=\mathrm{pH}=\frac{\left(\mathrm{E}_{\mathrm{X}}-\mathrm{E}_{\mathrm{s}}\right)}{0,05916}
$$

onde $E_{x}$ é o potencial observado, $E_{s}$ é o potencial do eletrodo de referência e $0,05916 \mathrm{~V}$ é o potencial de Nernst, a $25^{\circ} \mathrm{C}$.

Medidas precisas de $\mathrm{pH}$ são necessárias para a obtenção das constantes, sendo assim torna-se necessária uma prévia calibração dos eletrodos. No caso do eletrodo de vidro utiliza-se uma solução de concentração hidrogeniônica conhecida, 
e se for o caso na mesma força iônica das soluções a serem medidas.

A partir de uma equação genérica para o equilíbrio de um ácido em solução aquosa:

$$
\mathrm{HA} \rightleftharpoons \mathrm{H}^{+}+\mathrm{A}^{-}
$$

pode-se melhor exemplificar a obtenção da constante de dissociação/ionização. A equação que representa o equilíbrio acima é:

$$
K=\frac{\left[H^{+}\right]\left[A^{-}\right]}{[H A]}
$$

A partir do balanço de massa tem-se que:

$$
\begin{aligned}
& {[\mathrm{HA}]=\mathrm{C}_{\mathrm{HA}}-\left[\mathrm{A}^{-}\right]} \\
& {\left[\mathrm{A}^{-}\right]=\mathrm{C}_{\mathrm{H}^{+}}-\left[\mathrm{H}^{+}\right]}
\end{aligned}
$$

onde $\mathrm{C}_{\mathrm{HA}}$ é a concentração analítica da espécie em estudo, $\mathrm{C}_{\mathrm{H}^{+}}$é a concentração analítica do titulante, [HA] e $\left[\mathrm{A}^{-}\right]$são as concentrações das espécies $\mathrm{HA}_{\mathrm{A}} \mathrm{A}^{-}$, respectivamente, presentes em equilíbrio e $\left[\mathrm{H}^{+}\right]$é a concentração obtida a partir dos valores 
de $\mathrm{pH}$ medidos durante a titulação, utilizando-se eletrodo adequado.

Fazendo-se os devidos rearranjos matemáticos na equação (12) obtem-se a equação de Henderson-Haselbach:

$$
p H=p K+\log \frac{\left[A^{-}\right]}{[H A]}
$$

Assim, medindo-se o valor de $\mathrm{pH}$ e conhecendo-se a concentração das soluções durante a titulação, constrói-se um gráfico de $\mathrm{pH}$ versus logarítimo da razão das concentrações [A] $] /[\mathrm{HA}]$. Quando o logaritímo da razão é zero tem-se que $\mathrm{pH}$ é igual ao $\mathrm{pK}$.

\section{IV.2.3 - Método Espectrofotométrico}

A potenciometria é um método amplamente utilizado, porém alguns ácidos ou bases não são suficientemente solúveis para serem estudados desta forma. Sob este aspecto, os métodos espectrofotométricos apresentam grande vantagem frente aos potenciométricos pois são adequados à investigação de soluções muito diluídas e de compostos pouco solúveis no solvente em uso. Comparativamente, pode-se então considerar a espectrofotometria 
como o segundo melhor método para determinação de constantes de dissociação/ionização ${ }^{(42)}$.

Considerando condições de equilíbrio ácido-base entre uma espécie protonada e sua equivalente desprotonada, a respectiva constante de equilíbrio pode ser determinada por método espectrofotométrico se ambas apresentam características espectrais diferentes.

O método espectrofotométrico consiste, então, na medida da variação da absorbância do sistema em estudo, em um determinado comprimento de onda, em função da variação do $\mathrm{pH}$. A base do método está no conhecimento das absorbâncias das espécies totalmente protonada, desprotonada e da mistura de ambas em proporções diferentes.

Para o desenvolvimento deste método é necessário obter o espectro de absorbância das espécies HL e L (protonada e desprotonada), que podem ser denotados por $A_{H L}$ e $A_{L}$. Para isso, prepara-se a solução em estudo em condições de pH que permitam a predominância total da forma ácida e da forma básica. Utilizando-se os dois espectros escolhe-se o comprimento de onda onde as absorbâncias das duas espécies diferem o máximo uma da $\operatorname{outra}^{(49)}$.

No comprimento de onda selecionado mede-se a 
absorbância das duas espécies $\left(A_{L}, A_{H L}\right)$ e a absorbância das soluções (A) que apresentam a mesma concentração total mas diferentes razões [L]/[HL] pela imposição de diferentes valores de pH. O valor de $\mathrm{pK}$ pode, então, ser calculado a partir das equações ${ }^{(49)}$ :

$$
\begin{aligned}
& \mathrm{pH}=\mathrm{pK}+\log \frac{\left(\mathrm{A}_{\mathrm{L}}-\mathrm{A}\right)}{\left(\mathrm{A}-\mathrm{A}_{\mathrm{HL}}\right)} \\
& \text { ou } \\
& \mathrm{pH}=\mathrm{pK}+\log \frac{\left(\mathrm{A}-\mathrm{A}_{\mathrm{L}}\right)}{\left(\mathrm{A}_{\mathrm{HL}}-\mathrm{A}\right)}
\end{aligned}
$$

Dependendo dos valores de absorbância das espécies envolvidas, pode-se utilizar a equação 16 ou 17.

Constrói-se um gráfico de valores de $\mathrm{pH}$ versus o $\log$ da razão das absorbâncias, quando $\log$ da razão é igual a zero pH é igual a $\mathrm{pK}^{(42,49-51)}$.

Se nenhuma das espécies (protonada e desprotonada) absorve na região do visível ou do ultravioleta do espectro, então o valor de $\mathrm{pK}$ pode ser obtido por um método indireto, que se baseia na medida de absorbância de um indicador ácido-base 
que apresenta o valor da constante de ionização próximo ao da espécie em estudo. Em soluções muito diluídas do indicador, ou seja, concentração por volta de $10^{-5}$ mol. $\mathrm{L}^{-1}$, quantidades conhecidas das espécies em estudo, protonadas e não protonadas, $10^{-2}$ mol.L $L^{-1}$, são adicionadas e a absorbância das soluções é medida nos dois comprimentos de onda mais adequados para a determinação da absorbância das formas protonada e não protonada do indicador, assim o $\mathrm{pK}$ do equilíbrio em estudo pode ser calculado utilizando a equação:

$$
\mathrm{pK}=\mathrm{pK}_{\mathrm{I}}+\log \frac{[\mathrm{L}]}{[\mathrm{HL}]}+\log \frac{[\mathrm{HI}]}{[\mathrm{I}]}
$$

onde $\mathrm{pK}_{\mathrm{I}}$ é a constante de dissociação do indicador ácido-base e [I] e [HI] são, respectivamente, as concentrações da forma não protonada e protonada do indicador. A razão destas concentrações é calculada a partir das absorbâncias medidas ${ }^{(49,52)}$.

O método espectrofotométrico quando cuidadosamente utilizado pode apresentar resultados de alta precisão. Sistemas fechados podem evitar a evaporação do analito ou do solvente e a interferência de dióxido de carbono. A temperatura deve ser controlada utilizando-se um banho termostático. 


\section{V - ASPECTOS DAS MEDIDAS}

\section{POTENCIOMÉTRICAS (pH)}




\section{V.1 - O Eletrodo de Vidro}

As primeiras observações sobre o eletrodo de vidro foram realizadas por Cremer $^{(53)}$ por volta de 1906, e posteriormente, em estudos mais detalhados, por Haber e Klemensiewicz ${ }^{(54)}$. Estas investigações mostraram que um eletrodo de vidro sensível a íons hidrogênio apresentava resposta de acordo com o previsto pela equação de Nernst. Posteriormente, na década de 50 e início dos anos 60 , os grupos de Nicolsky e de Eisenman apresentaram teorias sobre a origem do potencial medido ${ }^{(53,55)}$.

O eletrodo de vidro é o mais amplamente utilizado entre os eletrodos sensíveis aos íons hidrogênio. Sua operação depende do potencial elétrico que surge quando uma membrana de vidro fica imersa numa solução; este potencial é uma função linear da concentração do íon hidrogênio na solução. Para medir a atividade hidrogeniônica da solução, o eletrodo de vidro deve, então, estar combinado a um eletrodo de referência, resultando por exemplo, a seguinte célula:

$\mathrm{Ag} / \mathrm{AgCl} \mid \mathrm{HCl}(0,1 \mathrm{M})$ vidro ||$\left[\mathrm{H}^{+}\right]$desc. $|\mathrm{NaCl}(3,0 \mathrm{M})| \mathrm{AgCl} / \mathrm{Ag}$

O potencial desta célula é dado por: 


$$
\mathrm{E}=\mathrm{E}^{\mathrm{o}}+\frac{\mathrm{RT}}{\mathrm{F}} \ln \mathrm{a}_{\mathrm{H}^{+}}+\mathrm{Ej}
$$

O termo $E^{o}$ é constante e inclui o potencial do eletrodo de referência e os potenciais padrão e assimétrico do eletrodo de vidro . Este último pode existir devido a diferenças na estrutura e composição das superfícies interna e externa da membrana de vidro $^{(56)}$, variando lentamente com o tempo de uso, à medida que o eletrodo torna-se mais ou menos hidratado e contaminado por outras soluções. O termo $\mathrm{Ej}$ é o potencial de junção líquidolíquido, que aparece na interface entre o eletrólito que compõe o eletrodo de referência e a solução externa.

Dependendo da concentração das soluções de medida e da força iônica da solução, a atividade do íon hidrogênio pode ser expressa em termos de concentração ${ }^{(57)}$. A equação (19), a $25^{\circ} \mathrm{C}$, torna-se então ${ }^{(58)}$ :

$$
\mathrm{E}=\mathrm{E}^{\mathrm{o}}+0,05916 \log \left[\mathrm{H}^{+}\right]+\mathrm{Ej}
$$

Quanto ao mecanismo de funcionamento do eletrodo de vidro, a teoria mais aceita baseia-se no mecanismo de "troca iônica" de $\mathrm{Na}^{+}$e $\mathrm{H}^{+}$que ocorre entre a solução e o vidro. As atividades de $\mathrm{Na}^{+}$e $\mathrm{H}^{+}$no vidro são proporcionais às suas frações 
molares, e o potencial observado do eletrodo de vidro é resultante da soma dos potenciais limítrofes de fase.

Se o vidro possui estrutura tetraédrica, tendo como átomo central o silício, pelo menos três vértices do tetraédro são compartilhados, o que significa que existe um átomo de oxigênio servindo como sítio negativo para a incorporação de um próton proveniente da solução na qual a membrana de vidro se encontra imersa $^{(53)}$.

Quando um eletrodo de vidro recém fabricado, composto de $\mathrm{Na}_{2} \mathrm{O}$ e $\mathrm{SiO}_{2}$, é condicionado em soluções aquosas de íons hidrogênio, o silicato de sódio da camada superficial se hidrolisa, originando uma camada de vidro hidratada. Íons hidrogênio, provenientes da solução, penetram na camada hidratada, alojando-se nos sítios negativos disponíveis, ao mesmo tempo em que íons sódio, inicialmente presentes no vidro, são transferidos para a solução. No interior do vidro, a camada de silicato de sódio permanece intacta, e o potencial Donnan é gerado através de um mecanismo de troca entre íons $\mathrm{H}^{+}$da camada hidratada e aqueles presentes na solução de medida(5). A partir deste estabelece-se o equilíbrio:

$$
\mathrm{H}^{+}{ }_{\text {sol }}+\mathrm{M}^{+}{ }_{\text {vidro }} \rightleftharpoons \mathrm{H}^{+}{ }_{\text {vidro }}+\mathrm{M}^{+}{ }_{\text {sol. }} \quad \text { (equil.6) }
$$


A natureza do vidro usado para a construção do eletrodo de vidro é muito importante. Não são apropriados os vidros duros, tipo Pyrex ${ }^{(40)}$.

Durante muitos anos foi universalmente usado para fabricação de eletrodos de vidro um vidro de cal-soda (Corning 015 ) com a composição aproximada $\mathrm{SiO}_{2} 72 \%, \mathrm{Na}_{2} \mathrm{O} 22 \%$ e $\mathrm{CaO}$ 6\%. Estes eletrodos são excepcionalmente satisfatórios no intervalo de $\mathrm{pH}$ de 1 a 9 , mas em soluções mais alcalinas apresentam "erro alcalino" e tendem a dar valores menores de $\mathrm{pH}$. O erro aumenta com a concentração de íons de metais alcalinos em solução; por exemplo, em valor de $\mathrm{pH} 12$, na presença de íons sódio, o erro varia de $-1,0$ a $-0,4$ unidade de $\mathrm{pH}$ na concentração de sódio de 1 mol. $\mathrm{L}^{-1}$ a 0,1 mol. $\mathrm{L}^{-1}$, respectivamente. Para eliminar parcialmente este erro substituiu-se todo ou a maior parte de sódio por lítio, na composição do vidro. Assim, um eletrodo com um vidro que tem composição $\mathrm{SiO}_{2} 63 \%, \mathrm{Li}_{2} \mathrm{O} 28 \%$, $\mathrm{Cs}_{2} \mathrm{O} 2 \%, \mathrm{BaO} 4 \%$ e $\mathrm{La}_{2} \mathrm{O}_{3} \quad 3 \%$ tem um erro de apenas $-0,12$ unidade de $\mathrm{pH}$, na presença de íons sódio com a concentração 2 mol. $\mathrm{L}^{-1(40)}$.

Existem também, eletrodos de vidro na forma compacta de um eletrodo combinado. Este é constituído pelo eletrodo 
indicador e um eletrodo de referência (prata-cloreto de prata) combinados em apenas uma unidade.

\section{V.2 - Calibração do Sistema de Medidas}

Para a determinação das constantes de dissociação/ionização é necessário o conhecimento da concentração do íon hidrogênio e como visto anteriormente, equação 20, a atividade do íon hidrogênio é fornecida pelo potencial da célula do estudo. Este potencial inclui o potencial do eletrodo de referência e os potenciais padrão e assimétrico do eletrodo de vidro.

Como as medidas dos valores de $\mathrm{pH}$ devem ser precisas, é necessária uma prévia calibração do sistema potenciométrico. Tal calibração é realizada utilizando-se uma solução de íons hidrogênio com concentração conhecida.

A recomendação de efetuar somente este procedimento pressupõe que o eletrodo apresenta uma resposta Nernstiana $(59,16 \mathrm{mV})$ por unidade de $\mathrm{pH}$. A calibração do eletrodo com uma solução de concentração hidrogeniônica conhecida elimina somente o problema relacionado com o potencial assimétrico ${ }^{(59)}$. 
Quanto ao potencial de junção, estudos realizados por Angnes ${ }^{(60)}$ mostraram que existe uma dependência linear entre a acidez da solução e o $E_{j}$, e que para valores de $\mathrm{pH}$ maiores que 3, o $E_{j}$ pode ser desprezado.

Devido ao fato da calibração compensar somente o potencial assimétrico, métodos mais confiáveis foram desenvolvidos para a determinação precisa da concentração de íons $\mathrm{H}^{+}$. Para isso contrói-se uma curva de calibração de $\mathrm{E}$ ou $\mathrm{pH}^{\prime}$ medido versus $\mathrm{pH}$ calculado. A relação existente entre $\mathrm{pH}$ ' medido e pH calculado foi estudada por McBryde ${ }^{(61)}$ que chegou à seguinte expressão geral:

$$
\mathrm{pH}^{\prime}=\text { intercepto }+ \text { "slope" } \cdot \mathrm{pH}
$$

ou

$$
\mathrm{pH}^{\prime}=\mathbf{b}+\mathbf{m} \cdot \mathrm{pH}
$$

onde $m$ representa o coeficiente angular da reta $\mathrm{e} b$ o coeficiente linear.

Quando a curva é construída com valores de potencial ao invés de $\mathrm{pH}$, tendo-se $\mathrm{E}(\mathrm{mV})$ medido versus $\mathrm{pH}$ calculado,a mesma relação pode ser expressa por:

$$
\mathrm{E}=\mathrm{b}+\mathrm{m} \cdot \mathrm{pH}
$$


onde o coeficiente angular corresponde ao parâmetro denominado "slope", que equivale ao fator de resposta do eletrodo de vidro.

Segundo a equação de Nernst simplificada:

$$
\mathrm{E}=\mathrm{E}^{\circ}-\frac{\mathrm{RT} \ln 10}{\mathrm{~F}} \mathrm{pH}
$$

em condições ideais, o "slope" assume o valor de $59,16 \mathrm{mV}$ por unidade de $\mathrm{pH}$, a $25^{\circ} \mathrm{C}^{(62)}$.

Silva e Neves ${ }^{(63)}$ demonstraram como $\mathrm{pHx}$ medido experimentalmente pode ser convertido no $\mathrm{pH}$ "verdadeiro", pHcorrigido:

$$
\text { pHcorr. }=\frac{S N \cdot p H x-(S N-S X) \cdot p H s}{S X}
$$

Tem-se portanto:

SN: "Slope" Nernstiano $=0,05916\left(25^{\circ} \mathrm{C}\right)$

SX : "Slope" experimental

pHs : pH do padrão $\cong 2,000$

$\mathrm{pHx}: \mathrm{pH}$ experimental

No presente trabalho, os valores de $\mathrm{pH}$ medidos foram então corrigidos utilizando-se a equação (25). 
V.3 - Fatores de Correção Utilizados nas Medidas de pH em Meio Não Aquoso e na Mistura de Solventes

Com o aumento no interesse da determinação das constantes de dissociação/ionização em solventes não aquosos ou mistos, tornou-se necessária a estimativa precisa e exata da concentração de íon hidrogênio nesses meios.

Lahiri e Aditya $^{(64)}$ discutiram alguns métodos utilizados para corrigir medidas de $\mathrm{pH}$ em mistura de solventes. Estes autores associaram as medidas da concentração do íon $\mathrm{H}^{+}$ em mistura de solventes com uma série de dificuldades:

(1) O potencial do eletrodo de vidro difere em meio aquoso e na mistura de solventes;

(2) O potencial de junção é uma magnitude incerta que aumenta com o aumento na porcentagem do componente orgânico;

(3) A solubilidade de eletrólitos diminue com o aumento da porcentagem do solvente orgânico;

(4) A sensibilidade do eletrodo de vidro diminui com o aumento da porcentagem do componente orgânico;

(5) Os coeficientes de atividade calculados com base na equação de Debye-Hückel podem apresentar consideráveis diferenças em relação ao valor verdadeiro. 
Van Uitert e $\operatorname{Hass}^{(65)}$ desenvolveram um método de corrreção de $\mathrm{pH}$ em dioxano (75\%), o qual foi utilizado em alguns trabalhos envolvendo a determinação das constantes de dissociação/ionização(66-71).

Para o desenvolvimento deste método Van Uitert e Hass verificaram, primeiramente, a resposta do eletrodo de vidro para íons hidrogênio frente ao eletrodo de hidrogênio. Para isso soluções de ácido acético contendo $\mathrm{NaCl}$ foram neutralizadas com solução de $\mathrm{NaOH}$ em $75 \%$ de dioxano e, em seguida, reacidificadas com $\mathrm{HCl}$ para obter também valores baixos de $\mathrm{B}$, símbolo designado para a escala de $\mathrm{pH}$ em soluções não aquosas, na faixa de 2 a 11 . Os valores de $B$ do eletrodo de vidro e as correspondentes f.e.m. do eletrodo de hidrogênio foram relacionados ${ }^{(65)}$.

Os resultados mostraram que a célula de vidrocalomelano mede a atividade do íon hidrogênio como definido pelo eletrodo de hidrogênio e que os valores de B são válidos numa ampla faixa. A correlação entre as medidas de $B$, pelo eletrodo de vidro-calomelano, e da f.e.m para a célula $\mathrm{H}_{2} / \mathrm{H}^{+}$, $\mathrm{Cl}^{-} / \mathrm{AgCl}-\mathrm{Ag}$ em $75 \%$ de dioxano foi de $0,0601 \mathrm{~V}$ a $30^{\circ} \mathrm{C}$.

Para efeito de calibração do sistema potenciométrico, prepararam uma série de soluções contendo $\mathrm{HCl}$ e $\mathrm{NaCl}$ na faixa 
de 0 a $75 \%$ de dioxano. A partir dos valores medidos de B e da concentração estequiométrica do íon hidrogênio $\left[\mathrm{H}^{+}\right]$, o fator de correção, $\mathrm{U}_{\mathrm{H}}$, necessário para obter a concentração hidrogeniônica, pode ser calculado por:

$$
\mathrm{U}_{\mathrm{H}}=\operatorname{antilog}(-\mathrm{B}) /\left[\mathrm{H}^{+}\right]
$$

Assim o pH poderá ser obtido através da expressão (26) modificada para:

$$
-\log \left[\mathrm{H}^{+}\right]=\mathrm{B}+\log \mathrm{U}_{\mathrm{H}}
$$

A fim de verificar se o fator de correção varia de acordo com o coeficiente de atividade do íon hidrogênio no meio iônico total, os valores de $U_{H}$ foram obtidos para soluções com diferentes porcentagens do solvente e concentrações do ácido e do sal. Com estes experimentos os autores ${ }^{(65)}$ confirmaram a relação existente entre a atividade iônica e o meio iônico. As variações observadas são função da alteração dos coeficientes de atividade pela variação da força iônica. Para compensação de tais efeitos Van Uitert e $\operatorname{Hass}^{(65)}$, utilizando todos os dados obtidos em diferentes concentrações iônicas, obtiveram o fator $\mathrm{U}_{\mathrm{H}}^{\circ}$ que corresponde à força iônica zero (diluição infinita). Para isso, corrigiram os valores de $U_{H}$ através da equação: 


$$
\mathrm{U}_{\mathrm{H}}^{\mathrm{o}}=\mathrm{U}_{\mathrm{H}}(1 / \gamma)
$$

onde $\gamma$ é o coeficiente de atividade para a composição do solvente utilizada e a concentração iônica na qual o respectivo $U_{H}$ foi determinado.

Utilizando valores de $\gamma$ fornecidos por Harned e Owen ${ }^{(72)}$ que foram obtidos variando-se a força iônica (I) do meio, ou seja em diferentes concentrações do eletrólito, calcularam valores de $\mathrm{U}^{\circ}{ }_{\mathrm{H}}$ para a faixa de porcentagem de dioxano utilizada.

Outro fator de correção de $\mathrm{pH}$ foi definido por Bates et $a l^{(73-75)}$, simbolizado por " $\delta$ " e aplicado na seguinte expressão:

$$
\mathrm{pa}_{\mathrm{H}}^{*}=\mathrm{pH}-\delta
$$

onde $\mathrm{pH}$ é o valor medido experimentalmente e $\mathrm{pa}_{\mathrm{H}}{ }^{*}$ refere-se ao valor experimental corrigido.

Segundo Bates et $a^{(74)}$ os valores de $\delta$ podem ser obtidos através da equação:

$$
\delta=E_{j}^{-}-\log _{m} \gamma_{H}
$$


onde ${ }_{\mathrm{m}} \gamma_{\mathrm{H}}$ é o coeficiente de atividade dos íons hidrogênio afetado pelo meio e $\overline{\mathrm{E}}_{\mathrm{j}}$ é o desvio (em unidades de $\mathrm{pH}$ ) causado pelo potencial de junção líquida residual.

Para abtenção de $\delta$ Bates et $\mathrm{al}^{(74)}$ relacionaram as medidas de $\mathrm{pH}$ utilizando duas células:

Pt $\mid \mathrm{H}_{2}$ (g, 1 atm), sol.X ou S $\mid$ KCl saturado(aq.) $\mid$ eletrodo de referência (I)

$\mathrm{Pt} \mid \mathrm{H}_{2}$ (g, 1 atm), sol. tampão X (em água-etanol) $\left|\mathrm{Cl}^{-}, \mathrm{AgCl}\right| \mathrm{Ag}$

onde $\mathrm{X}$ e $\mathrm{S}$ representam a solução problema e a padrão em meio aquoso, respectivamente, na célula (I). Na célula (II), $\mathrm{X}$ representa soluções tampão de fosfato em meio misto.

Utilizando a célula (I), a equação geral relativa ao potencial do eletrodo da amostra (X) ou da solução padrão (S) é dada por:

$\mathrm{E}_{(\mathrm{x}, \mathrm{s})}=\mathrm{E}_{\text {ref. }}-\mathrm{E}^{\mathrm{o}} \mathrm{H}^{+} / \mathrm{H}_{2}-\frac{\mathrm{RT} \ln 10}{\mathrm{~F}} \log \mathrm{a}_{\mathrm{H}(\mathrm{x}, \mathrm{s})}+\mathrm{E}_{\mathrm{j}(\mathrm{x}, \mathrm{s})}$

Considerando a equação acima e que o potencial de junção líquida é suficientemente constante para soluções aquosas 
de força iônica menor que 0,1 e $\mathrm{pH}$ entre 2,5 e 11,5 , a relação entre o $\mathrm{pH}$ da amostra $\left(\mathrm{pH}_{\mathrm{x}}\right)$ e o $\mathrm{pH}_{\mathrm{s}}$ da solução padrão, ambas em meio aquoso, é dada por ${ }^{(74)}$ :

$$
\mathrm{pH}_{\mathrm{x}}=\mathrm{pH}_{\mathrm{s}}+\frac{\mathrm{E}_{\mathrm{x}}-\mathrm{E}_{\mathrm{s}}}{(\mathrm{RT} \ln 10) / \mathrm{F}}
$$

Com relação à célula (II) em solvente misto, pode-se fazer o mesmo raciocínio e relacionar o potencial operacional (E) com o potencial padrão da célula (II) simbolizada por ${ }_{w} E^{\circ}$, em meio aquoso.

Comparando dados obtidos com as células (I) e (II) relativas ao uso de eletrodos de hidrogênio Bates et al. ${ }^{(74)}$ calcularam então os termos de correção ( $\delta$ ) para diferentes proporções de metanol-água e etanol-água. No caso do etanol-água os valores encontrados estão colocados na Tabela IV.

Tabela IV - Fator de correção $\delta$ para medidas de $\mathrm{pH}$ em diferentes porcentagens de etanol-água ${ }^{(74)}$.

\begin{tabular}{cccccccc}
\hline \hline \% etanol (V/V) & 0 & 20 & 40 & 59 & 79 & 89 & 100 \\
\hline$\delta$ & 0 & 0,003 & 0,086 & 0,221 & 0,196 & $-0,032$ & $-2,91$ \\
$\left(\bar{E}_{\mathrm{j}}-\log _{\mathrm{m}} \gamma_{\mathrm{H}}\right)$ & & & & & & &
\end{tabular}


Desta forma, os valores de $\mathrm{pH}$ lidos podem ser corrigidos subtraindo-se os teores $\delta$ acima listados. Tem-se, assim, os valores de $\mathrm{pa}_{\mathrm{H}}{ }^{*}$ que são relativos ao estado padrão aquoso.

Estes fatores de correção foram também determinados por Douhéret ${ }^{(76)}$ na mistura de solventes como águadimetilsulfóxido. Estes dados foram utilizados por Boraei e Ahmed ${ }^{(77)}$ na determinação da constante de dissociação de algumas mercaptobenzoazóis em misturas de solventes.

Além do review ${ }^{(75)}$ já citado sobre medidas de concentração hidrogeniônica em solventes mistos, o grupo de Lahiri ${ }^{(64)}$ apresentou também um método para correção dos valores de $\mathrm{pH}$ em função do uso de solventes aquo-orgânicos.

Seguindo o método proposto por Van Uitert e Haas ${ }^{(65)}$ aplicado a misturas de dioxano-água, ao invés de $\mathrm{HCl}$, Lahiri utilizou soluções de $\mathrm{HClO}_{4} \quad 1.10^{-4}$ mol.L $\mathrm{L}^{-1}$ como padrão nas medidas de $\mathrm{pH}$ em solventes mistos. O método foi aplicado a medidas do ion hidrogênio em misturas etanol-, metanol-, isopropanol-e dioxano-água.

Para a utilização do meio aquo-etanólico, de interesse no presente trabalho, os valores de $\log \mathrm{U}_{\mathrm{H}}^{\circ}$ (em unidades de $\mathrm{pH}$ ) encontrados $^{(65)}$ estão listados na Tabela V. 
Como as correções de $\mathrm{pH}$ devem ser efetuadas, os valores de $\log \mathrm{U}_{\mathrm{H}}^{\circ}$ da Tabela $\mathrm{V}$ devem ser algebricamente somados às medidas de $\mathrm{pH}$ do peagâmetro.

A correção pode ainda ser extrapolada à diluição infinita combinando-se adequadamente a equação 27 e 28. A expressão geral é a seguinte:

$$
-\log \left[\mathrm{H}^{+}\right]=\mathrm{B}+\log \mathrm{U}_{\mathrm{H}}^{\mathrm{o}}+\log \gamma_{ \pm}
$$

Tabela V - Fator de correção $\left(\log \mathrm{U}_{\mathrm{H}}^{\mathrm{o}}\right)$ para medidas de $\mathrm{pH}$ em diferentes porcentagens de etanol-água ${ }^{(65)}$.

\begin{tabular}{cccc}
\hline \%etanol & $\log _{\mathrm{H}}^{\mathrm{o}}$ & $\%$ etanol & $\log ^{\mathrm{o}}{ }_{\mathrm{H}}$ \\
\hline 10 & $-0,02$ & 62 & $-0,27$ \\
20 & $-0,04$ & 72 & $-0,33$ \\
41 & $-0,05$ & 82 & $-0,30$ \\
51 & $-0,09$ & 91 & $-0,18$ \\
\hline
\end{tabular}

Valores de $\log \mathrm{U}_{\mathrm{H}}^{\mathrm{o}}$ encontrados por Irving e Manhot ${ }^{(78)}$ e Van Uitert e Hass ${ }^{(65)}$ foram comparadas por Lahiri e Aditya ${ }^{(64)}$ e evidenciaram uma boa concordância. Esta concordância também 
foi verificada com os dados obtidos por Lahiri e Aditya ${ }^{(64)}$ para baixas porcentagens do solvente orgânico. Entretanto, para valores altos, houve uma considerável discrepância. Tal fato é atribuído à maior associação do $\mathrm{HCl}$ comparado ao $\mathrm{HClO}_{4}$, em altas porcentagens do solvente orgânico.

Assim, o uso do método de Van Uitert e Hass modificado pelo uso do $\mathrm{HClO}_{4}$ pode ser convenientemente empregado, segundo Lahiri e Aditya ${ }^{(64)}$ para medidas da concentração do íon hidrogênio em solventes mistos; especialmente pela falta de tampões padrões preparados nesses meios e pelo pouco conhecimento sobre o efeito do meio.

Muitas publicações foram encontradas sobre as correções de $\mathrm{pH}$ em meio aquo-orgânico, entretanto, a grande maioria se refere às propostas de Bates, Lahiri e Van Uitert e Hass. Nada se encontra confirmando ou não a exatidão de qualquer uma delas, neste sentido o próprio Bates manifestou sua incerteza sobre a exatidão na aplicação dos termos de correção sobre o $\mathrm{pH}$.

A análise da literatura sobre as medidas de $\left[\mathrm{H}^{+}\right], \mathrm{a}_{\mathrm{H}}{ }^{+}$ ou pH mostra também de forma clara as dificuldades encontradas tanto para assegurar a exatidão no uso de diferentes eletrodos, quanto para a determinação de pH confiável em diferentes meios, 
aplicação de fatores de correção, ou utilização de soluções tampão padrões, etc.

Lewis, em 1923, afirmou ${ }^{(64)}$ "No presente momento devemos concluir que a determinação da atividade absoluta de íons é um problema interessante mas ainda não resolvido". Meio século depois, Lahiri e Aditya ${ }^{(64)}$ confirmaram que o estado de conhecimento até aquele momento não havia, também, sido capaz de trazer soluções definitivas. Tal situação parece que se mantém até a presente data ${ }^{(79)}$, pois diversos são os fatores que influenciam uma medida de $\mathrm{pH}$ e, neste sentido, até o funcionamento do eletrodo de vidro (o mais utilizado desde a década de 50) conta com várias hipóteses não plenamente confirmadas. 


\section{VI - PARTE EXPERIMENTAL E}

\section{TRATAMENTO DE DADOS}




\section{VI.1 - Reagentes, Equipamentos e Acessórios}

Todos os reagentes utilizados foram de grau analítico. As soluções estoque de $\mathrm{HCl}, \mathrm{HClO}_{4}$ e $\mathrm{NaOH}$ foram padronizadas pelo método potenciométrico e depois diluídas nas proporções de etanol desejadas. O etanol utilizado foi $95 \%$ de procedência Merck.

Antes do preparo de todas as soluções efetuou-se a eliminação do $\mathrm{CO}_{2}$ através da fervura seguida do borbulhamento de nitrogênio, na água deionizada utilizada para o preparo destas.

Os incrementos de $\mathrm{HCl}, \mathrm{HClO}_{4}$ e $\mathrm{NaOH}$, no estudo utilizando-se o método potenciométrico, foram adicionados à solução de estudo através de uma bureta de pistão de $5,00 \mathrm{~mL}$ modelo E 274 da Metrohm. Alíquotas das soluções a serem tituladas foram obtidas a partir de uma pipeta volumétrica de $5,05 \mathrm{~mL}$.

Quanto ao método espectrofotométrico, utilizou-se uma pipeta de $0,9485 \mathrm{~mL}$ para as alíquotas da solução de DPKBH e uma micropipeta de 200 a $1000 \mu \mathrm{L}$ modelo Finnpipette da Labsystems, para as alíquotas de $\mathrm{HClO}_{4}$ e $\mathrm{NaOH}$.

$\mathrm{O}$ valor de $\mathrm{pH}$ foi medido com eletrodo de vidro combinado, modelos 6.0203 .100 e 6.0233 .100 e potenciômetro 
modelo 654, todos da Metrohm.

Espectrofotômetro de feixe duplo modelo U-3000 da Hitachi foi utilizado nas medidas espectrofotométricas.

A condutância, no estudo da interação DPKBH e $\mathrm{HClO}_{4}$, foi medida com uma célula de condutividade modelo 7A04 da Analyser e condutivímetro modelo B330 da Micronal.

A temperatura foi mantida a $(25,0 \pm 0,1)$ utilizando-se banhos termostáticos, modelo Q-215 da Quimis e a $(25,000 \pm$ $0,005)^{\circ} \mathrm{C}$ modelo $\mathrm{CB} 8-30 \mathrm{e}$ da Heto.

\section{VI.2 - Limpeza da Vidraria}

O DPKBH apresentou tendência em adsorver na vidraria, bem como na membrana de vidro do eletrodo. Para certificar-se dessa tendência, a um balão volumétrico de $10 \mathrm{~mL}$ adicionou-se $3 \mathrm{~mL}$ de DPKBH $1,0.10^{-3}$ mol. $\mathrm{L}^{-1}$ e deixou-se esta solução por 60 minutos. Retirou-se a solução e lavou-se o balão com $\mathrm{H}_{2} \mathrm{O}$ destilada e por fim com $3 \mathrm{~mL}$ de etanol $95 \%$. Colocouse este volume de etanol em uma cubeta e mediu-se a absorbância contra etanol $95 \%$. O espectro obtido está representado na Figura 2, onde duas bandas de absorção características do DPKBH são observadas. 
Assim, para a retirada do DPKBH adsorvido foi necessário, em todas as etapas, lavar a vidraria com $\mathrm{HNO}_{3} 10 \%$. A membrana do eletrodo de vidro foi também colocada na mesma solução de ácido durante 20 segundos.

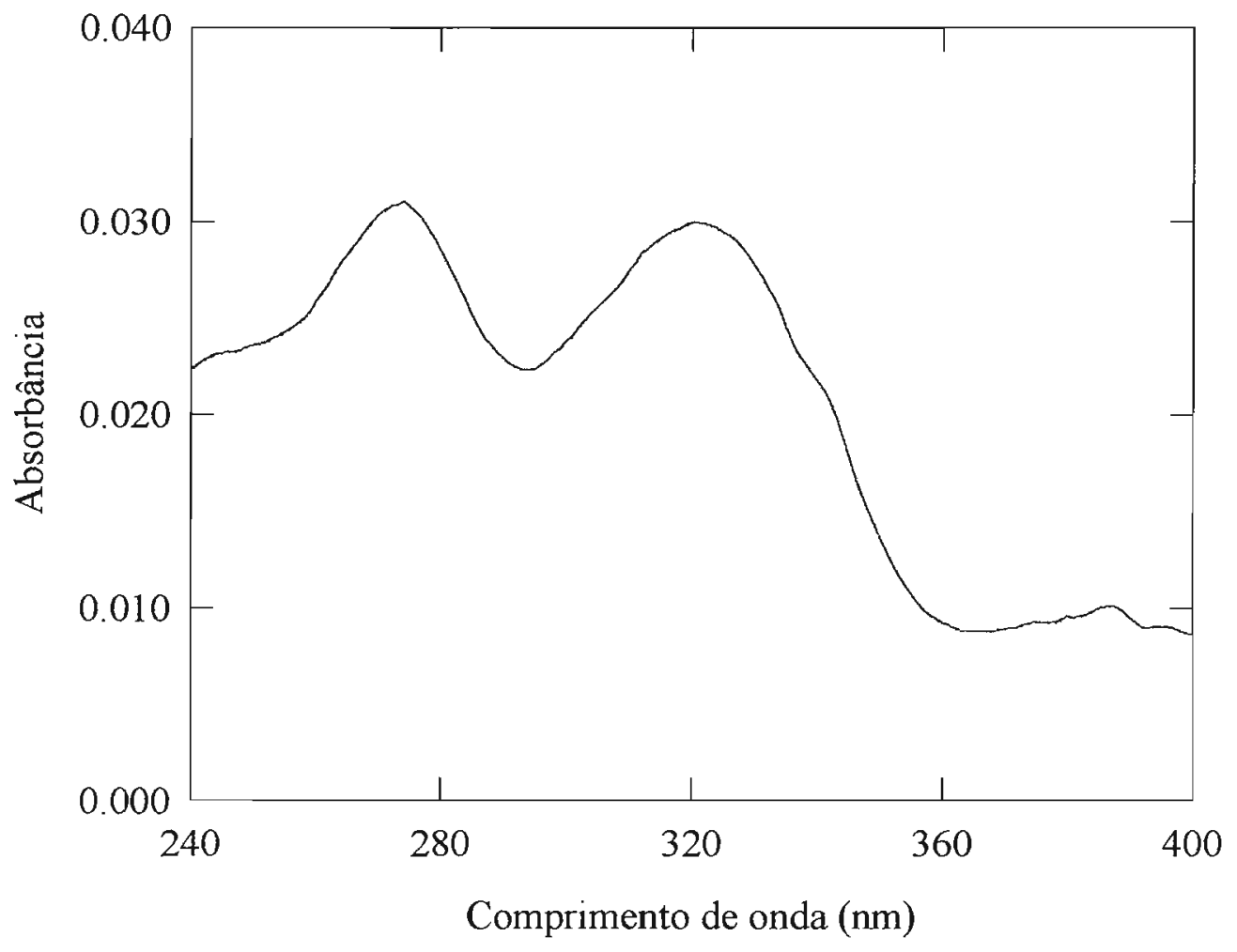

Figura 2 - Espectro da solução de etanol $95 \%$ utilizada para lavar o balão volumétrico de $10 \mathrm{~mL}$, após conter DPKBH. 


\section{VI.3 - Síntese do DPKBH}

Sintetizou-se o DPKBH seguindo-se o procedimento descrito por Garcia-Vargas ${ }^{(2)}$. Obteve-se este reagente a partir de uma mistura equimolar de di-2-piridil cetona $(10 \mathrm{~g})$ e benzoilhidrazina $(7,5 \mathrm{~g})$ em etanol e algumas gotas (10 gotas) de ácido clorídrico concentrado. A mistura foi refluxada por uma hora. Após o resfriamento adicionou-se cerca de $600 \mathrm{~mL}$ de água destilada, numa proporção de 1:3 (orgânico/água). Algumas gotas de hidróxido de sódio foram adicionadas até pH igual a 5 .

Aguardou-se a formação do precipitado, e a seguir, o precipitado resultante foi filtrado a vácuo e coletado em um funil de Büchner. Realizou-se a recristalização, por três vezes, adicionando-se uma quantidade mínima de etanol para solubilizar o precipitado.

Após a síntese, testes foram realizados a fim de confirmar a pureza do precipitado, tal como ponto de fusão, quando se obteve o valor de $136^{\circ} \mathrm{C}$ e espectro de absorção do DPKBH, coerentes com a literatura ${ }^{(2)}$. 
VI.4 - Determinação do Fator de Resposta ("Slope") do Eletrodo de Vidro em 10, 19, 29 e $48 \%$ de etanol

Considerando-se que medidas absolutas de pH serão efetuadas, torna-se necessário, previamente, conhecer o comportamento de eletrodo de vidro ("slope"), para corrigir os valores de $\mathrm{pH}$ experimentais a serem utilizados para a determinação dos pKs do DPKBH.

O fator de resposta, "slope", do eletrodo de vidro foi, então, determinado fazendo-se, através de uma bureta de pistão de $5,00 \mathrm{~mL}$, adições de pequenos volumes de solução de $\mathrm{NaOH}$ $0,03 \mathrm{~mol} . \mathrm{L}^{-1}$, previamente padronizada e diluída na porcentagem de etanol do estudo, a 5,05 $\mathrm{mL}$ de uma solução padrão de $\mathrm{HCl}$ 0,01 mol. $\mathrm{L}^{-1}$, preparada na mesma porcentagem de etanol e medindo-se os respectivos valores de potencial, E.

Os valores de $\mathrm{pH}$ teóricos foram calculados a partir da expressão:

$$
p H=-\log \left[H^{+}\right]=\frac{\left(C_{a} \cdot V_{a}\right)-\left(C_{b} \cdot V_{b}\right)}{V_{T}}
$$

onde: 
$\mathrm{C}_{\mathrm{a}}, \mathrm{C}_{\mathrm{b}}$ são as concentrações e $\mathrm{V}_{\mathrm{a}}$ e $\mathrm{V}_{\mathrm{b}}$ os volumes de ácido clorídrico e hidróxido de sódio, respectivamente e $V_{T}$ é o volume total que representa a soma do volume de ácido clorídrico $(5,05 \mathrm{~mL})$ e hidróxido de sódio adicionado.

Os valores de potencial medidos versus $\mathrm{pH}$ calculado fornecem uma reta cujo coeficiente angular corresponde ao termo que permite corrigir as medidas de $\mathrm{pH}$ das soluções de trabalho, "slope".

VI.5 - Determinação das Constantes de Dissociação/Ionização em 10, 19, 29 e $48 \%$ de Etanol pelo Método Potenciométrico

O equilíbrio de protonação, anteriormente apresentado, do DPKBH, pode ser representado através de:

$\mathrm{RNH}^{+} \rightleftharpoons \mathrm{RN}+\mathrm{H}^{+}$

onde, $\mathrm{RNH}^{+}$e $\mathrm{RN}$ é a forma protonada e não protonada do DPKBH, respectivamente.

Para determinação das constantes de dissociação, diversas soluções contendo diferentes razões $\mathrm{RN} / \mathrm{RNH}^{+}$foram preparadas. Para tanto soluções de DPKBH com concentração 
aproximadamente igual a $1.10^{-3} \mathrm{~mol} . \mathrm{L}^{-1}$, preparadas dissolvendo-se uma quantidade conhecida de DPKBH em etanol $95 \%$ em um balão volumétrico de $49,95 \mathrm{~mL}$, eram diluídas a uma determinada porcentagem de etanol. Num processo de titulação, incrementos de solução de $\mathrm{HClO}_{4}$ eram adicionados utilizando-se uma bureta de pistão de $5,00 \mathrm{~mL}$. Soluções de $\mathrm{HClO}_{4}$ com concentração aproximadamente igual a $3.10^{-3} \mathrm{~mol} \cdot \mathrm{L}^{-1}$ foram previamente padronizadas e diluídas (com a mesma porcentagem de etanol da solução de DPKBH).

A equação que define o equilibrio 35 é dada por:

$$
\mathrm{K}_{1}=\frac{[\mathrm{RN}]\left[\mathrm{H}^{+}\right]}{\left[\mathrm{RNH}^{+}\right]}
$$

e $\mathrm{K}_{1}$ representa a constante de dissociação ácida do DPKBH. A equação (36) pode ser transformada na equação de HendersonHasselbalch ${ }^{(36)}$, escrita a seguir:

$$
\mathrm{pH}=\mathrm{pK}_{1}+\log \frac{[\mathrm{RN}]}{\left[\mathrm{RNH}^{+}\right]}
$$

$\mathrm{O}$ valor de $\mathrm{pK}_{1}$ pode então ser obtido a partir dessa equação (37) e dos devidos balanços de massa para o equilíbrio, 
conforme as equações (38) e (39):

$$
\begin{aligned}
& {\left[\mathrm{RNH}^{+}\right]=\mathrm{C}_{\mathrm{H}^{+}}-\left[\mathrm{H}^{+}\right]} \\
& {[\mathrm{RN}]=\mathrm{C}_{\mathrm{RN}}-\left[\mathrm{RNH}^{+}\right]}
\end{aligned}
$$

onde $\left[\mathrm{RNH}^{+}\right]$representa a concentração de DPKBH protonado no equilíbrio, $\mathrm{C}_{\mathrm{H}^{+}}$a concentração analítica de $\mathrm{HClO}_{4},\left[\mathrm{H}^{+}\right]$é obtido através do $\mathrm{pH}$ lido no potenciômetro, [RN] a concentração de DPKBH não protonado no equilíbrio e $C_{R N}$ a concentração analítica de DPKBH. A Tabela VI exemplifica os cálculos efetuados, através do "software" Sigma Plot versão 3.2, a fim de obter-se os parâmetros mencionados anteriormente.

A partir da forma enólica do DPKBH, pode-se, então, considerar um segundo equilíbrio através de:

$$
\mathrm{ROH} \rightleftharpoons \mathrm{RO}^{-}+\mathrm{H}^{+}
$$

onde, ROH é o DPKBH e $\mathrm{RO}^{-}$é a forma aniônica do DPKBH. 
Tabela VI - Valores obtidos para uma titulação de 5,05 $\mathrm{mL}$ de DPKBH $1,01.10^{-3}$ mol.L $L^{-1}$ com $\mathrm{HClO}_{4} 4,18.10^{-3}$ mol. $\mathrm{L}^{-1}$ ambos em $10 \%$ de etanol, a $25^{\circ} \mathrm{C}$. O valor de "slope" utilizado para correção de $\mathrm{pH}$ foi de $54,56 \mathrm{mV}^{*}$.

\begin{tabular}{ccccccc}
\hline \hline volume & $\mathrm{pH}$ & $\mathrm{pH}$ corr & {$\left[\mathrm{H}^{+}\right]$} & {$\left[\mathrm{RNH}^{+}\right]$} & {$[\mathrm{RN}]$} & $\log$ razão \\
\hline 1,30 & 3,187 & 3,287 & $5,16 \mathrm{E}-04$ & $3,39 \mathrm{E}-04$ & $4,64 \mathrm{E}-04$ & 0,137 \\
1,35 & 3,173 & 3,272 & $5,35 \mathrm{E}-04$ & $3,47 \mathrm{E}-04$ & $4,50 \mathrm{E}-04$ & 0,113 \\
1,40 & 3,160 & 3,258 & $5,52 \mathrm{E}-04$ & $3,55 \mathrm{E}-04$ & $4,36 \mathrm{E}-04$ & 0,0893 \\
1,45 & 3,146 & 3,242 & $5,73 \mathrm{E}-04$ & $3,59 \mathrm{E}-04$ & $4,26 \mathrm{E}-04$ & 0,0743 \\
1,50 & 3,136 & 3,231 & $5,88 \mathrm{E}-04$ & $3,70 \mathrm{E}-04$ & $4,09 \mathrm{E}-04$ & 0,0435 \\
1,55 & 3,124 & 3,219 & $6,04 \mathrm{E}-04$ & $3,78 \mathrm{E}-04$ & $3,95 \mathrm{E}-04$ & 0,0191 \\
1,60 & 3,111 & 3,204 & $6,25 \mathrm{E}-04$ & $3,81 \mathrm{E}-04$ & $3,86 \mathrm{E}-04$ & 0,00566 \\
1,65 & 3,101 & 3,194 & $6,39 \mathrm{E}-04$ & $3,90 \mathrm{E}-04$ & $3,71 \mathrm{E}-04$ & $-0,0217$ \\
1,70 & 3,094 & 3,186 & $6,52 \mathrm{E}-04$ & $4,01 \mathrm{E}-04$ & $3,55 \mathrm{E}-04$ & $-0,0529$ \\
1,75 & 3,082 & 3,173 & $6,71 \mathrm{E}-04$ & $4,05 \mathrm{E}-04$ & $3,45 \mathrm{E}-04$ & $-0,0696$ \\
1,80 & 3,074 & 3,164 & $6,86 \mathrm{E}-04$ & $4,12 \mathrm{E}-04$ & $3,33 \mathrm{E}-04$ & $-0,0925$ \\
1,85 & 3,062 & 3,151 & $7,06 \mathrm{E}-04$ & $4,15 \mathrm{E}-04$ & $3,24 \mathrm{E}-04$ & $-0,108$ \\
1,90 & 3,055 & 3,144 & $7,18 \mathrm{E}-04$ & $4,25 \mathrm{E}-04$ & $3,09 \mathrm{E}-04$ & $-0,138$ \\
\hline \hline
\end{tabular}

valor que será apresentado no capítulo VII

Para determinação das constantes de ionização, diversas soluções contendo diferentes razões $\mathrm{RO}^{-} / \mathrm{ROH}$ foram preparadas. Para tanto soluções de DPKBH, preparadas da mesma forma como apresentado anteriormente, eram diluídas a uma 
determinada porcentagem de etanol. Também com processo de titulação, incrementos de solução de $\mathrm{NaOH}$ eram adicionados utilizando uma bureta de pistão de $5,00 \mathrm{~mL}$. Soluções de $\mathrm{NaOH}$ com concentração aproximadamente igual a $3.10^{-3}$ mol. $L^{-1}$ foram previamente padronizadas e diluídas (com a mesma porcentagem de etanol da solução de DPKBH).

A equação que define o equilibrio 40 é dada por:

$$
K_{2}=\frac{\left[R O^{-}\right]\left[H^{+}\right]}{[R O H]}
$$

e $\mathrm{K}_{2}$ representa a constante de ionização do DPKBH. Aquela equação pode ser transformada na equação de HendersonHasselbalch ${ }^{(36)}$, conforme a expressão abaixo:

$$
p H=p K_{2}+\log \frac{\left[R O^{-}\right]}{[R O H]}
$$

$O$ valor de $\mathrm{pK}_{2}$ pode então ser obtido a partir da equação acima e dos devidos balanços de massa para o equilíbrio, conforme mostram as equações (43) e (44):

$$
\begin{aligned}
& {\left[\mathrm{RO}^{-}\right]=\mathrm{C}_{\mathrm{RO}}--\left[\mathrm{H}^{+}\right]} \\
& {[\mathrm{ROH}]=\mathrm{C}_{\mathrm{ROH}}-\left[\mathrm{RO}^{-}\right]}
\end{aligned}
$$


onde $\left[\mathrm{RO}^{-}\right]$representa a concentração de DPKBH na forma aniônica no equilíbrio, $\mathrm{C}_{\mathrm{RO}}-$ corresponde à concentração analítica de $\mathrm{NaOH},\left[\mathrm{H}^{+}\right]$é obtido através do pH lido no potenciômetro, [ROH] a concentração de DPKBH no equilíbrio e $\mathrm{C}_{\mathrm{ROH}}$ a concentração analítica do DPKBH. A Tabela VII exemplifica os cálculos efetuados, através do "software" Sigma Plot versão 3.2, a fim de obter-se os parâmetros mencionados anteriormente.

Tabela VII - Valores obtidos para uma titulação de 5,05 $\mathrm{mL}$ de DPKBH $1,00.10^{-3}$ mol. $L^{-1}$ com $\mathrm{NaOH} 3,00.10^{-3}$ mol. $\mathrm{L}^{-1}$ ambos em $48 \%$ de etanol, a $25^{\circ} \mathrm{C}$. O valor de "slope" utilizado para correção de $\mathrm{pH}$ foi de $56,93 \mathrm{mV}^{*}$.

\begin{tabular}{ccccccc}
\hline \hline volume & $\mathrm{pH}$ & $\mathrm{pH}$ corr & {$\left[\mathrm{H}^{+}\right]$} & {$[\mathrm{RO}]$} & {$[\mathrm{ROH}]$} & $\log$ razão \\
\hline 0,65 & 10,894 & 11,324 & $4,73 \mathrm{E}-12$ & $3,42 \mathrm{E}-04$ & $5,44 \mathrm{E}-04$ & $-0,201$ \\
0,70 & 10,919 & 11,351 & $4,46 \mathrm{E}-12$ & $3,66 \mathrm{E}-04$ & $5,13 \mathrm{E}-04$ & $-0,147$ \\
0,75 & 10,933 & 11,365 & $4,31 \mathrm{E}-12$ & $3,88 \mathrm{E}-04$ & $4,82 \mathrm{E}-04$ & $-0,0940$ \\
0,80 & 10,953 & 11,386 & $4,11 \mathrm{E}-12$ & $4,11 \mathrm{E}-04$ & $4,53 \mathrm{E}-04$ & $-0,0420$ \\
0,85 & 10,970 & 11,404 & $3,94 \mathrm{E}-12$ & $4,33 \mathrm{E}-04$ & $4,23 \mathrm{E}-04$ & 0,00948 \\
0,90 & 10,983 & 11,418 & $3,82 \mathrm{E}-12$ & $4,54 \mathrm{E}-04$ & $3,95 \mathrm{E}-04$ & 0,0610 \\
0,95 & 10,995 & 11,430 & $3,71 \mathrm{E}-12$ & $4,76 \mathrm{E}-04$ & $3,66 \mathrm{E}-04$ & 0,0113 \\
1,00 & 11,014 & 11,450 & $3,55 \mathrm{E}-12$ & $4,96 \mathrm{E}-04$ & $3,38 \mathrm{E}-04$ & 0,166 \\
1,05 & 11,022 & 11,459 & $3,48 \mathrm{E}-12$ & $5,17 \mathrm{E}-04$ & $3,11 \mathrm{E}-04$ & 0,221 \\
\hline
\end{tabular}

valor que será apresentado no capítulo VII 


\section{VI.6 - Determinação das Constantes de Dissociação/Ionização em 10 e $48 \%$ de Etanol pelo Método Espectrofotométrico}

Considerando condições de equilíbrio ácido-base entre uma espécie protonada e sua equivalente desprotonada, a respectiva constante de equilíbrio pode ser determinada pelo método espectrofotométrico se ambas apresentam características espectrais diferentes.

O método espectrofotométrico consiste, então, na medida da variação da absorbância do sistema em estudo, em um determinado comprimento de onda, em função da variação do $\mathrm{pH}$. A base do método está no conhecimento das absorbâncias das espécies totalmente protonada, desprotonada e da mistura de ambas em proporções diferentes.

Considerando-se o equilíbrio de desprotonação:

$$
\mathrm{RNH}^{+} \rightleftharpoons \mathrm{RN}+\mathrm{H}^{+}
$$

numa mistura das espécies $\mathrm{RN}$ e $\mathrm{RNH}^{+}$, as absorbâncias parciais podem ser representadas através de frações molares das absorbâncias obtidas para o DPKBH totalmente protonado e desprotonado. Assim, a absorbância da mistura pode ser 
considerada:

$\mathrm{A}_{\text {mist. }}=\mathrm{x}_{\mathrm{RN}} \mathrm{A}_{\mathrm{RN}}+\mathrm{x}_{\mathrm{RNH}^{+}} \mathrm{A}_{\mathrm{RNH}^{+}}$

onde:

$\mathrm{A}_{\mathrm{RNH}^{+}}=$absorbância do DPKBH totalmente na forma protonada

$\mathrm{x}_{\mathrm{RNH}^{+}}=$fração molar da forma protonada na mistura

$A_{R N}=$ absorbância do DPKBH totalmente na forma não protonada

$\mathrm{x}_{\mathrm{RN}}=$ fração molar da forma não protonada na mistura

Sabe-se que:

$\mathrm{x}_{\mathrm{RN}}+\mathrm{x}_{\mathrm{RNH}^{+}}=1$ ou $\quad \mathrm{x}_{\mathrm{RN}}=1-\mathrm{x}_{\mathrm{RNH}^{+}}$

Utilizando-se as equações (45) e (46) pode-se obter:

$\mathrm{x}_{\mathrm{RNH}^{+}}=\frac{\mathrm{A}_{\text {mist. }}-\mathrm{A}_{\mathrm{RN}}}{\mathrm{A}_{\mathrm{RNH}^{+}}-\mathrm{A}_{\mathrm{RN}}}$

ou

$\left(1-\mathrm{x}_{\mathrm{RNH}^{+}}\right)=\frac{\mathrm{A}_{\mathrm{RNH}^{+}}-\mathrm{A}_{\text {mist. }}}{\mathrm{A}_{\mathrm{RNH}^{+}}-\mathrm{A}_{\mathrm{RN}}}$ 
ou

$\frac{1-\mathrm{x}_{\mathrm{RNH}^{+}}}{\mathrm{x}_{\mathrm{RNH}^{+}}}=\frac{\mathrm{A}_{\mathrm{RNH}^{+}}-\mathrm{A}_{\text {mist. }}}{\mathrm{A}_{\text {mist. }}-\mathrm{A}_{\mathrm{RN}}}$

A partir do equilíbrio genérico, tem-se a constante de dissociação:

$$
\mathrm{K}_{1}=\frac{[R N]\left[H^{+}\right]}{\left[R N H^{+}\right]}
$$

Considerando-se que o balanço de massas para o DPKBH é dado por: $\mathrm{C}_{\mathrm{T}}=[\mathrm{RN}]+\left[\mathrm{RNH}^{+}\right]$, pode-se substituir os termos da equação (36) usando-se a equação (46) e obter a seguinte expressão:

$$
\mathrm{K}_{1} \mathrm{C}_{\mathrm{T}} \mathrm{x}_{\mathrm{RNH}^{+}}=\mathrm{C}_{\mathrm{T}}\left(1-\mathrm{x}_{\mathrm{RNH}^{+}}\right)\left[\mathrm{H}^{+}\right]
$$

A equação (50) pode ser rearranjada em:

$$
\mathrm{K}_{1}=\frac{1-\mathrm{x}_{\mathrm{RNH}^{+}}}{\mathrm{x}_{\mathrm{RNH}^{+}}}\left[\mathrm{H}^{+}\right]
$$


A combinação das equações (49) e (51) resulta $\mathrm{em}^{(80)}$ :

$$
\mathrm{K}_{1}=\frac{\mathrm{A}_{\mathrm{RNH}^{+}}-\mathrm{A}_{\text {mist. }}}{\mathrm{A}_{\text {mist }}-\mathrm{A}_{\mathrm{RN}}}\left[\mathrm{H}^{+}\right]
$$

e, aplicando-se -log obtém-se ${ }^{(42)}$ :

$$
\mathrm{pH}=\mathrm{pK}_{1}+\log \frac{\mathrm{A}_{\mathrm{RNH}^{+}}-\mathrm{A}_{\text {mist. }}}{\mathrm{A}_{\text {mist. }}-\mathrm{A}_{\mathrm{RN}}}
$$

Para a obtenção da absorbância do DPKBH na forma totalmente protonada pipetou-se $0,9485 \mathrm{~mL}$ de uma solução de DPKBH para um balão volumétrico de $10,0 \mathrm{~mL}$ e adicionou-se um volume de $\mathrm{HClO}_{4}$, suficiente para obter-se um valor de $\mathrm{pH}$ que levasse à total predominância da espécie $\mathrm{RNH}^{+}$. Para a obtenção da absorbância do DPKBH na forma neutra pipetou-se $0,9485 \mathrm{~mL}$ de uma solução de DPKBH de concentração $2,45 \cdot 10^{-4}$ mol. $\mathrm{L}^{-1}$ em etanol para um balão volumétrico de $10,0 \mathrm{~mL}$ e diluiu-se a solução à porcentagem de etanol do estudo com água destilada. Quanto à obtenção das soluções onde as duas formas estão presentes pipetou-se $0,9485 \mathrm{~mL}$ de DPKBH e através de micropipetas foram adicionados diferentes volumes de $\mathrm{HClO}_{4}$, a fim de obter várias soluções em diferentes valores de $\mathrm{pH}$.

Da mesma forma considera-se o equilíbrio de 
ionização:

$$
\mathrm{ROH} \rightleftharpoons \mathrm{RO}^{-}+\mathrm{H}^{+}
$$

onde a base do método está no conhecimento das absorbâncias das espécies totalmente aniônica, neutra e da mistura de ambas em proporções diferentes.

Através de equações equivalentes às usadas para $\mathrm{pK}_{1}$, chega-se à equação:

$$
\mathrm{K}_{2}=\frac{\mathrm{A}_{\mathrm{ROH}}-\mathrm{A}_{\text {mist. }}\left[\mathrm{H}^{+}\right]}{\mathrm{A}_{\text {mist. }}-\mathrm{A}_{\mathrm{RO}}^{-}}
$$

Aplicando-se logarítmo a equação (54), obtém-se ${ }^{(42)}$ :

$$
\mathrm{pH}=\mathrm{pK}_{2}+\log \frac{\mathrm{A}_{\mathrm{ROH}}-\mathrm{A}_{\text {mist. }}}{\mathrm{A}_{\text {mist. }}-\mathrm{A}_{\mathrm{RO}}{ }^{-}}
$$

Para a obtenção da absorbância do DPKBH na forma totalmente aniônica pipetou-se $0,9485 \mathrm{~mL}$ de uma solução de DPKBH para um balão volumétrico de $10,0 \mathrm{~mL}$ e adicionou-se um volume de $\mathrm{NaOH}$, suficiente para obter-se um valor de $\mathrm{pH}$ que levasse à total predominância da espécie $\mathrm{RO}^{-}$. Para a obtenção da absorbância do DPKBH na forma neutra seguiu-se o procedimento citado anteriormente. Quanto à obtenção das soluções onde as duas formas estão presentes pipetou-se $0,9485 \mathrm{~mL}$ de DPKBH e 
adicionou-se, através de micropipetas, diferentes volumes de $\mathrm{NaOH}$ a fim de obter várias soluções em diferentes valores de $\mathrm{pH}$. 


\section{VII-RESULTADOS EXPERIMENTAIS}


VII.1-"Slope" do Eletrodo de Vidro em 10, 19, 29 e $48 \%$ de Etanol

Como mencionado no tópico VI.4 tornou-se necessária a determinação do "slope" do eletrodo de vidro, nas porcentagens de etanol $10,19,29$ e $48 \%$.

Os valores de "slope" e coeficiente de correlação obtidos pelo método dos mínimos quadrados (regressão linear) para titulações de $\mathrm{HCl}$ com $\mathrm{NaOH}$ em $10,19,29$ e $48 \%$ de etanol encontram-se nas Tabelas VIII,IX, X e XI, respectivamente.

Tabela VIII - Coeficientes de correlação e angular calculados a partir dos dados de E versus $\mathrm{pH}$ obtidos em seis titulações de $5,05 \mathrm{~mL}$ de $\mathrm{HCl} 1,00.10^{-2}$ mol. $\mathrm{L}^{-1} \operatorname{com~NaOH~} 3,00 \cdot 10^{-2} \mathrm{~mol} \cdot \mathrm{L}^{-1}$, em $10 \%$ de etanol e a $(25,0 \pm 0,1)^{\circ} \mathrm{C}$.

\begin{tabular}{ccc}
\hline Série & Coeficiente Correlação & Coeficiente Angular (mV) \\
\hline 1 & 0,9999 & $54,30^{*}$ \\
2 & 0,9999 & 54,49 \\
3 & 0,9996 & 54,51 \\
4 & 0,9999 & 54,61 \\
5 & 0,9999 & 54,64 \\
6 & 0,9999 & $54,74^{*}$ \\
\hline \hline
\end{tabular}

*valores não considerados no cálculo da média 
Tabela IX - Coeficientes de correlação e angular calculados a partir dos dados de E versus $\mathrm{pH}$ obtidos em cinco titulações de

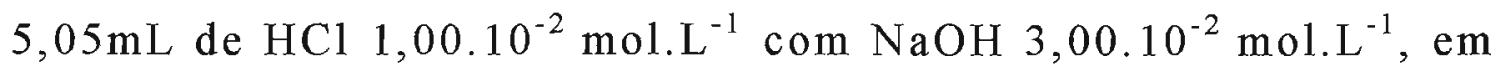
$19 \%$ de etanol e a $(25,0 \pm 0,1)^{\circ} \mathrm{C}$.

\begin{tabular}{ccc}
\hline \hline Série & Coeficiente Correlação & Coeficiente Angular (mV) \\
\hline 1 & 0,9990 & $53,35^{*}$ \\
2 & 0,9999 & 53,85 \\
3 & 0,9999 & 53,86 \\
4 & 0,9999 & 53,94 \\
5 & 0,9999 & $53,55^{*}$ \\
\hline
\end{tabular}

*valores não considerados no cálculo da média

Tabela X - Coeficientes de correlação e angular calculados a partir dos dados de E versus pH obtidos em cinco titulações de $5,05 \mathrm{~mL}$ de $\mathrm{HCl} 1,00.10^{-2}$ mol. $\mathrm{L}^{-1} \operatorname{com~NaOH~} 3,00 \cdot 10^{-2} \mathrm{~mol} \cdot \mathrm{L}^{-1}$, em $29 \%$ de etanol e a $(25,0 \pm 0,1)^{\circ} \mathrm{C}$.

\begin{tabular}{ccc}
\hline Série & Coeficiente Correlação & Coeficiente Angular (mV) \\
\hline 1 & 0,9999 & 51,17 \\
2 & 0,9999 & 51,16 \\
3 & 0,9999 & 51,10 \\
4 & 0,9998 & 51,11 \\
5 & 0,9999 & $51,68^{*}$ \\
\hline \hline
\end{tabular}

*valor não considerado no cálculo da média 
Tabela XI - Coeficientes de correlação e angular calculados a partir dos dados de E versus $\mathrm{pH}$ obtido em cinco titulações de

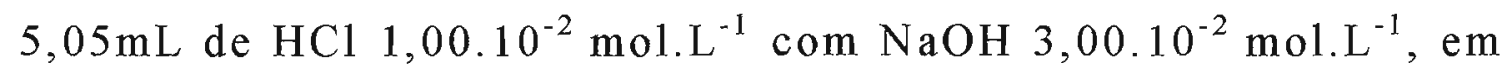
$48 \%$ de etanol e a $(25,000 \pm 0,005)^{\circ} \mathrm{C}$. Para um novo eletrodo.

\begin{tabular}{ccc}
\hline \hline Série & Coeficiente Correlação & Coeficiente Angular (mV) \\
\hline 1 & 0,9996 & 56,93 \\
2 & 0,9998 & 56,94 \\
3 & 0,9999 & 56,93 \\
4 & 0,9998 & $57,12^{*}$ \\
5 & 0,9998 & $58,40^{*}$ \\
\hline \hline
\end{tabular}

*valores não considerados no cálculo da média

Os dados obtidos para uma série de medidas, nas respectivas porcentagens de etanol, estão representados nas Figuras 3, 4, 5 e 6, respectivamente.

Os valores de coeficiente angular e desvio padrão para titulações de $\mathrm{HCl}$ com $\mathrm{NaOH}$ em $10,19,29$ e $48 \%$ de etanol encontram-se na Tabela XII.

Feita a determinação do "slope" do eletrodo, tornou-se necessário dispor de uma solução padrão, de pH conhecido, para calibração do eletrodo nas condições de estudo. Para isso utilizouse uma solução de hidrogenoftalato de potássio em etanol nas mesmas porcentagens estudadas. 


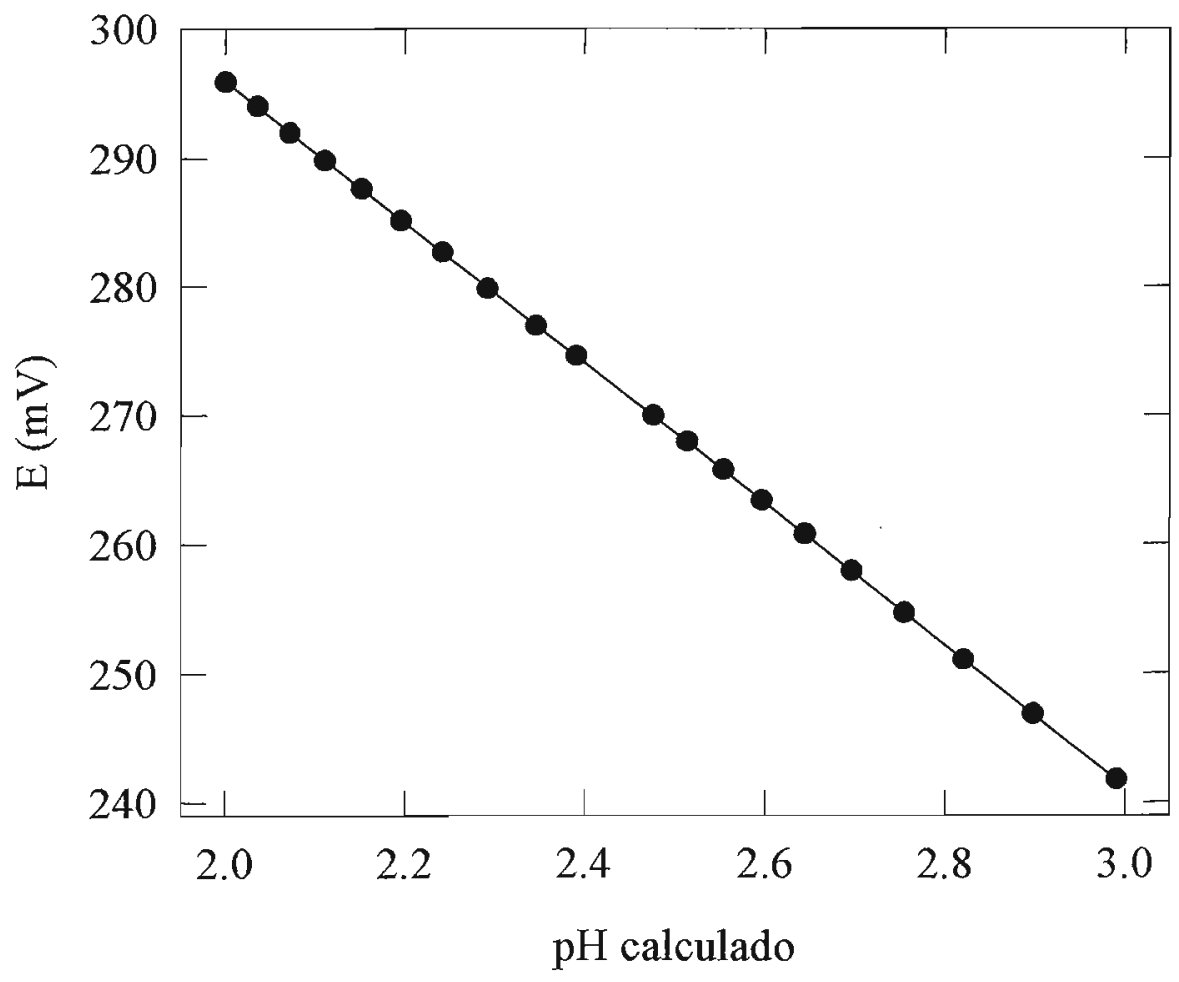

Figura 3 - Valores experimentais de potencial versus $\mathrm{pH}$ calculado para titulação de $5,05 \mathrm{~mL}$ de $\mathrm{HCl} 1,00.10^{-2} \mathrm{~mol}^{-1}$ com $\mathrm{NaOH} 3,00 \cdot 10^{-2} \mathrm{~mol} \cdot \mathrm{L}^{-1}$ a $25,0 \pm 0,1^{\circ} \mathrm{C}$ em etanol $10 \%$.

Assim, o eletrodo foi calibrado com uma solução de $\mathrm{HCl}$ com concentração aproximadamente 0,0100 mol. $\mathrm{L}^{-1}$ e consequentemente um $\mathrm{pH} \cong 2,00$. A seguir, foram feitas várias leituras de soluções de hidrogenoftalato de potássio $(\mathrm{pH}=4,00)$ 
em meio aquoso em etanol 10, 19, 29 e 48\%. Os valores reais obtidos para estas soluções estão apresentados na Tabela XIII.

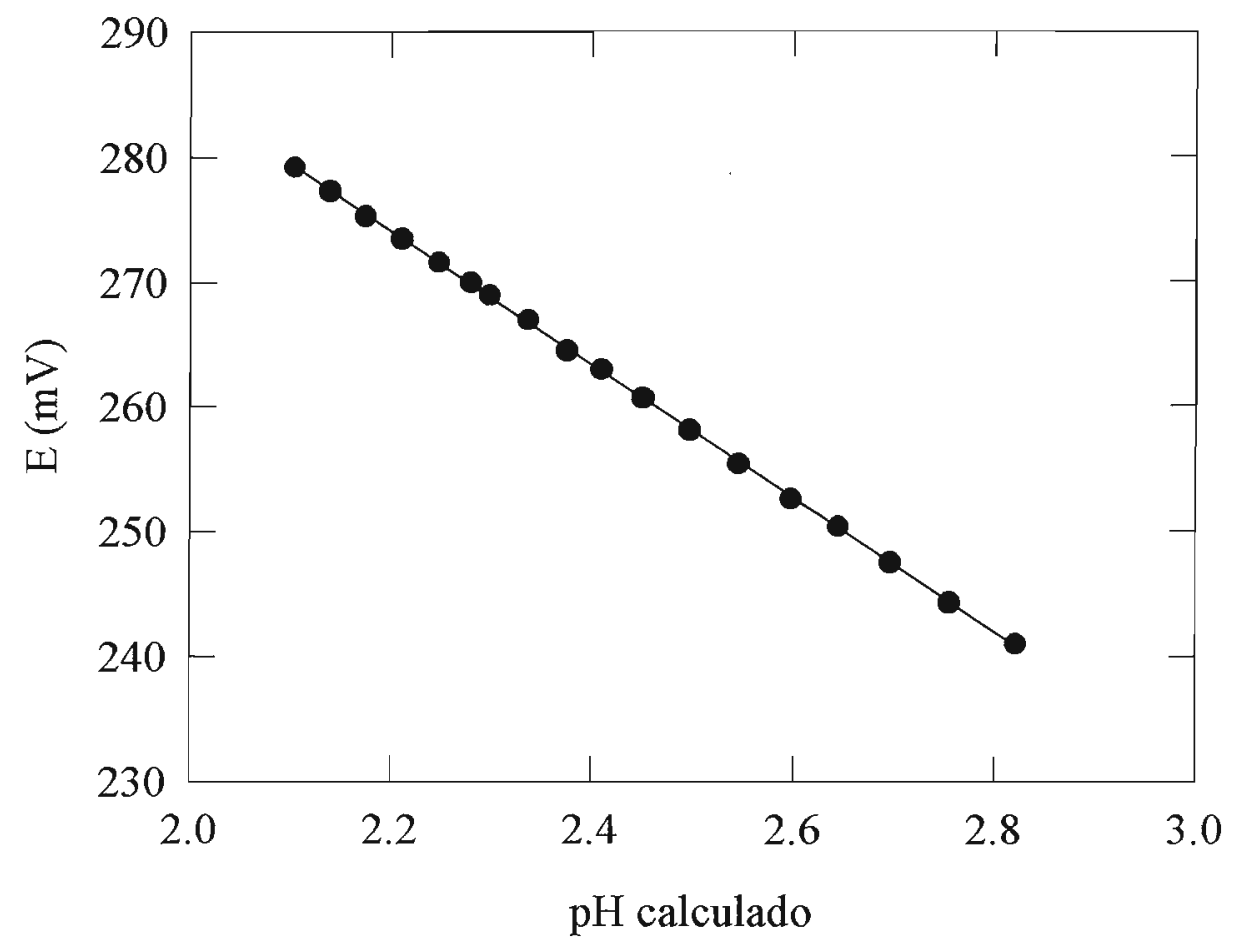

Figura 4 - Valores experimentais de potencial versus $\mathrm{pH}$ calculado para titulação de $5,05 \mathrm{~mL}$ de $\mathrm{HCl} 1,00 \cdot 10^{-2} \mathrm{~mol}^{-1} \mathrm{com}$ $\mathrm{NaOH} 3,00 \cdot 10^{-2}$ mol. $\mathrm{L}^{-1}$ a $25,0 \pm 0,1^{\circ} \mathrm{C}$ em etanol $19 \%$. 


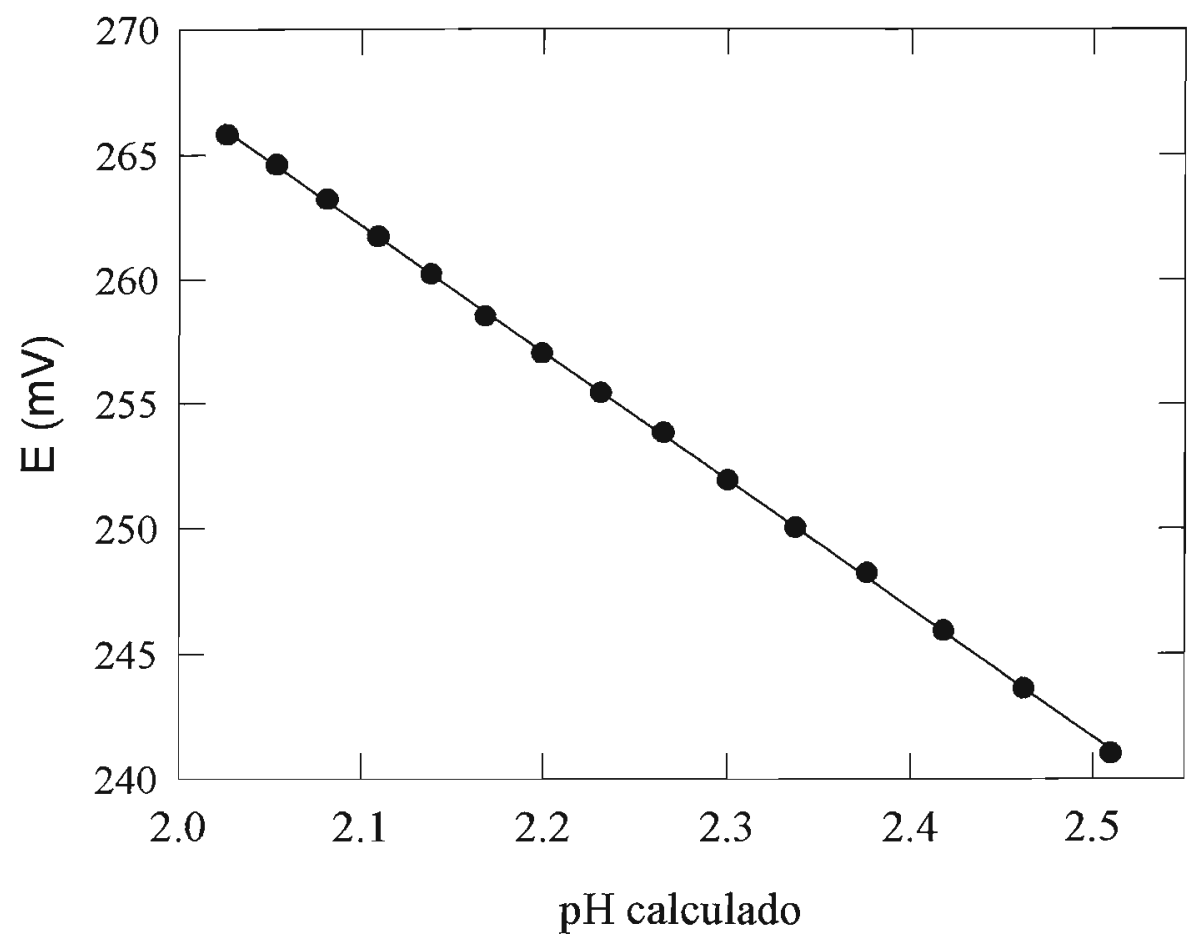

Figura 5 - Valores experimentais de potencial versus $\mathrm{pH}$ calculado para titulação de $5,05 \mathrm{~mL}$ de $\mathrm{HCl} 1,00.10^{-2}$ mol. $\mathrm{L}^{-1}$ com $\mathrm{NaOH} 3,00 \cdot 10^{-2}$ mol. $\mathrm{L}^{-1}$ a $25,0 \pm 0,1^{\circ} \mathrm{C}$ em etanol $29 \%$. 


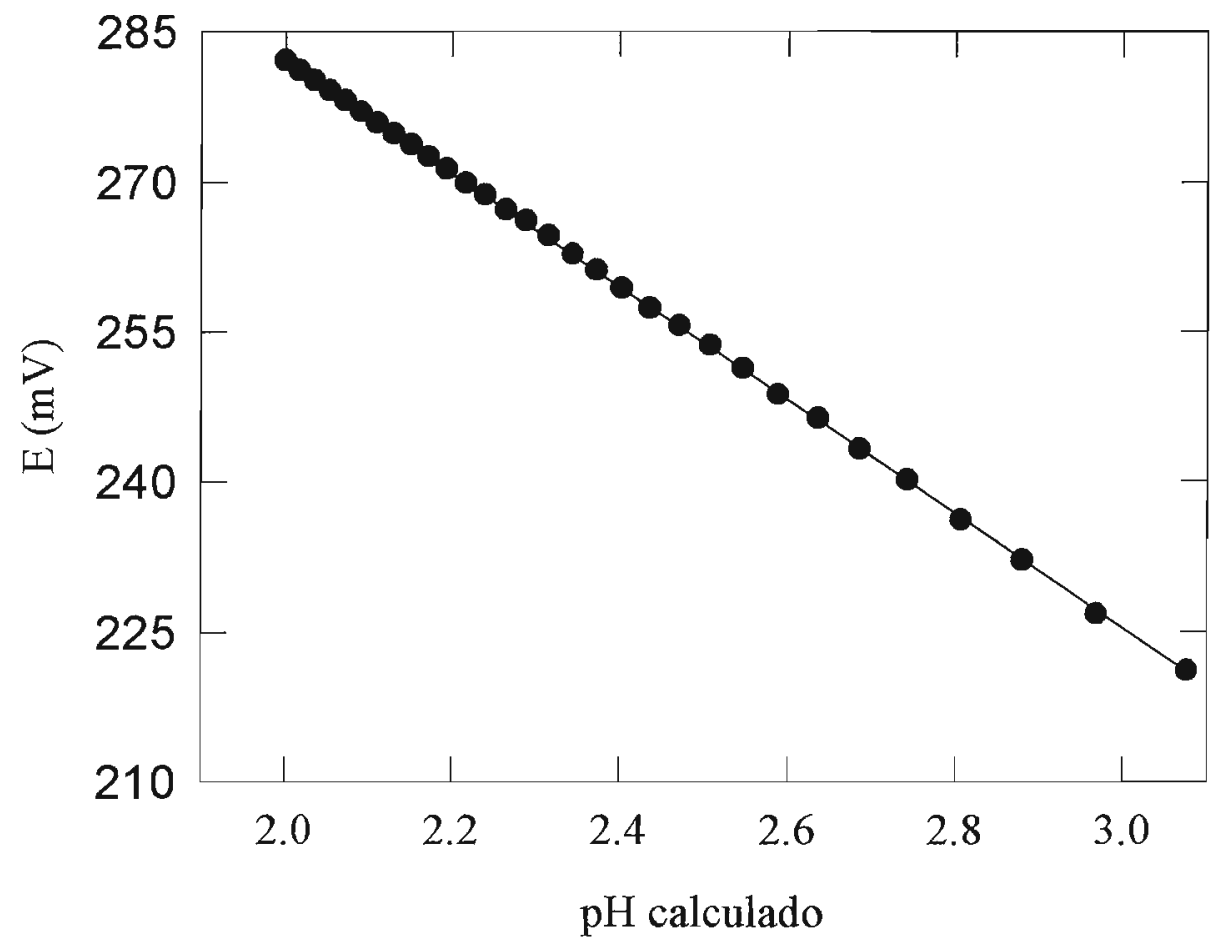

Figura 6- Valores experimentais de potencial versus $\mathrm{pH}$ calculado para titulação de $5,05 \mathrm{~mL}$ de $\mathrm{HCl} 1,00 \cdot 10^{-2} \mathrm{~mol} \cdot \mathrm{L}^{-1}$ com $\mathrm{NaOH} 3,00 \cdot 10^{-2}$ mol. $\mathrm{L}^{-1}$ a $25,000 \pm 0,005^{\circ} \mathrm{C}$ em etanol $48 \%$. Para um novo eletrodo. 
Tabela XII - Valores de coeficiente angular ("slope") e desvio padrão obtidos da titulação de $\mathrm{HCl}$ com $\mathrm{NaOH}$, em diferentes porcentagens de etanol.

\begin{tabular}{ccc}
\hline \hline \%Etanol & Coeficiente Angular & Desvio Padrão \\
\hline 10 & 54,56 & 0,07 \\
19 & 53,88 & 0,05 \\
29 & 51,14 & 0,04 \\
48 & 56,93 & 0,01 \\
\hline \hline
\end{tabular}

Tabela XIII - Valores de pH das soluções de hidrogenoftalato de potássio 0,05 mol. $\mathrm{L}^{-1} \mathrm{em}$ diferentes porcentagens de etanol.

\begin{tabular}{cc}
\hline \% Etanol & $\mathrm{pH}$ \\
\hline 10 & 4,086 \\
19 & 4,442 \\
29 & 4,694 \\
48 & 5,172 \\
\hline \hline
\end{tabular}


VII.2 - Determinação Potenciométrica das Constantes de Dissociação/Ionização

\author{
VII.2.1 - Obtenção da Constante de Dissociação $\left(K_{1}\right)$ em \\ $10,19,29$ e $48 \%$ de Etanol
}

Com as medidas de $\mathrm{pH}$ obtidas experimentalmente, durante as titulações das soluções de $\mathrm{DPKBH}$ com $\mathrm{HClO}_{4}$, ambos em $10,19,29$ e $48 \%$ de etanol, corrigidas pelo fator de resposta do eletrodo, equação 25 , e o logaritmo da razão $\left[\mathrm{RN} / \mathrm{RNH}^{+}\right.$] construiu-se os gráficos de $\mathrm{pH}$ corrigido versus logarítmo da razão (calculado).

Nas Figuras $7,8,9$ e 10 estão representados alguns dados para uma série de titulações nas porcentagens de etanol de estudo, onde obtém-se uma reta cuja intersecção com o eixo das ordenadas fornece o valor de $\mathrm{pK}_{1}$.

Os valores de coeficiente de correlação e $\mathrm{pK}_{1}$, obtidos após o método dos mínimos quadrados para o DPKBH em 10, 19, 29 e $48 \%$ de etanol, estão representados nas Tabelas XIV, XV e XVI e XVII, respectivamente. 
Os valores de $\mathrm{pK}_{1}$ e respectivos desvios padrão para o DPKBH em 10, 19, 29 e $48 \%$ de etanol encontram-se na Tabela XVIII.

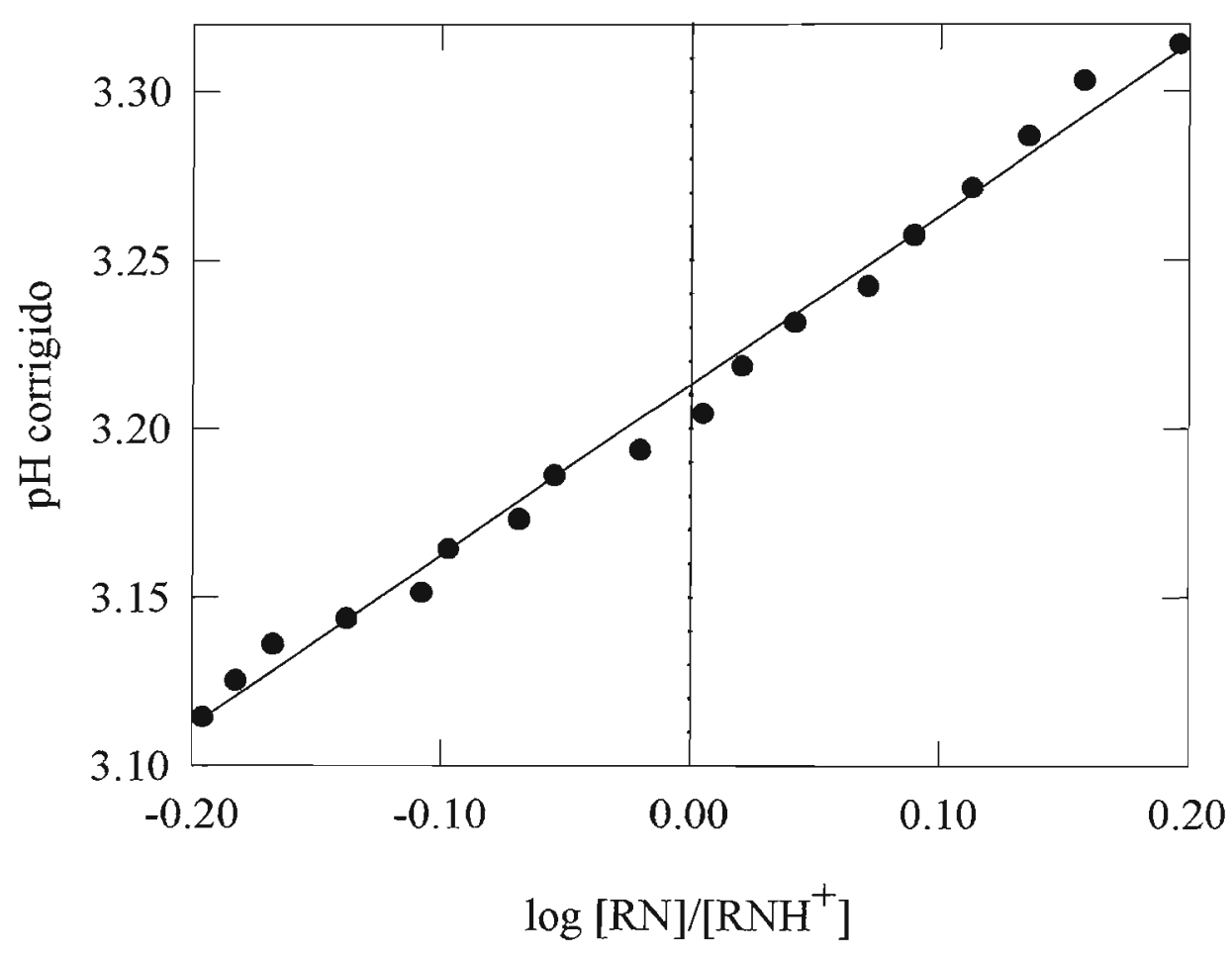

Figura 7 - Valores de $\mathrm{pH}$ corrigido versus logarítmo da razão obtidos para uma titulação de DPKBH $1,00.10^{-3}$ mol.L $L^{-1}$ com $\mathrm{HClO}_{4} 4,18.10^{-3}$ mol. $\mathrm{L}^{-1}$ em etanol $10 \%$ a $(25,0 \pm 0,1){ }^{\circ} \mathrm{C}$. 


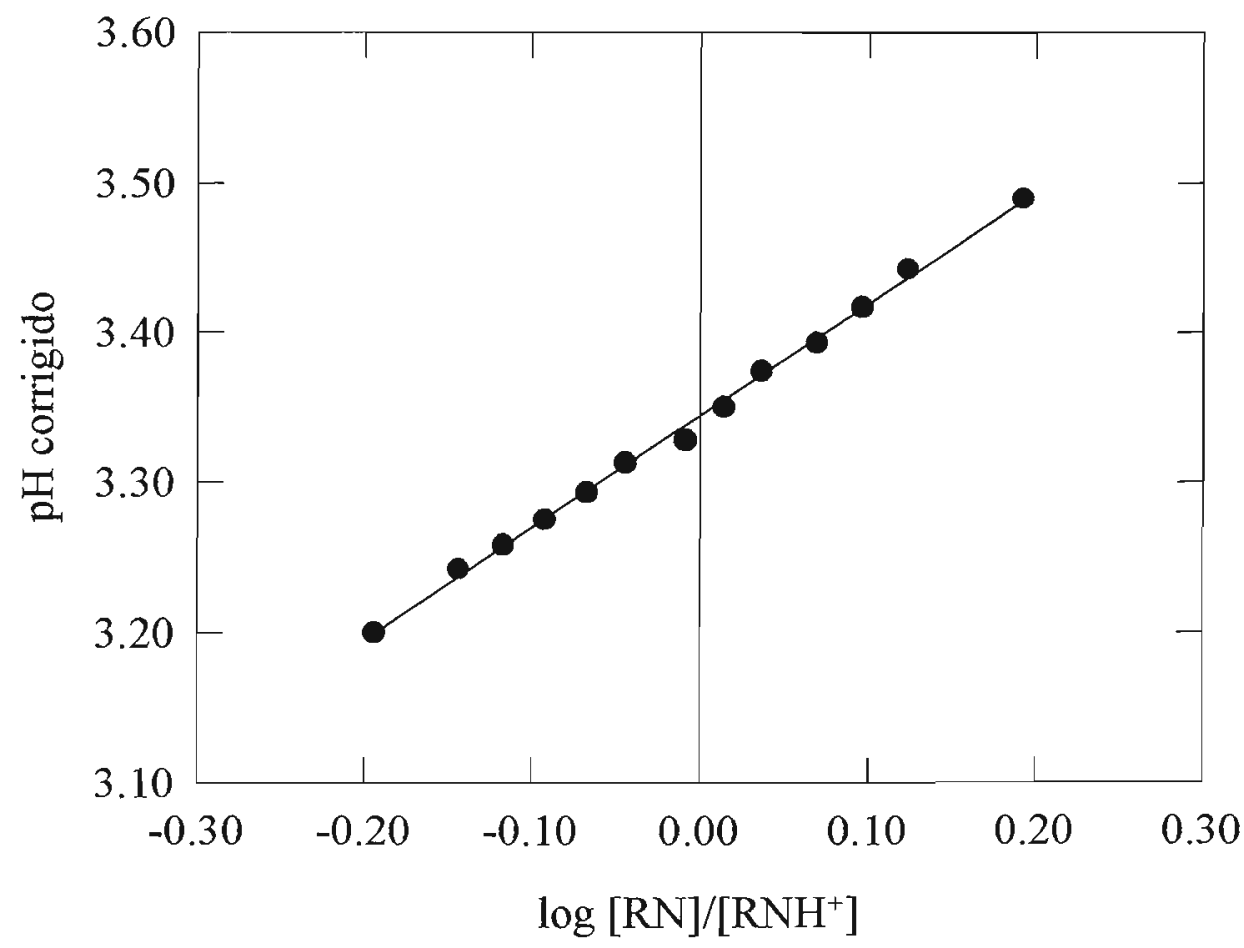

Figura 8 - Valores de $\mathrm{pH}$ corrigido versus logarítmo da razão obtidos para uma titulação de DPKBH $1,01.10^{-3}$ mol. $\mathrm{L}^{-1}$ com $\mathrm{HClO}_{4} 3,37.10^{-3}$ mol. $\mathrm{L}^{-1}$ em etanol $19 \%$ a $(25,0 \pm 0,1)^{\circ} \mathrm{C}$. 


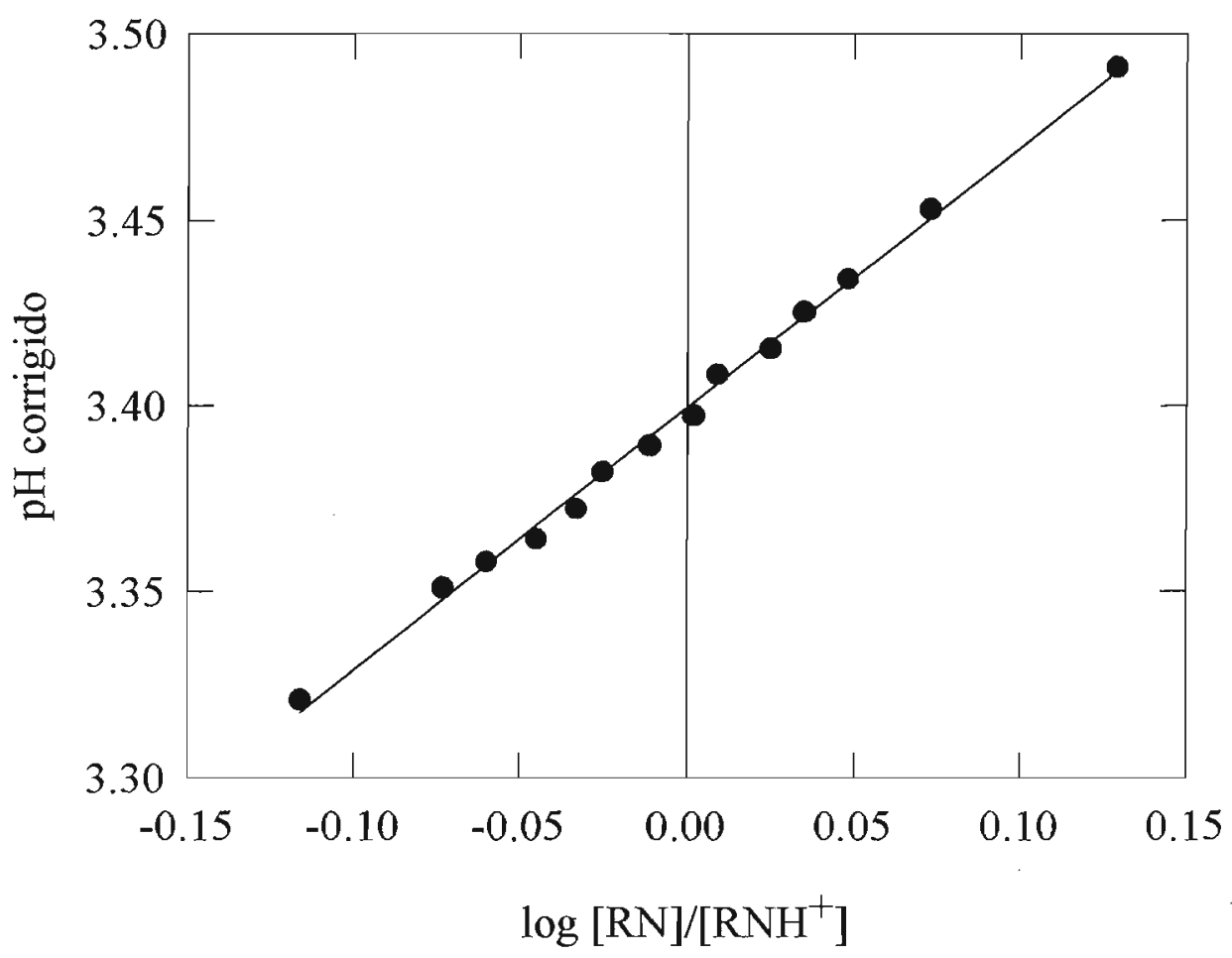

Figura 9 - Valores de $\mathrm{pH}$ corrigido versus logarítmo da razão obtidos para uma titulação de DPKBH $1,08.10^{-3}$ mol. $L^{-1}$ com $\mathrm{HClO}_{4} 3,89.10^{-3}$ mol. $\mathrm{L}^{-1}$ em etanol $29 \%$ a $(25,0 \pm 0,1){ }^{\circ} \mathrm{C}$. 


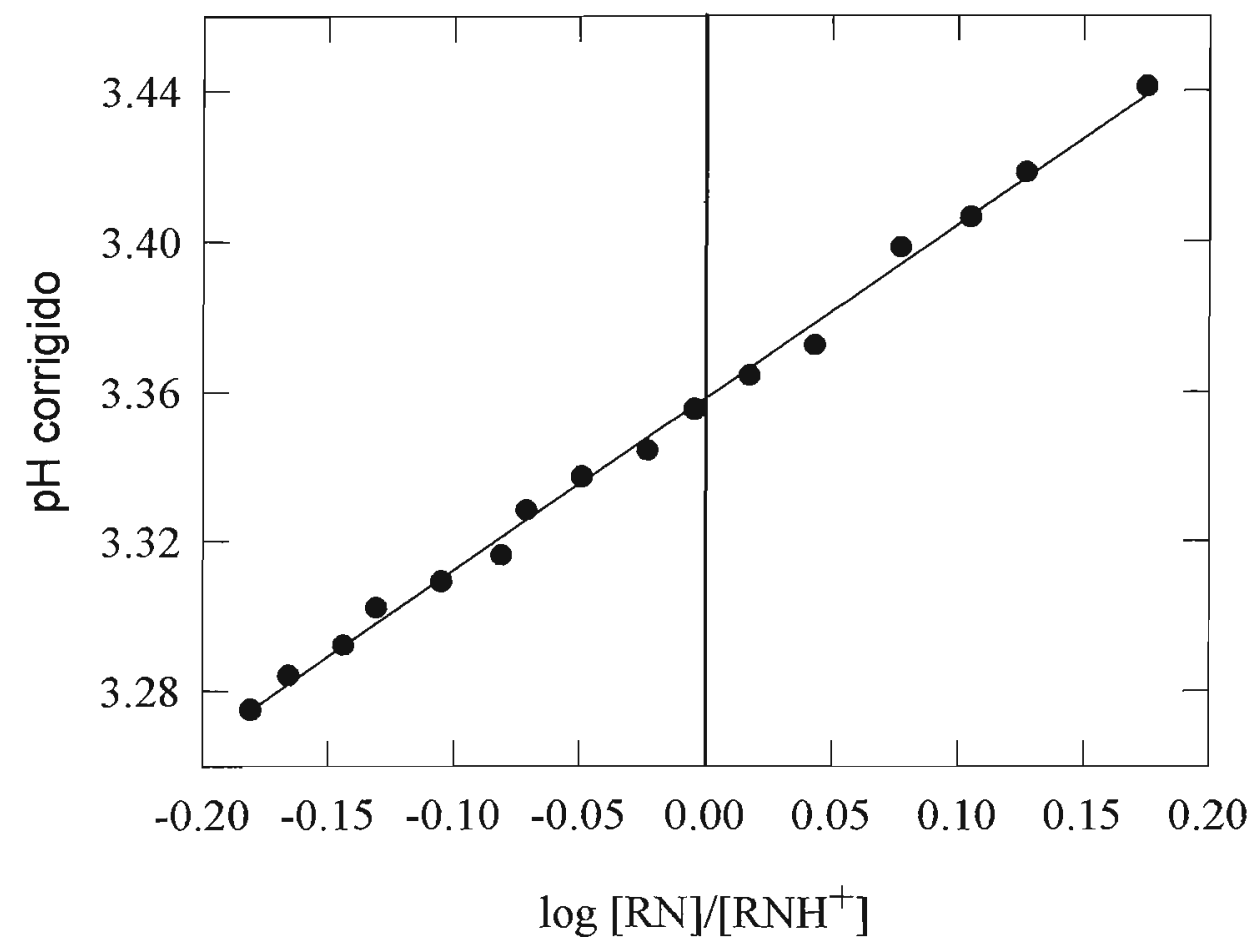

Figura 10 - Valores de $\mathrm{pH}$ corrigido versus logarítmo da razão obtidos para uma titulação de DPKBH $1,00.10^{-3}$ mol. $\mathrm{L}^{-1}$ com $\mathrm{HClO}_{4} 3,02 \cdot 10^{-1} \mathrm{~mol} \cdot \mathrm{L}^{-1}$ em etanol $48 \%$ a $(25,000 \pm 0,005){ }^{\circ} \mathrm{C}$. 
Tabela XIV - Valores obtidos da titulação de DPKBH 1,00.10 $0^{-3}$ mol. $\mathrm{L}^{-1}$ com $\mathrm{HClO}_{4} 4,18.10^{-3}$ mol. $\mathrm{L}^{-1}$ em etanol $10 \%$, após tratamento pelo método dos mínimos quadrados.

\begin{tabular}{ccc}
\hline \hline Série & Coeficiente Correlação & $\mathrm{pK}_{1}$ \\
\hline 1 & 0,9999 & $3,043^{*}$ \\
2 & 0,9990 & $3,184^{*}$ \\
3 & 0,9998 & 3,210 \\
4 & 0,9998 & 3,213 \\
5 & 0,9997 & 3,213 \\
6 & 0,9994 & 3,205 \\
\hline \hline
\end{tabular}

valores não considerados na média

Tabela XV - Valores obtidos da titulação de DPKBH 1,01.10 $0^{-3}$ mol. $\mathrm{L}^{-1}$ com $\mathrm{HClO}_{4} 3,77.10^{-3}$ mol.L $\mathrm{L}^{-1}$ em etanol $19 \%$, após tratamento pelo método dos mínimos quadrados.

\begin{tabular}{ccc}
\hline \hline Série & Coeficiente Correlação & $\mathrm{pK}_{1}$ \\
\hline 1 & 0,9993 & 3,346 \\
2 & 0,9995 & 3,344 \\
3 & 0,9992 & 3,345 \\
4 & 0,9999 & 3,340 \\
5 & 0,9992 & 3,350 \\
\hline \hline
\end{tabular}


Tabela XVI- Valores obtidos da titulação de DPKBH

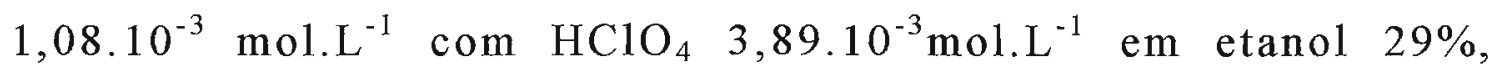
após tratamento pelo método dos mínimos quadrados.

\begin{tabular}{ccc}
\hline \hline Série & Coeficiente Correlação & $\mathrm{pK}_{1}$ \\
\hline 1 & 0,9992 & 3,397 \\
2 & 0,9996 & 3,397 \\
3 & 0,9997 & 3,398 \\
4 & 0,9993 & 3,399 \\
5 & 0,9996 & 3,401 \\
6 & 0,9996 & $3,406^{*}$ \\
\hline \hline
\end{tabular}

*valor não considerado na média

Tabela XVII - Valores obtidos da titulação de DPKBH $1,00.10^{-3}$ mol. $\mathrm{L}^{-1}$ com $\mathrm{HClO}_{4} 3,02.10^{-3}$ mol.L $\mathrm{L}^{-1}$ em etanol $48 \%$, após tratamento pelo método dos mínimos quadrados.

\begin{tabular}{ccc}
\hline \hline Série & Coeficiente Correlação & $\mathrm{pK}_{1}$ \\
\hline 1 & 0,9995 & 3,356 \\
2 & 0,9996 & 3,358 \\
3 & 0,9999 & 3,361 \\
4 & 0,9992 & 3,371 \\
5 & 0,9996 & $3,381^{*}$ \\
\hline \hline
\end{tabular}

valor não considerado na média 
Tabela XVIII - Valores de $\mathrm{pK}_{1}$ e repectivos desvios padrão para o DPKBH em diferentes porcentagens de etanol.

\begin{tabular}{ccc}
\hline \hline \% Etanol & $\mathrm{pK}_{1}$ & desvio padrão \\
\hline 10 & 3,210 & 0,003 \\
19 & 3,342 & 0,004 \\
29 & 3,398 & 0,002 \\
48 & 3,362 & 0,007 \\
\hline
\end{tabular}

VII.2.2 - Obtenção da Constante de Ionização $\left(K_{2}\right)$ em 10, 19,29 e $48 \%$ de Etanol

Com as medidas de $\mathrm{pH}$ obtidas experimentalmente, durante as titulações das soluções de DPKBH com $\mathrm{NaOH}$ ambos em $10,19,29$ e $48 \%$ de etanol, corrigidas pelo fator de resposta do eletrodo, equação 25 , e o logarítmo da razão [RO/ROH] construiu-se os gráficos de $\mathrm{pH}$ corrigido versus logarítmo da razão (calculado).

Nas Figuras 11, 12, 13 e 14 estão representados alguns dados para uma série de titulações nas porcentagens de etanol de estudo, onde obtém-se uma reta cuja intersecção com o eixo das ordenadas fornece o valor de $\mathrm{pK}_{2}$. 
Os valores de coeficiente de correlação e $\mathrm{pK}_{2}$, obtidos após o método dos mínimos quadrados para o DPKBH em 10, 19, 29 e $48 \%$ de etanol, estão representados nas Tabelas XIX, XX, XXI e XXII, respectivamente.

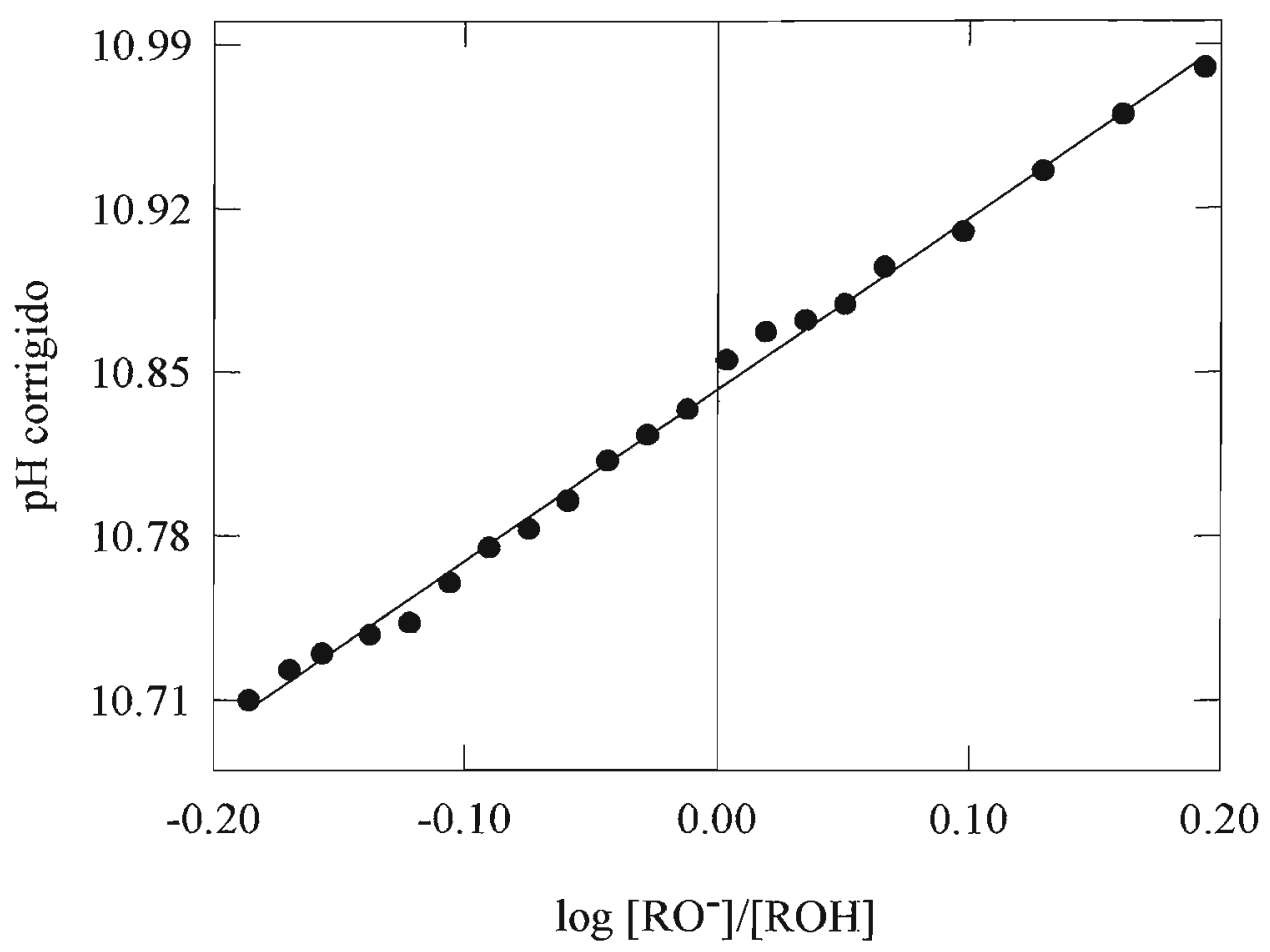

Figura 11 - Valores de $\mathrm{pH}$ corrigidos versus logarítmo da razão obtidos para uma titulação de DPKBH $5,24.10^{-4}$ mol.L $L^{-1}$ com $\mathrm{NaOH} 9,49 \cdot 10^{-4}$ mol. $\mathrm{L}^{-\mathrm{I}}$ em etanol $10 \%$ a $(25,0 \pm 0,1)^{\circ} \mathrm{C}$. 
Os valores de $\mathrm{pK}_{2}$ e respectivos desvios padrão para o DPKBH em $10,19,29$ e $48 \%$ de etanol encontram-se na Tabela XXIII.

A Tabela XXIV reune todos os valores de $\mathrm{pK}_{1}, \mathrm{pK}_{2} \mathrm{e}$ respectivas constantes de dissociação/ionização do DPKBH.

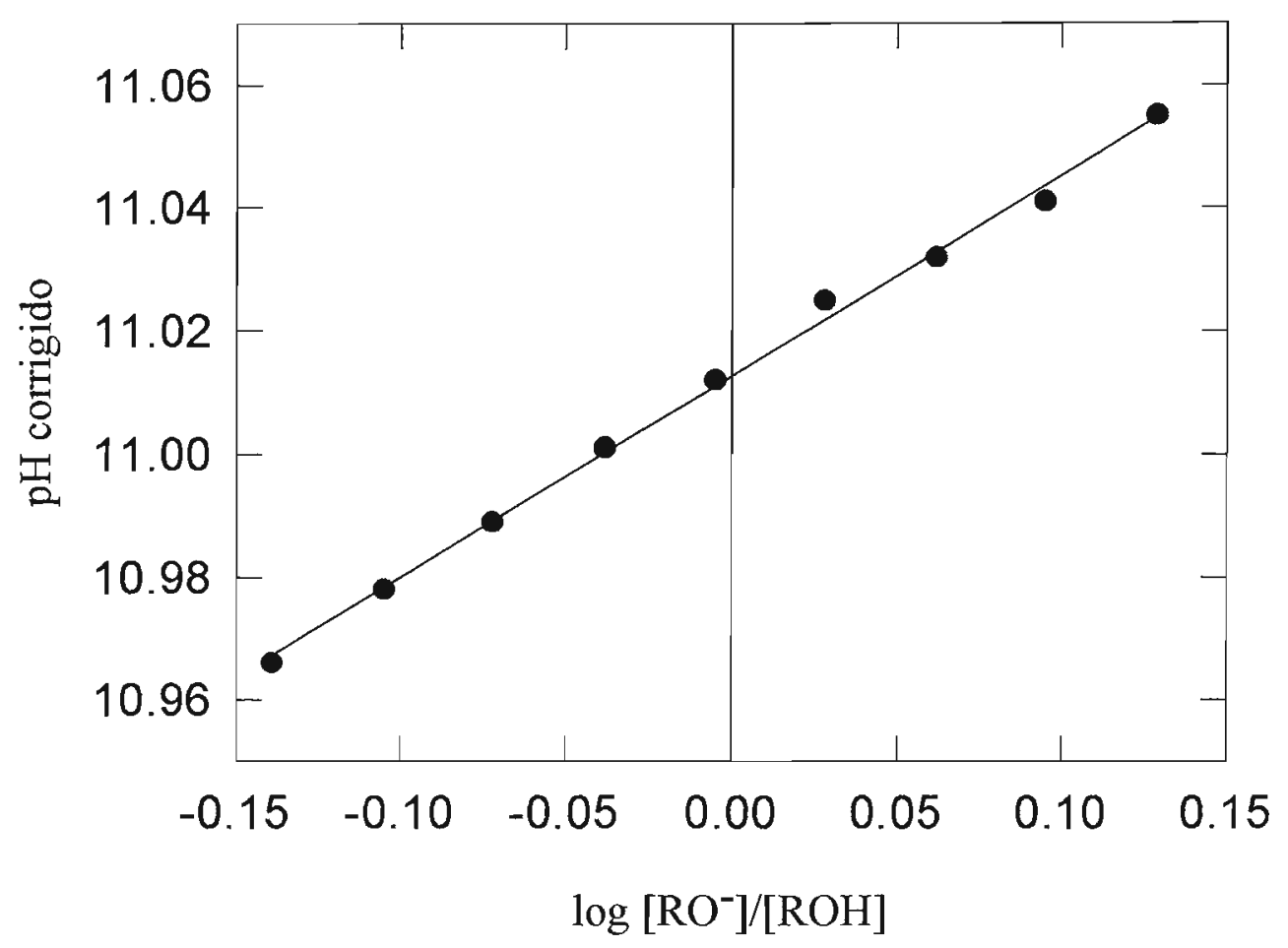

Figura 12 - Valores de pH corrigidos versus logarítmo da razão obtidos para uma titulação de DPKBH $1,02.10^{-3}$ mol. $\mathrm{L}^{-1}$ com $\mathrm{NaOH} 3,92 \cdot 10^{-3}$ mol. $\mathrm{L}^{-1}$ em etanol $19 \%$ a $(25,0 \pm 0,1)^{\circ} \mathrm{C}$. 


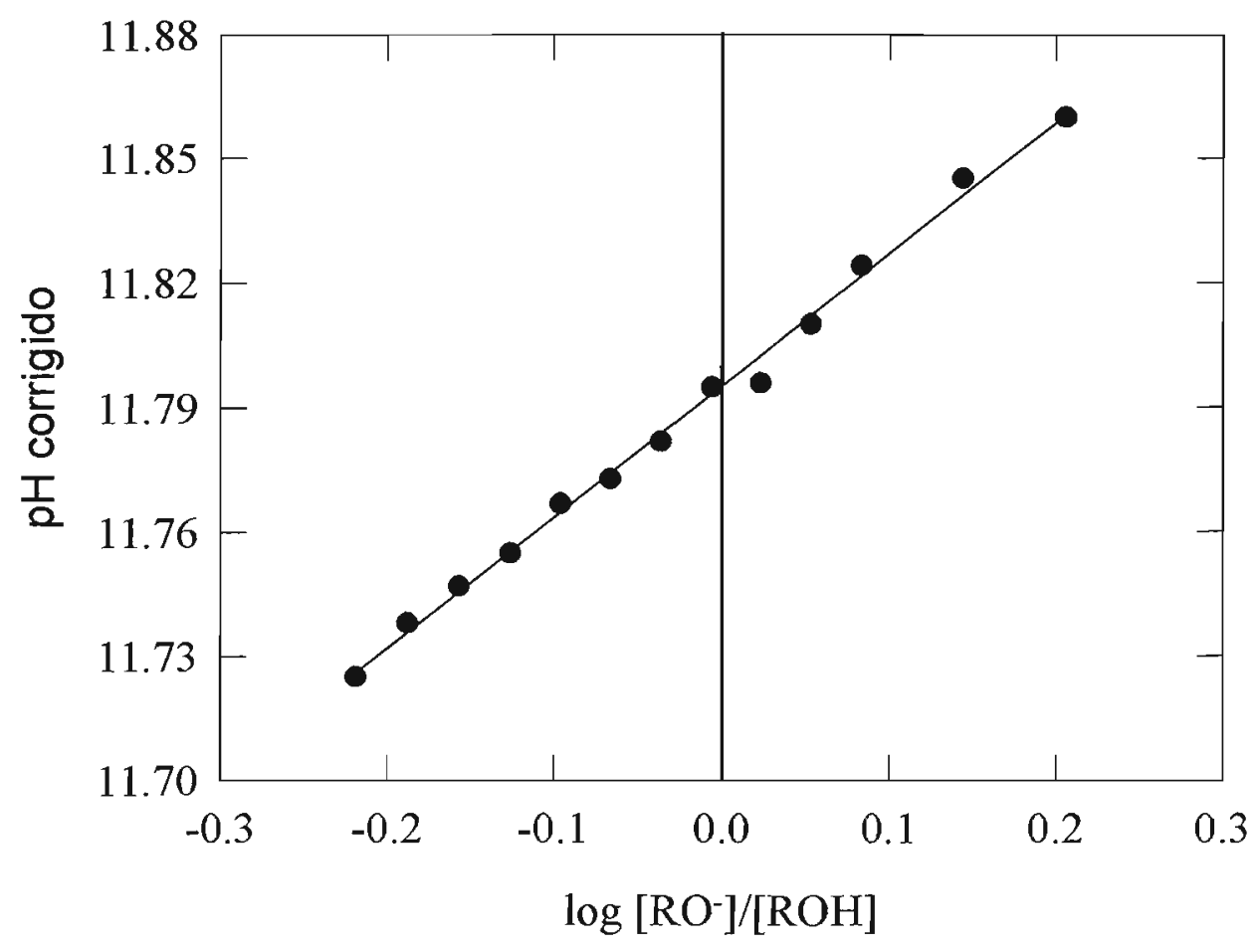

Figura 13 - Valores de pH corrigidos versus logarítmo da razão obtidos para uma titulação de DPKBH $1,08.10^{-3}$ mol.L $L^{-1}$ com $\mathrm{NaOH} 3,70 \cdot 10^{-3}$ mol. $\mathrm{L}^{-1}$ em etanol $29 \%$ a $(25,0 \pm 0,1)^{\circ} \mathrm{C}$. 


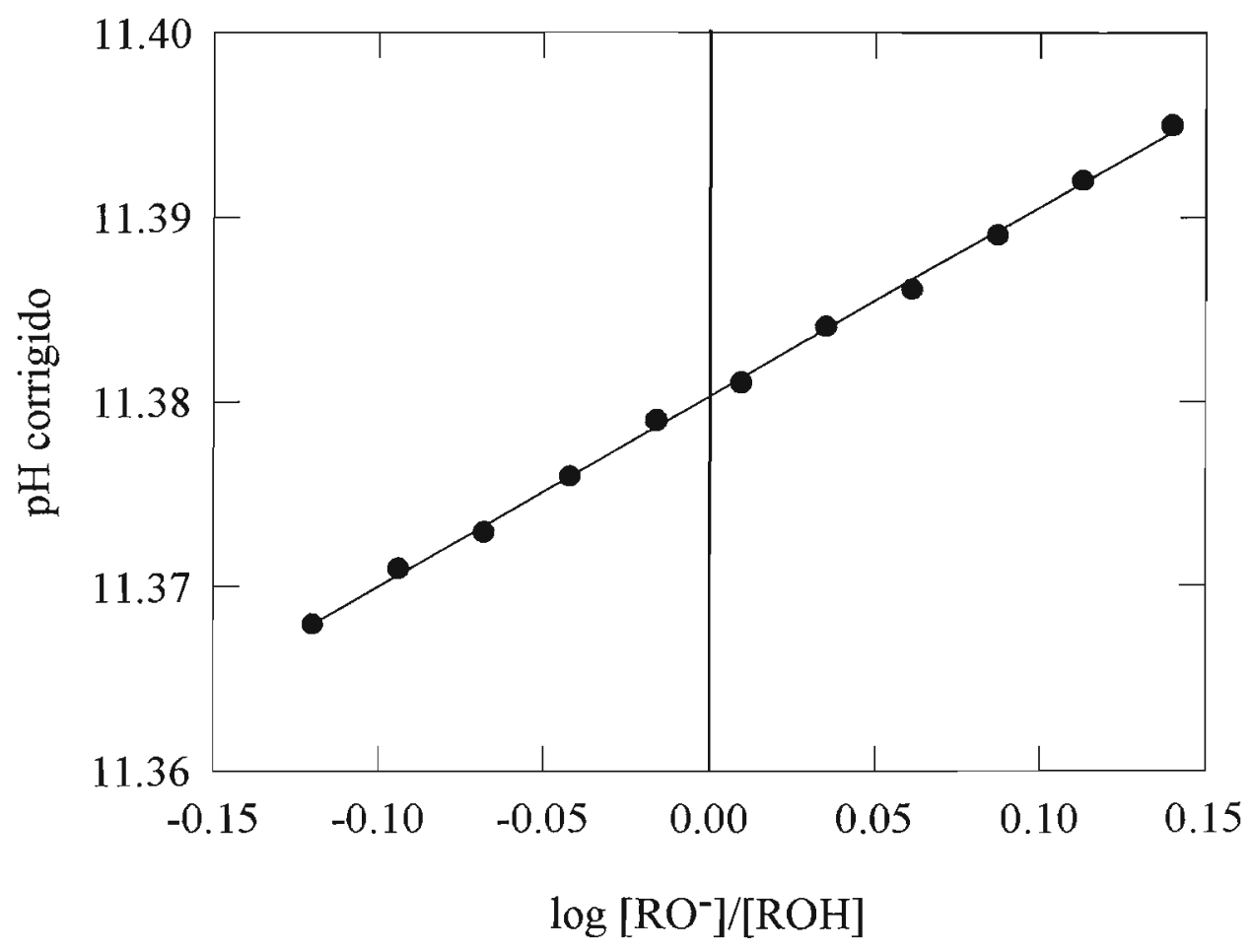

Figura 14 - Valores de $\mathrm{pH}$ corrigidos versus logarítmo da razão obtidos para uma titulação de DPKBH $1,00.10^{-3}$ mol.L $L^{-1}$ com $\mathrm{NaOH} 3,00.10^{-3}$ mol. $\mathrm{L}^{-1}$ em etanol $48 \%$ a $(25,00 \pm 0,05)^{\circ} \mathrm{C}$. 
Tabela XIX - Valores obtidos da titulação de DPKBH 9,49.1 $0^{-4}$ mol. $\mathrm{L}^{-1}$ com $\mathrm{NaOH} 5,24 \cdot 10^{-4}$ mol. $\mathrm{L}^{-1}$ em etanol $10 \%$, após tratamento pelo método dos mínimos quadrados.

\begin{tabular}{ccc}
\hline \hline Série & Coeficiente Correlação & $\mathrm{pK}_{2}$ \\
\hline 1 & 0,9999 & 10,824 \\
2 & 0,9999 & 10,825 \\
3 & 0,9993 & 10,835 \\
4 & 0,9998 & 10,838 \\
5 & 0,9998 & 10,840 \\
6 & 0,9990 & $10,896^{*}$
\end{tabular}

*valor não considerado na média

Tabela XX - Valores obtidos da titulação de DPKBH

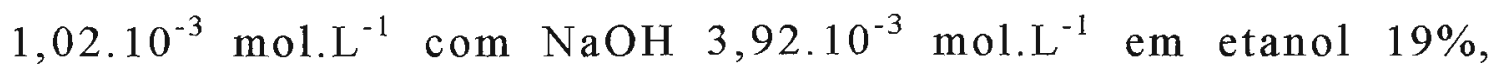
após tratamento pelo método dos mínimos quadrados.

\begin{tabular}{ccc}
\hline \hline Série & Coeficiente Correlação & $\mathrm{pK}_{2}$ \\
\hline 1 & 0,9995 & 11,009 \\
2 & 0,9998 & 11,013 \\
3 & 0,9990 & 11,013 \\
4 & 0,9998 & 11,013 \\
5 & 0,9994 & 11,020 \\
\hline \hline
\end{tabular}


Tabela XXI - Valores obtidos da titulação de DPKBH $1,08 \cdot 10^{-3}$ mol. $L^{-1}$ com $\mathrm{NaOH} 3,70.10^{-3}$ mol. $\mathrm{L}^{-1}$ em etanol $29 \%$, após tratamento pelo método dos mínimos quadrados.

\begin{tabular}{ccc}
\hline Série & Coeficiente Correlação & $\mathrm{pK}_{2}$ \\
\hline 1 & 0,9992 & $11,757^{*}$ \\
2 & 0,9993 & 11,783 \\
3 & 0,9999 & 11,791 \\
4 & 0,9995 & 11,797 \\
5 & 0,9997 & 11,800 \\
\hline
\end{tabular}

*valor não considerado na média

Tabela XXII - Valores obtidos da titulação de DPKBH 1,00.10 $0^{-3}$ mol. $\mathrm{L}^{-1}$ com $\mathrm{NaOH} 3,00 \cdot 10^{-3}$ mol. $\mathrm{L}^{-1}$ em etanol $48 \%$, após tratamento pelo método dos mínimos quadrados.

\begin{tabular}{ccc}
\hline \hline Série & Coeficiente Correlação & $\mathrm{pK}_{2}$ \\
\hline 1 & 0,9996 & 11,360 \\
2 & 0,9998 & 11,370 \\
3 & 0,9995 & 11,380 \\
4 & 0,9992 & 11,380 \\
5 & 0,9990 & 11,400 \\
6 & 0,9991 & 11,400 \\
\hline \hline
\end{tabular}


Tabela XXIII - Valores de $\mathrm{pK}_{2}$ e respectivos desvios padrão para o DPKBH em diferentes porcentagens de etanol.

\begin{tabular}{ccc}
\hline \% Etanol & $\mathrm{p \textrm {K } _ { 2 }}$ & desvio padrão \\
\hline 10 & 10,834 & 0,007 \\
19 & 11,013 & 0,004 \\
29 & 11,793 & 0,007 \\
48 & 11,382 & 0,016 \\
\hline \hline
\end{tabular}

Tabela XXIV- Valores de pK e $\mathrm{K}$ do DPKBH em diferentes porcentagens de etanol.

\begin{tabular}{ccccc}
\hline \% Etanol & $\mathrm{pK}_{1}$ & $\mathrm{~K}_{1}(\mathrm{~mol} / \mathrm{L})$ & $\mathrm{pK}_{2}$ & $\mathrm{~K}_{2}(\mathrm{~mol} / \mathrm{L})$ \\
\hline 10 & 3,210 & $6,17.10^{-4}$ & 10,834 & $1,46.10^{-11}$ \\
19 & 3,342 & $4,55 \cdot 10^{-4}$ & 11,013 & $9,70.10^{-12}$ \\
29 & 3,398 & $4,00.10^{-4}$ & 11,793 & $1,61.10^{-12}$ \\
48 & 3,362 & $4,34.10^{-4}$ & 11,382 & $4,15.10^{-12}$ \\
\hline \hline
\end{tabular}


VII.3 - Determinação Espectrofotométrica das Constantes de Dissociação/Ionização

VII.3.1 - Determinação das Constantes de Dissociação/Ionização do DPKBH em 10 e $48 \%$ de Etanol

Para a determinação dos valores de $\mathrm{pK}_{1}$ e $\mathrm{pK}_{2}$ tornouse necessário adotar os seguintes procedimentos:

- obtenção dos espectros de absorbância do DPKBH nas formas envolvidas no equilíbrio em estudo;

- escolha do comprimento de onda de trabalho;

- determinação do "slope" do eletrodo de vidro;

- preparo das soluções do estudo e leitura de absorbância.

VII.3.1.1 - Determinação dos Espectros de Absorbância do DPKBH nas Formas Envolvidas nos Equilíbrios

Para a determinação dos espectros de absorbância é necessário o prévio conhecimento do valor de $\mathrm{pH}$ em que ocorre a predominância das espécies, protonada $\left(\mathrm{RNH}^{+}\right)$, aniônica $\left(\mathrm{RO}^{-}\right) \mathrm{e}$ neutra (RN ou ROH). Para isso utiliza-se o diagrama de distribuição $\alpha, \%$ versus $\mathrm{pH}$. Este gráfico, representado na Figura 
15, foi construído partindo-se de resultados obtidos potenciometricamente e descritos anteriormente.

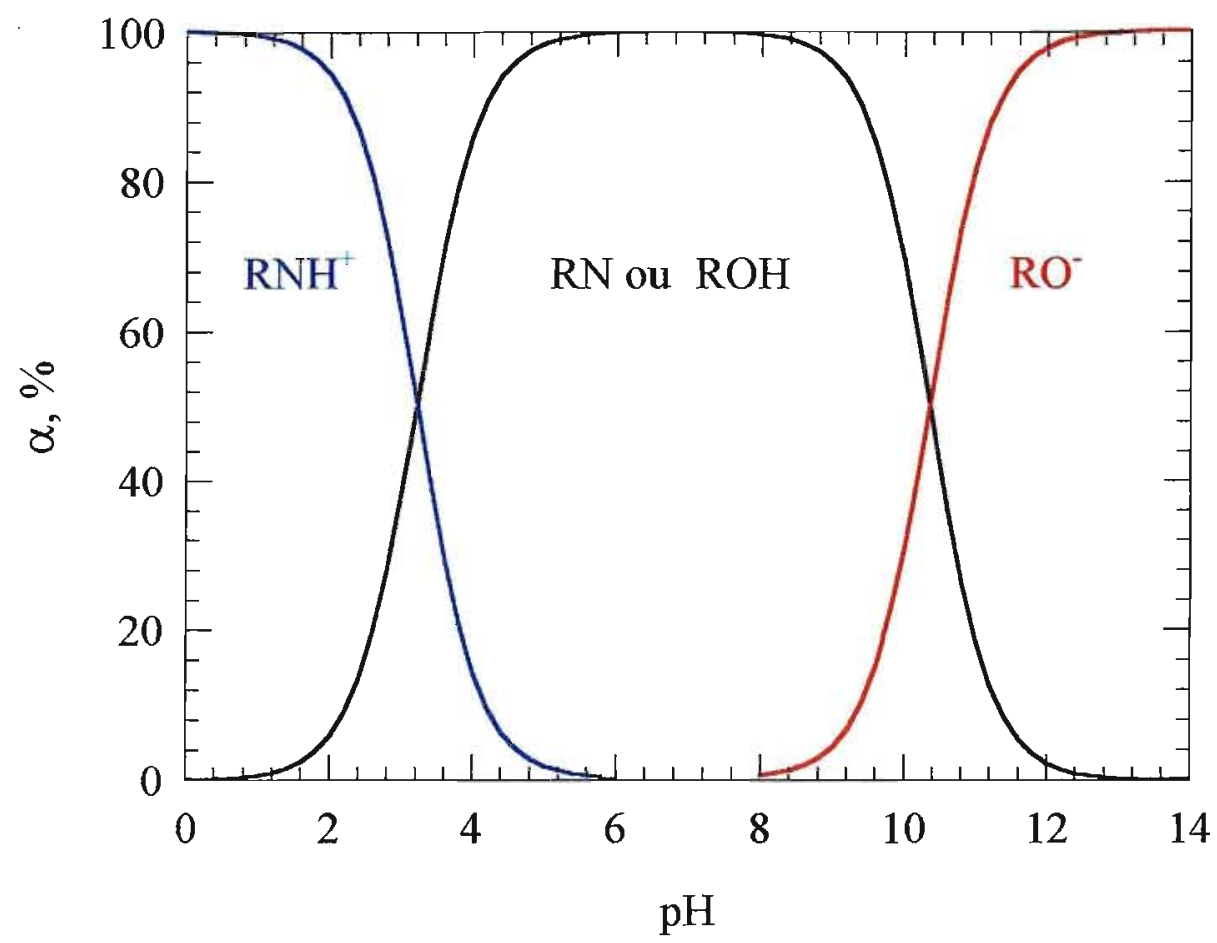

Figura 15 - Distribuição das espécies, $\alpha \%$, de DPKBH em função do pH. $\mathrm{K}_{1}=6,17 \cdot 10^{-4}$ e $\mathrm{K}_{2}=1,46 \cdot 10^{-11} \mathrm{~mol} \cdot \mathrm{L}^{-1}$.

Observa-se que ocorre a predominância total da forma neutra do DPKBH em valores de $\mathrm{pH}$ na faixa de 6 a 8 e da forma protonada em valores de $\mathrm{pH} \leq 1$ assim como da forma aniônica em valores de $\mathrm{pH} \geq 13$. 
VII.3.1.2 - Determinação do "Slope" em 10 e $48 \%$ de Etanol

Determinou-se, como descrito anteriormente, o "slope" em 10 e $48 \%$ de etanol. Os resultados obtidos foram de $(54,96 \pm 0,07) \mathrm{mV}$ e $(56,93 \pm 0,01) \mathrm{mV}$ e serão utilizados para corrigir os valores de $\mathrm{pH}$ com a equação $25^{(63)}$.

Feita a determinação do "slope" do eletrodo, utilizouse uma solução de hidrogenoftalato de potássio em 10 e $48 \%$ de etanol, $\mathrm{pH}=4,083$ e 5,172 respectivamente, para calibração do eletrodo nas condições de estudo.

\section{VII.3.2 - Obtenção do $K_{2}$ em 10 e $48 \%$ de Etanol}

Como mencionado anteriormente é necessário primeiramente obter-se o espectro de absorbância das espécies envolvidas no equlíbrio, como do DPKBH na forma totalmente protonada, neutra, aniônica e da mistura.

Para a determinação do $\mathrm{K}_{2}$ foi necessário inicialmente obter os espectros de absorbância de DPKBH, em 10 e $48 \%$ de etanol, nas formas totalmente neutra e âniônica. Os espectros em $10 \%$ de etanol estão representados na Figura 16, onde pode-se 
observar que o espectro de DPKBH na forma neutra apresenta máxima absorbância em $312 \mathrm{~nm}$ porém, o espectro de absorbância na forma aniônica não apresenta boa definição, sendo assim, a partir da Figura 16 pode-se determinar somente o comprimento de onda de trabalho e a máxima absorbância de ROH. Os espectros em $48 \%$ de etanol apresentaram comportamento semelhante ocorrendo somente um deslocamento no espectro e o máximo de absorbância para a forma neutra foi $319 \mathrm{~nm}$.

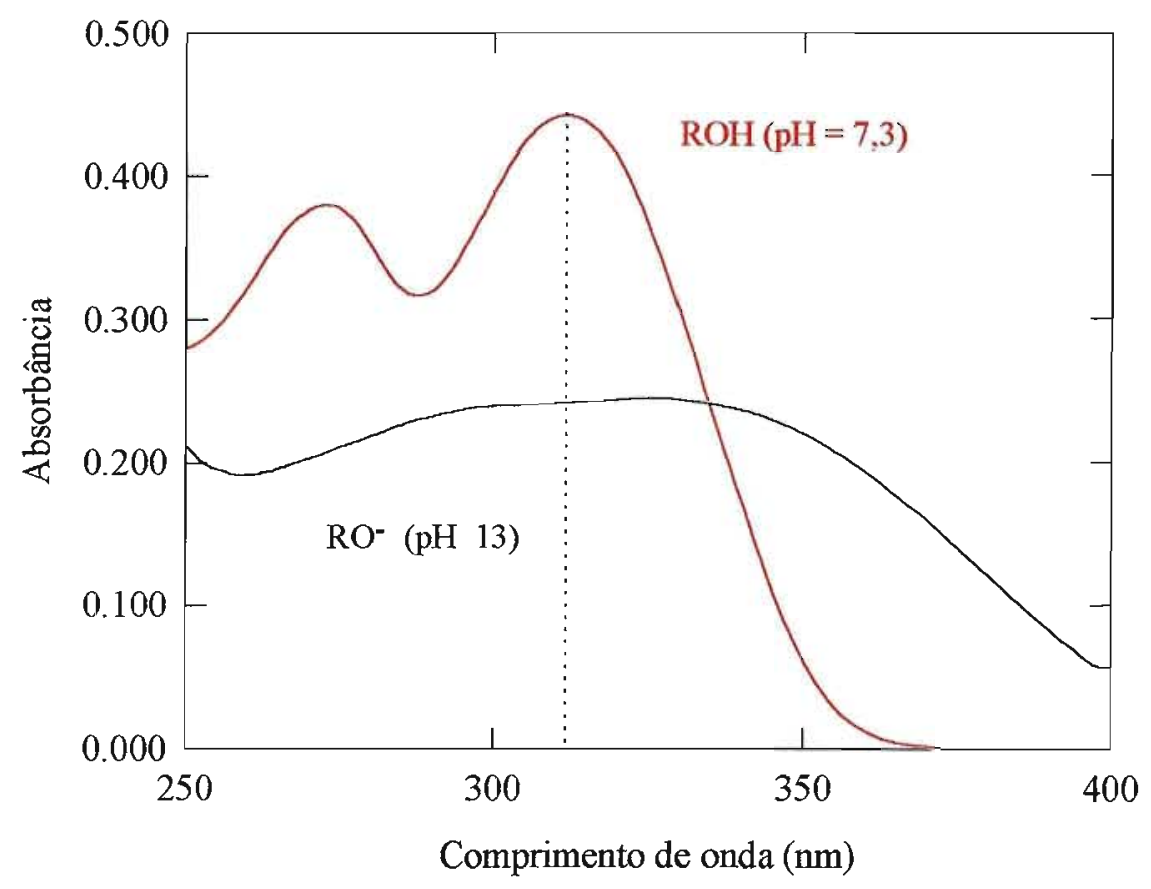

Figura 16 - Espectros das formas neutra e aniônica do DPKBH $2,37.10^{-5}$ mol. $\mathrm{L}^{-1}$ em $10 \%$ de etanol destacando-se o comprimento de onda de trabalho (linha preta). 
Devido a isso, resolveu-se procurar em literatura algum meio de obter-se o valor das constantes sem o prévio conhecimento da absorbância do DPKBH na forma totalmente aniônica. Utilizando-se como base alguns trabalhos ${ }^{(81-84)}$ e a equação (54) obteve-se:

$$
A_{\text {mist. }}=A_{\mathrm{RO}-}+\frac{1}{K_{2}}\left(A_{\mathrm{ROH}}-A_{\text {mist. }}\right) \cdot\left[\mathrm{H}^{+}\right]
$$

que permite obter o valor de máxima absorbância de $\mathrm{RO}^{-}$e a constante de ionização $\left(\mathrm{K}_{2}\right)$.

Para a utilização da equação (56) é necessário obter-se os espectros do DPKBH em diferentes valores de $\mathrm{pH}$, em 10 e $48 \%$ de etanol, e assim determinar-se as absorbâncias destas soluções. Os espectros obtidos em 10 e $48 \%$ de etanol estão representados nas Figuras 17 e 18 , respectivamente.

Utilizando-se a equação (56) construiu-se um gráfico de $\mathrm{A}_{\text {mistura }}$ versus $\left(\mathrm{A}_{\mathrm{ROH}}-\mathrm{A}_{\mathrm{mistura}}\right) \cdot\left[\mathrm{H}^{+}\right] . \mathrm{O}$ coeficiente angular da reta apresenta o valor de $1 / K_{2}$ e com isto pode-se calcular o valor de $\mathrm{K}_{2}$. O coeficiente linear representa a absorbância do DPKBH na forma anionica ( $\left.A_{R O-}\right)$. Os gráficos em 10 e $48 \%$ de etanol estão representados nas Figuras 19 e 20. 


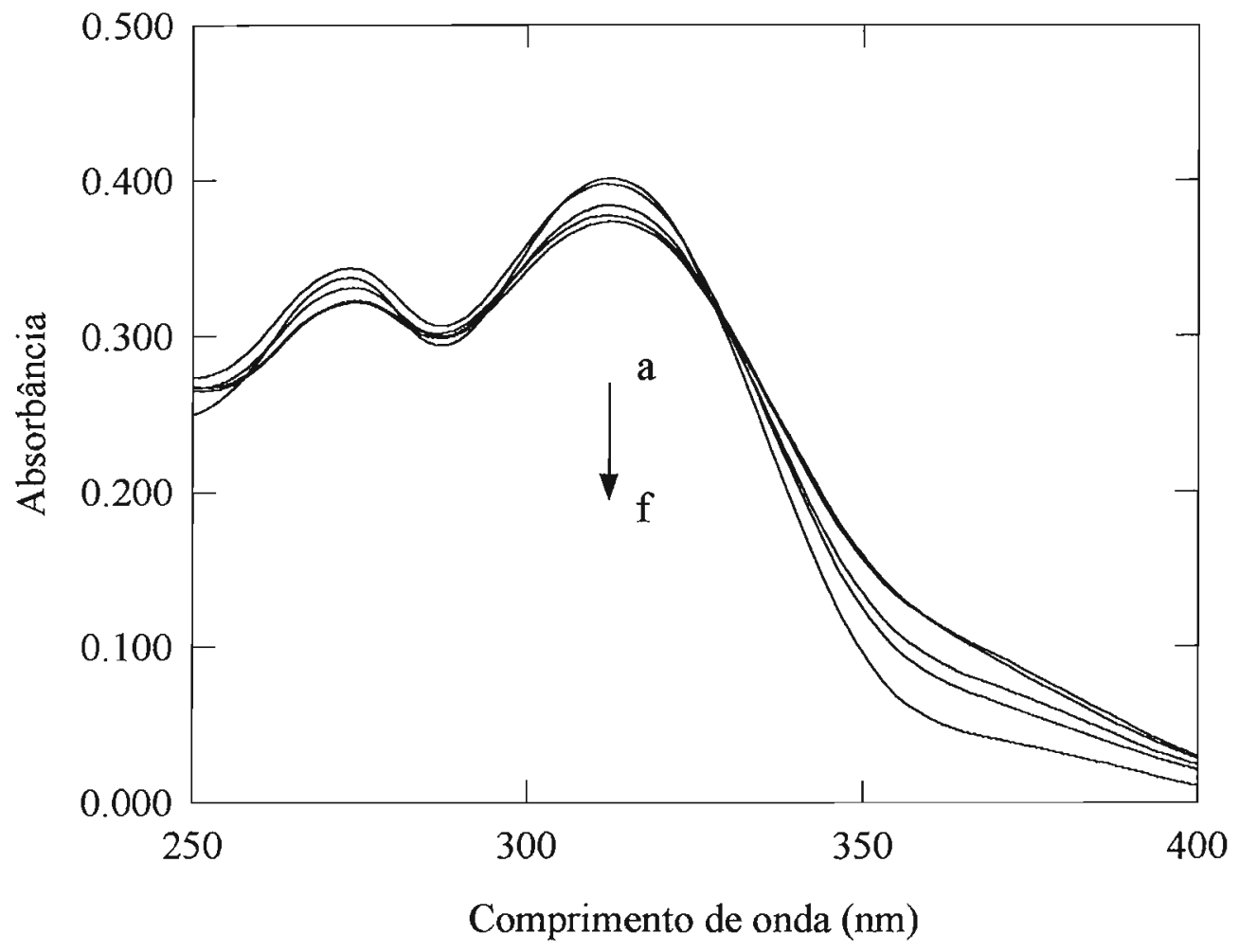

Figura 17 - Valores de absorbância versus comprimento de onda para soluções de DPKBH em $10 \%$ de etanol para diversos valores de pH. (a) 10,697 , (b) 10,748 , (c) 10,837 , (d) 11,051 , (e) 11,143 e (f) $11,286 .[\mathrm{ROH}]+\left[\mathrm{RO}^{-}\right]=2,37 \cdot 10^{-5} \mathrm{~mol} \cdot \mathrm{L}^{-1}$ 


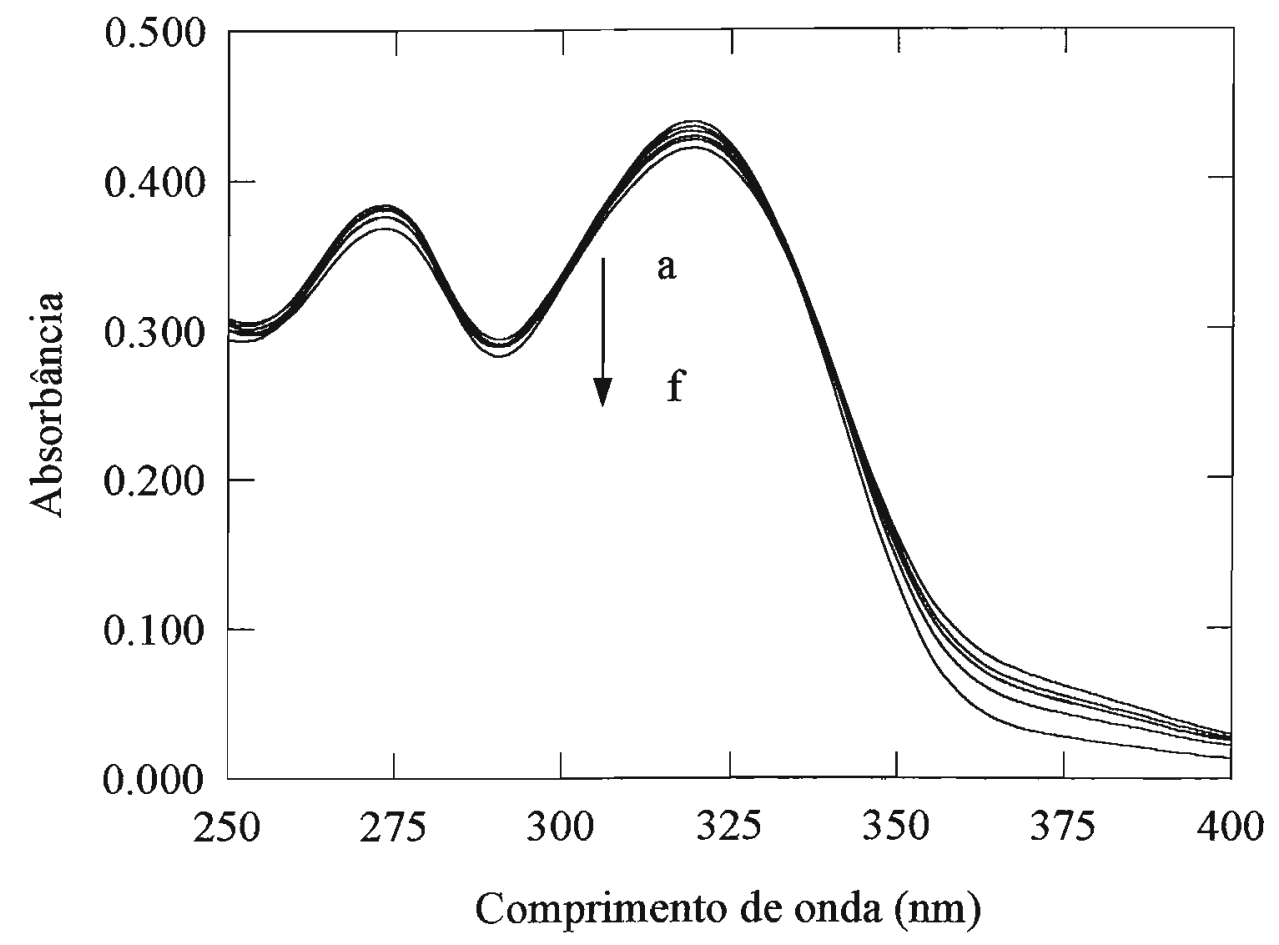

Figura 18 - Valores de absorbância versus comprimento de onda para soluções de DPKBH em $48 \%$ de etanol para diversos valores de pH.(a) 11,249 , (b) 11,358 , (c) 11,491 , (d) 11.571 , (e) $11,641 \mathrm{e}$ (f) $11,753 \cdot[\mathrm{ROH}]+\left[\mathrm{RO}^{-}\right]=2,46 \cdot 10^{-5} \mathrm{~mol} \cdot \mathrm{L}^{-1}$ 


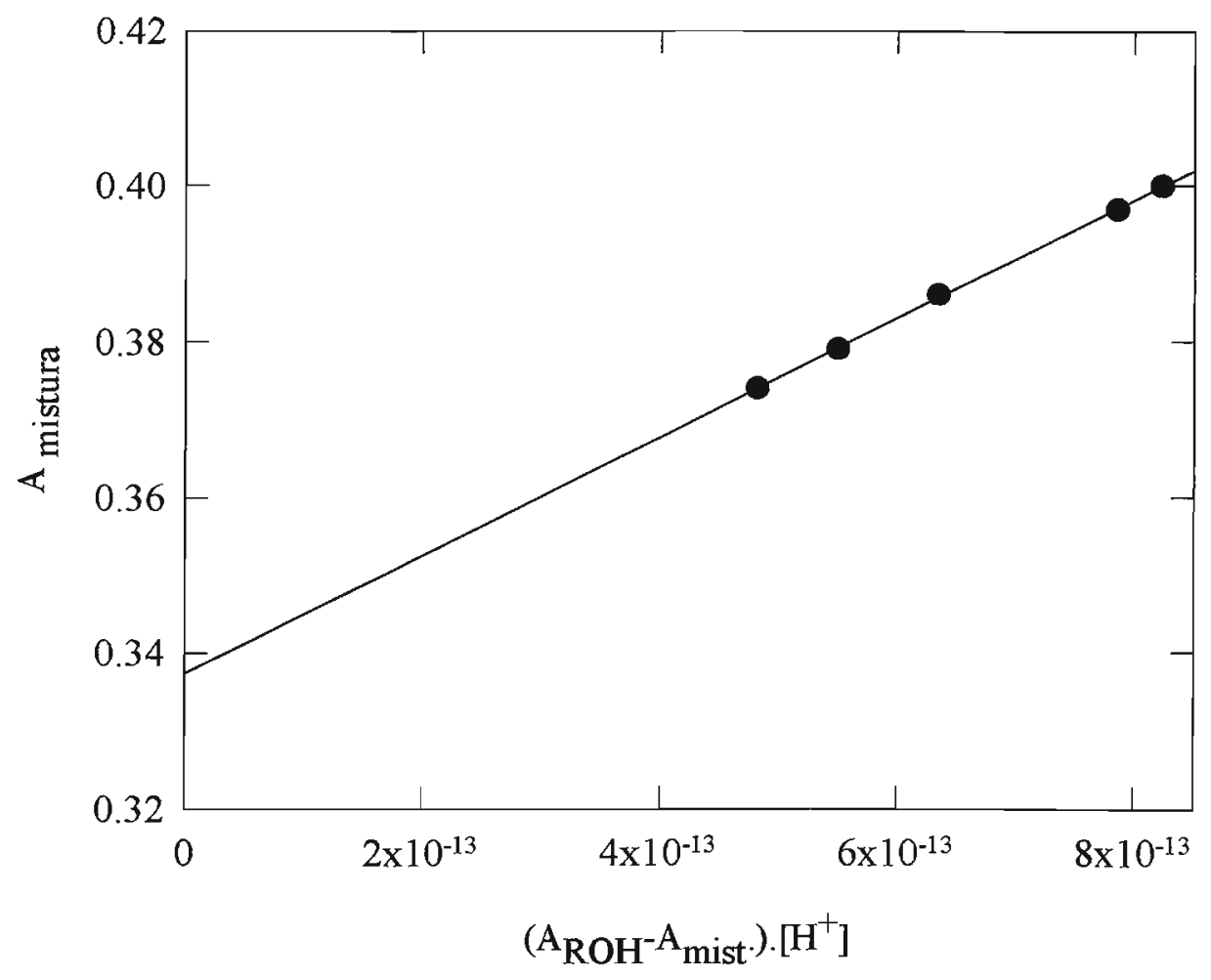

Figura 19 - Absorbância das misturas $\left(\mathrm{ROH}+\mathrm{RO}^{-}\right)$em diferentes valores de $\mathrm{pH}$ versus $\left(\mathrm{A}_{\mathrm{ROH}}-\mathrm{A}_{\text {mistura }}\right) \cdot\left[\mathrm{H}^{+}\right]$em $10 \%$ de etanol. $[\mathrm{ROH}]+\left[\mathrm{RO}^{-}\right]=2,37 \cdot 10^{-5} \mathrm{~mol} \cdot \mathrm{L}^{-1}$.

Os valores de $\mathrm{A}_{\mathrm{RO}}-\mathrm{e} \mathrm{pK}_{2}$ encontrados, em 10 e $48 \%$ de etanol, estão representados na Tabela XXV. 


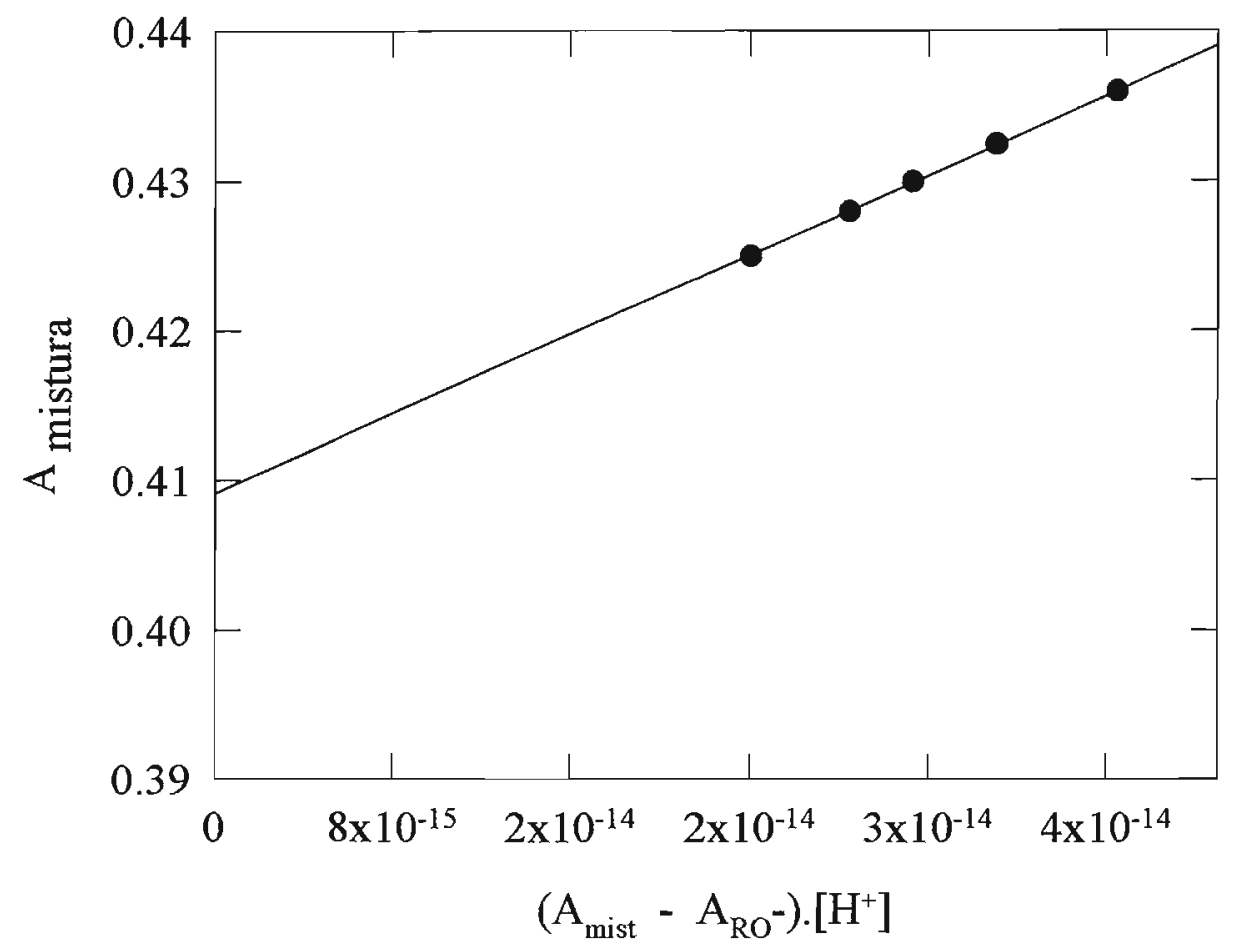

Figura 20 - Absorbância das misturas $\left(\mathrm{ROH}+\mathrm{RO}^{-}\right)$em diferentes valores de $\mathrm{pH}$ versus $\left(\mathrm{A}_{\mathrm{ROH}}-\mathrm{A}_{\text {mistura }}\right) \cdot\left[\mathrm{H}^{+}\right]$em $48 \%$ de etanol. $[\mathrm{ROH}]+\left[\mathrm{RO}^{-}\right]=2,46 \cdot 10^{-5} \mathrm{~mol} \cdot \mathrm{L}^{-1}$.

Tabela XXV - Valores de $\mathrm{K}_{2}$ e de absorbância máxima da forma aniônica, em 10 e $48 \%$ de etanol, obtidos pelo método da estimativa.

\begin{tabular}{cccc}
\hline \hline \% de etanol & $\mathrm{A}_{\mathrm{RO}^{-}}$ & $\mathrm{K}_{2}\left(\mathrm{~mol}^{-1}\right)$ & $\mathrm{pK}_{2}$ \\
\hline 10 & 0,337 & $1,31.10^{-11}$ & 10,880 \\
48 & 0,409 & $1,51.10^{-12}$ & 11,820 \\
\hline \hline
\end{tabular}


VII.3.3 - Obtenção do $K_{1}$ em 10 e $48 \%$ de Etanol

Para a determinação do $K_{1}$ foi necessário inicialmente obter os espectros de absorbância de DPKBH, em 10 e $48 \%$ de etanol, nas formas totalmente neutra e protonada.

A partir da Figura 21 pode-se conhecer o comprimento de onda para a determinação da absorbância das espécies e também o máximo de absorbância de RN (312 nm) e $\mathrm{RNH}^{+}$ (333 nm) em 10\% de etanol. Adotou-se o valor de comprimento de onda que corresponde ao máximo de absorbância da espécie protonada e onde a diferença de absorbância observada entre as duas espécies (neutra e protonada) é maior, ou seja; em $333 \mathrm{~nm}$.

Quanto à obtenção dos espectros, das formas neutra e protonada, em $48 \%$ de etanol seguiu-se o mesmo procedimento. Porém devido a algumas dúvidas que surgiram resolveu-se preparar soluções de DPKBH que apresentassem valores de pH ainda menores que aquele necessário para a obtenção da forma totalmente protonada. Sendo assim preparou-se soluções de DPKBH e adicionou-se a esta diferentes volumes de $\mathrm{HClO}_{4}$ $6 \mathrm{~mol} \cdot \mathrm{L}^{-1}$ 


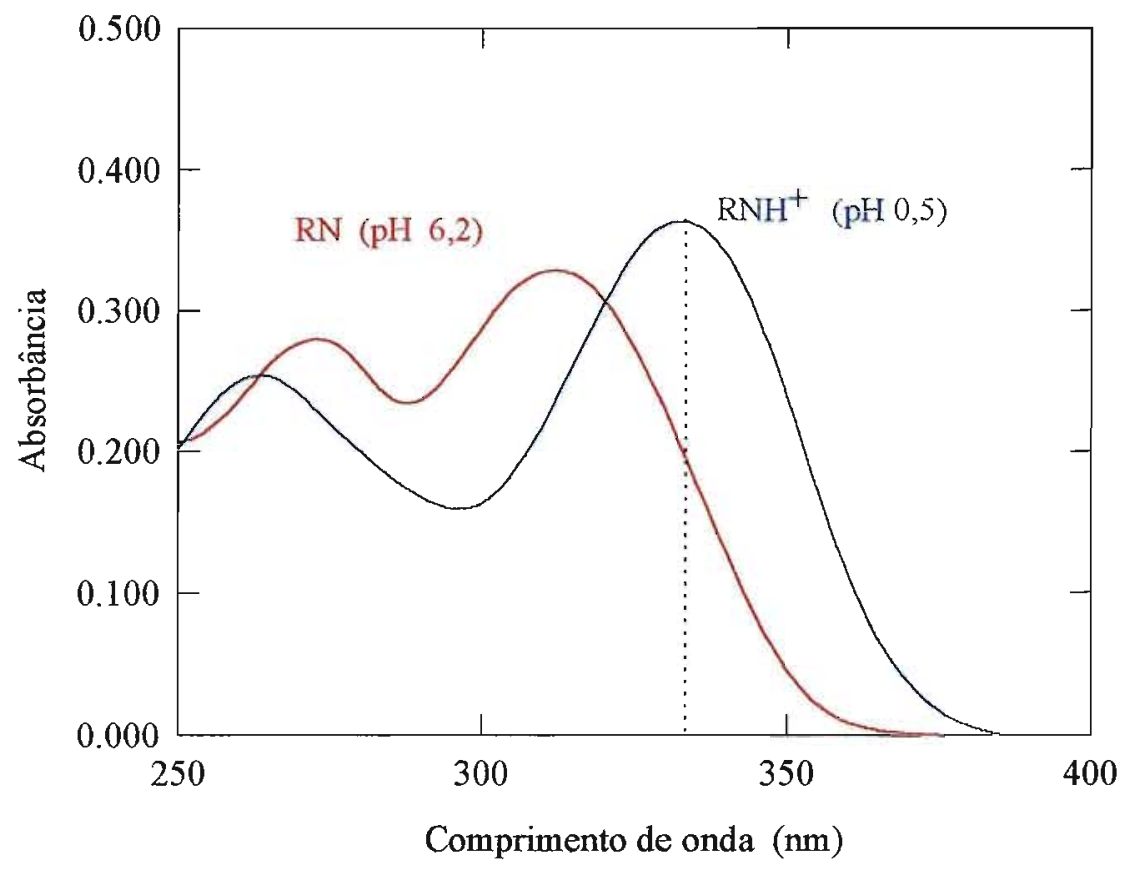

Figura 21 - Espectros das formas neutra e protonada do DPKBH $2,45 \cdot 10^{-5} \mathrm{~mol} / \mathrm{L}$ em $10 \%$ de etanol destacando-se o comprimento de onda de trabalho (linha preta).

Os espectros das soluções em $48 \%$ de etanol estão representados na Figura 22, onde observa-se que com o aumento da concentração de $\mathrm{H}^{+}$e consequente diminuição de $\mathrm{pH}$ ocorre um aumento da absorbância, demonstrando que pode estar ocorrendo a formação de uma outra espécie, talvez $\mathrm{RNH}_{2}{ }^{2+}$. 


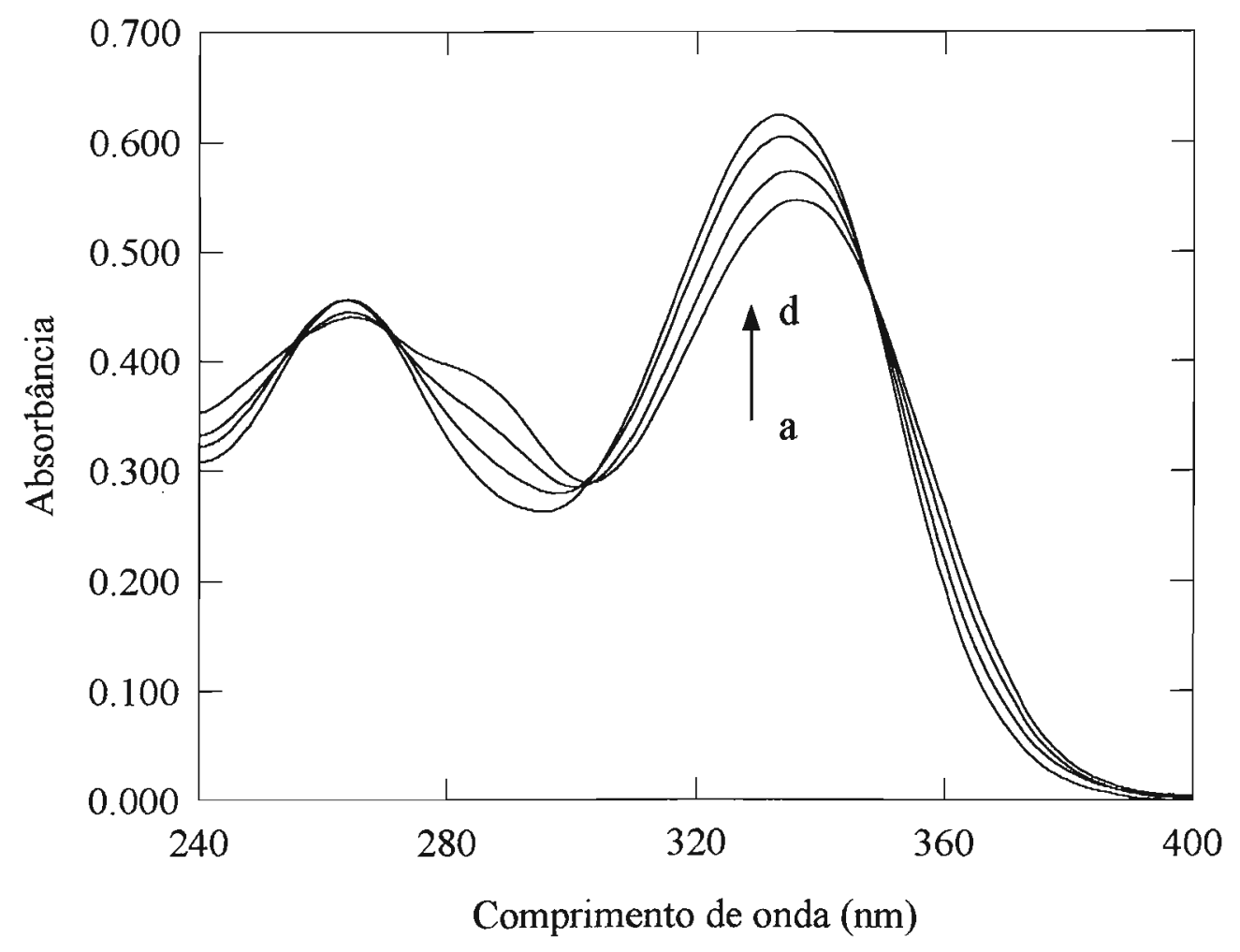

Figura 22 - Espectros obtidos para soluções de DPKBH $2,37 \cdot 10^{-5} \mathrm{~mol} \cdot \mathrm{L}^{-1}$, em $48 \%$ de etanol, em diferentes valores de $\mathrm{pH}$. (a) 0,22 , (b) 0,08, (c)-0,25 e (d)-0,38, obtidas por cálculo.

Como no valor de pH igual a 0,22 tem-se já a total predominância da espécia protonada o espectro (a) foi escolhido para determinar-se a absorbância dessa espécie. 
A Figura 23 contem os espectros das espécies neutra (RN) e protonada $\left(\mathrm{RNH}^{+}\right)$. Pode-se, então, conhecer o comprimento de onda para a determinação da absorbância das espécies e também o máximo de absorbância de RN (319 nm) e $\mathrm{RNH}^{+}(336 \mathrm{~nm})$ em $48 \%$ de etanol. Adotou-se o valor de comprimento de onda que corresponde ao máximo de absorbância da espécie protonada e onde a diferença de absorbância observada entre as duas espécies (neutra e protonada) é maior, ou seja; em $336 \mathrm{~nm}$.

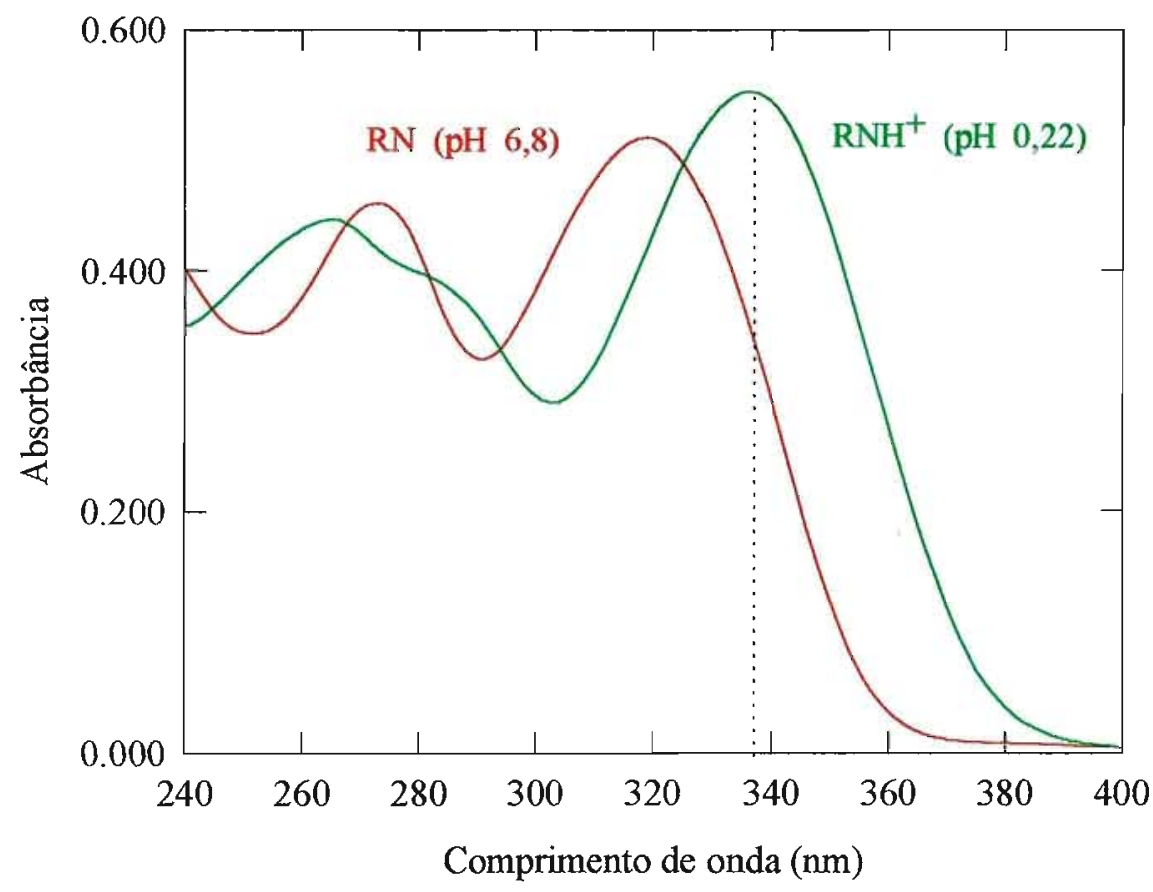

Figura 23 - Espectros das formas neutra e protonada do DPKBH $2,37.10^{-5}$ mol. $\mathrm{L}^{-1}$ em $48 \%$ de etanol destacando-se o comprimento de onda de trabalho (linha preta). 
Depois de determinar-se o comprimento de onda de trabalho, vários espectros em diferentes valores de $\mathrm{pH}$ foram obtidos em 10 e $48 \%$ de etanol e estão apresentados nas Figuras 24 e 25 , respectivamente.

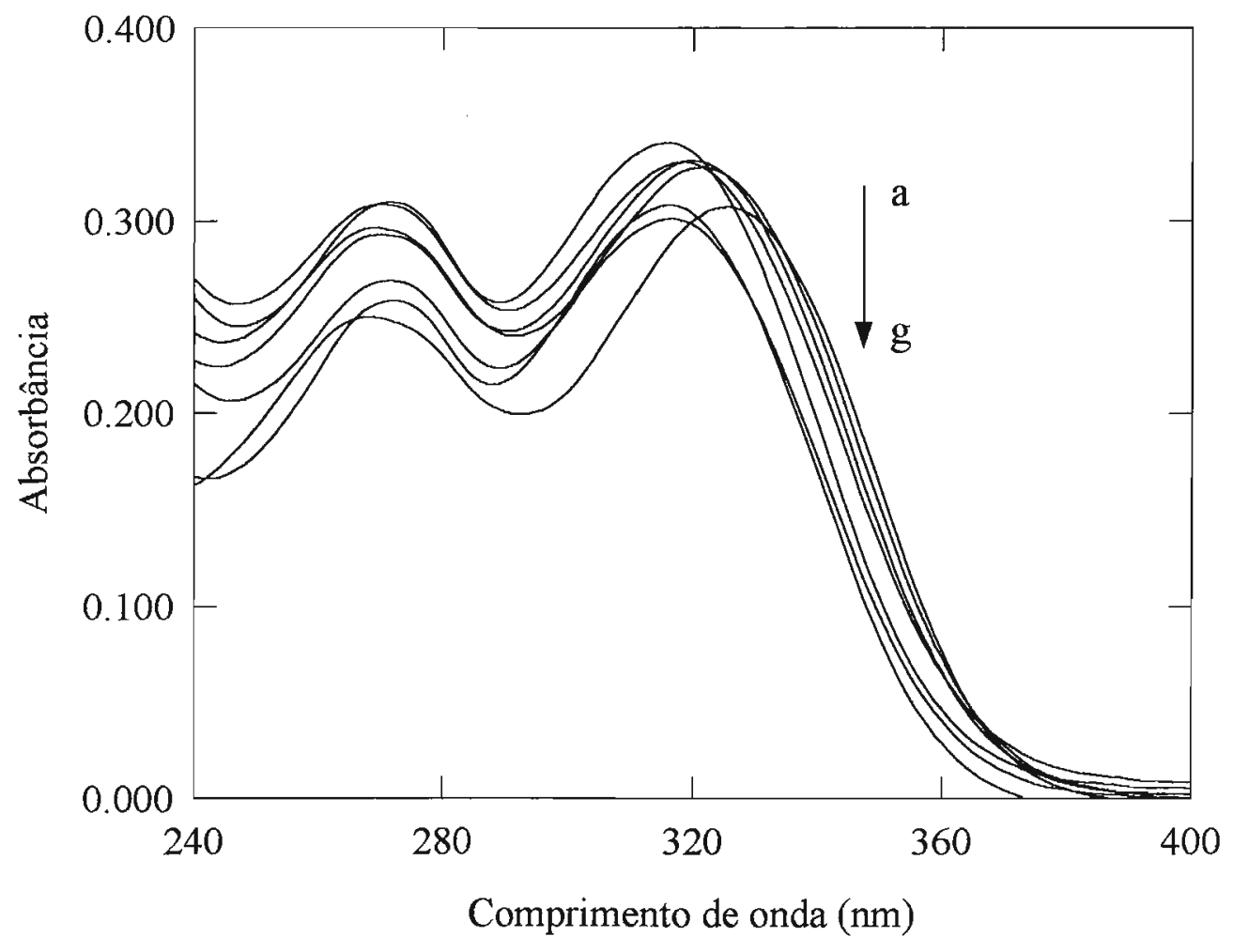

Figura 24 - Valores de absorbância versus comprimento de onda obtidos em $10 \%$ de etanol para diversos valores de $\mathrm{pH}$. (a) 2,721 , (b) 3,117 , (c) 3,156 , (d) 3,189 , (e) 3,261 , (f) 3,507 e (g) 3,593. $[\mathrm{RN}]+\left[\mathrm{RNH}^{+}\right]=2,45 \cdot 10^{-5} \mathrm{~mol} \cdot \mathrm{L}^{-1}$. 


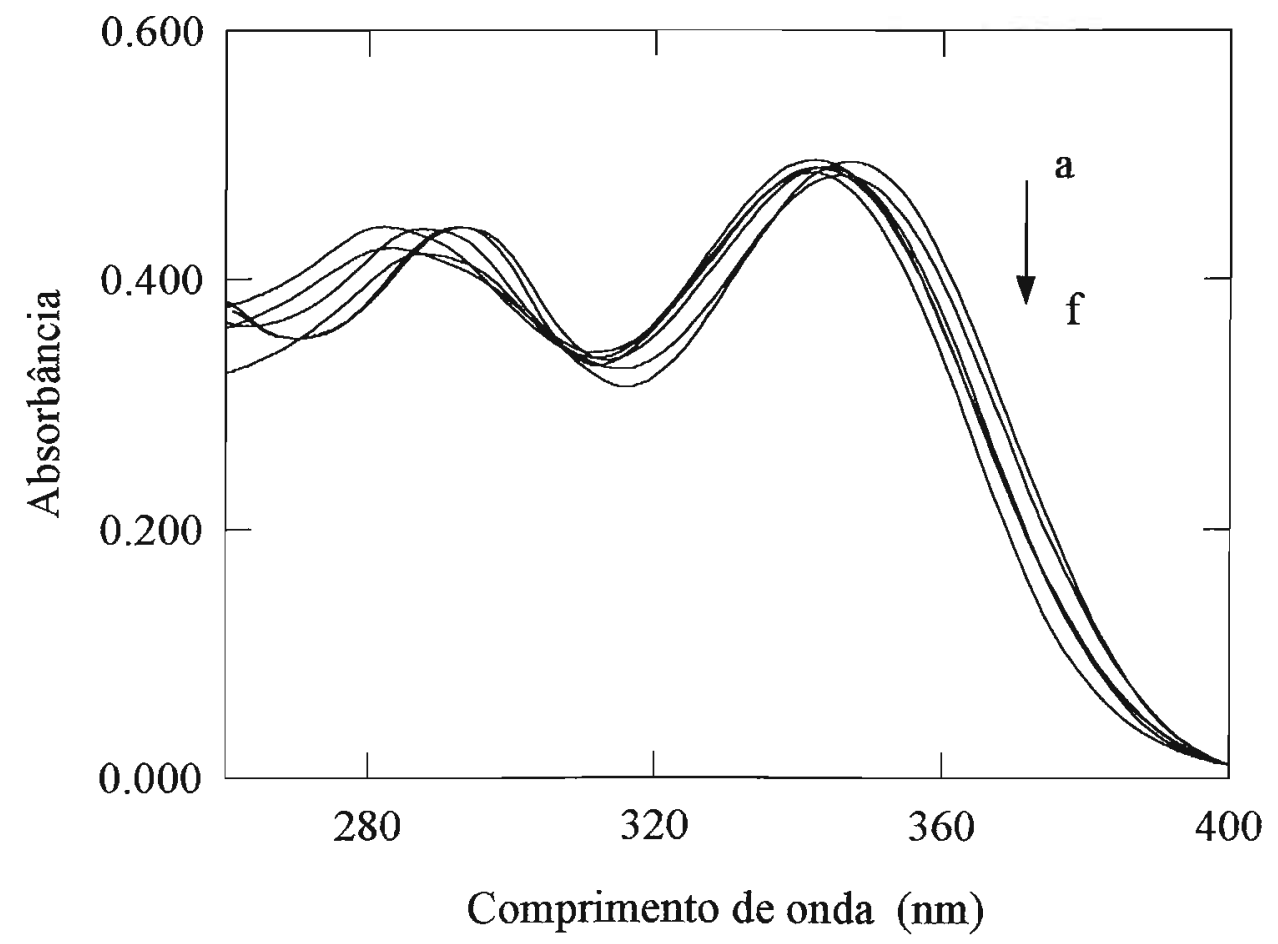

Figura 25 - Valores de absorbância versus comprimento de onda obtidos em $48 \%$ de etanol para diversos valores de pH. (a) 2,440, (b) 2,527, (c) 2,653, (d) 2,736 , (e) 2,932 , (f) 3,076. $[\mathrm{RN}]+\left[\mathrm{RNH}^{+}\right]=2,37 \cdot 10^{-5} \mathrm{~mol} \cdot \mathrm{L}^{-1}$.

Com as medidas de $\mathrm{pH}$ experimentais, corrigidas pelo fator de resposta do eletrodo, e o logarítmo de $\frac{A_{\mathrm{RNH}^{+}}-A_{\text {mist. }}}{A_{\text {mist. }}-A_{R N}}$ equação (54), em 319 nm, constrói-se um gráfico onde observa- 
se uma reta cuja intersecção com o eixo das ordenadas (em logarítmo igual a zero) fornece o valor de $\mathrm{pK}_{1}$ em 10 e $48 \%$ de etanol. As Figuras 26 e 27 representam estes gráficos.

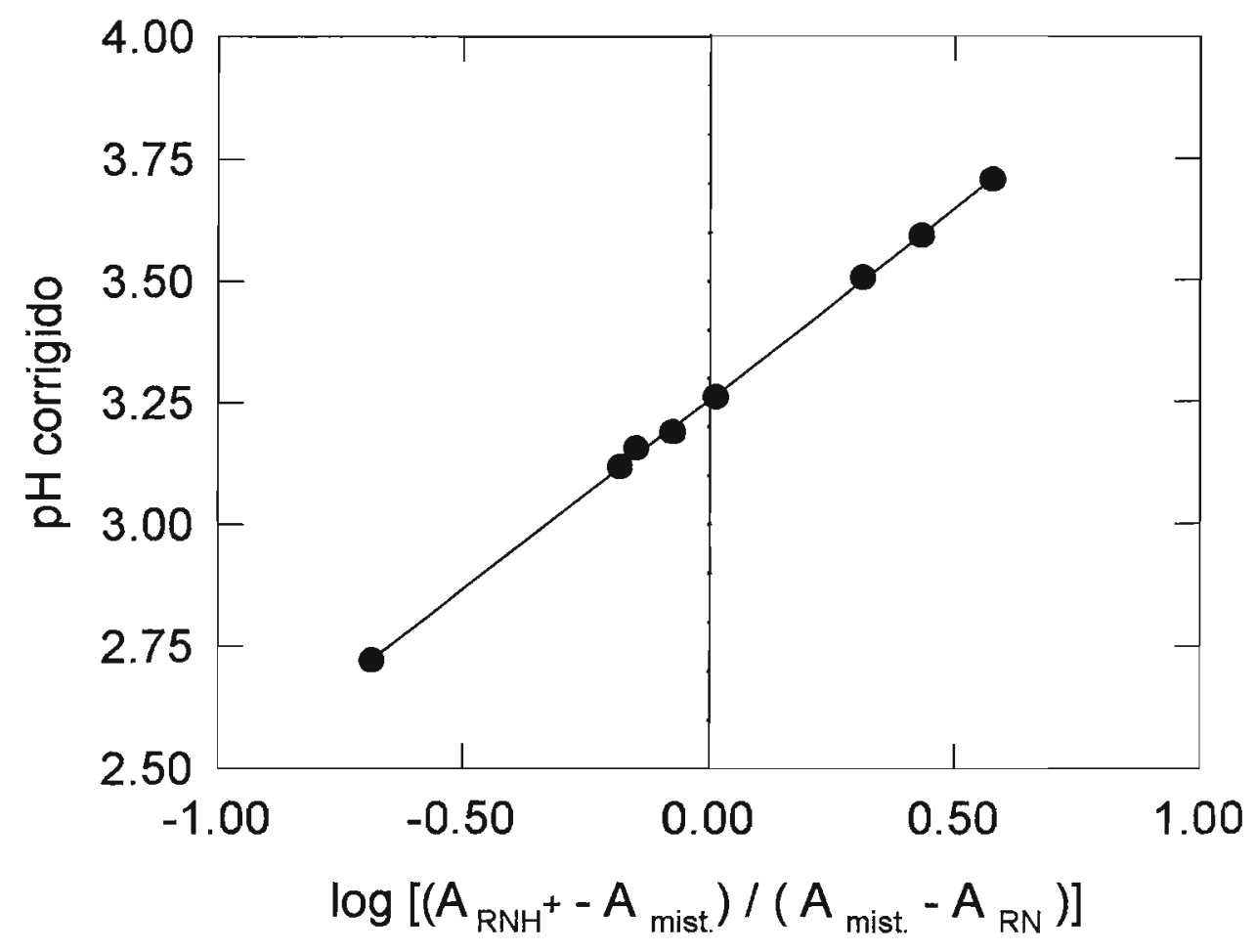

Figura $26-\mathrm{pH}$ corrigido versus logarítmo das absorbâncias das espécies envolvidas no equilíbrio de dissociação em $10 \%$ de etanol a $(25,000 \pm 0,005)^{\circ} \mathrm{C}$. 
A Tabela XXVI apresenta os valores de $\mathrm{pK}_{1}$ e $\mathrm{K}_{1}$ em 10 e $48 \%$ de etanol determinados utilizando-se medidas espectrofotométricas.

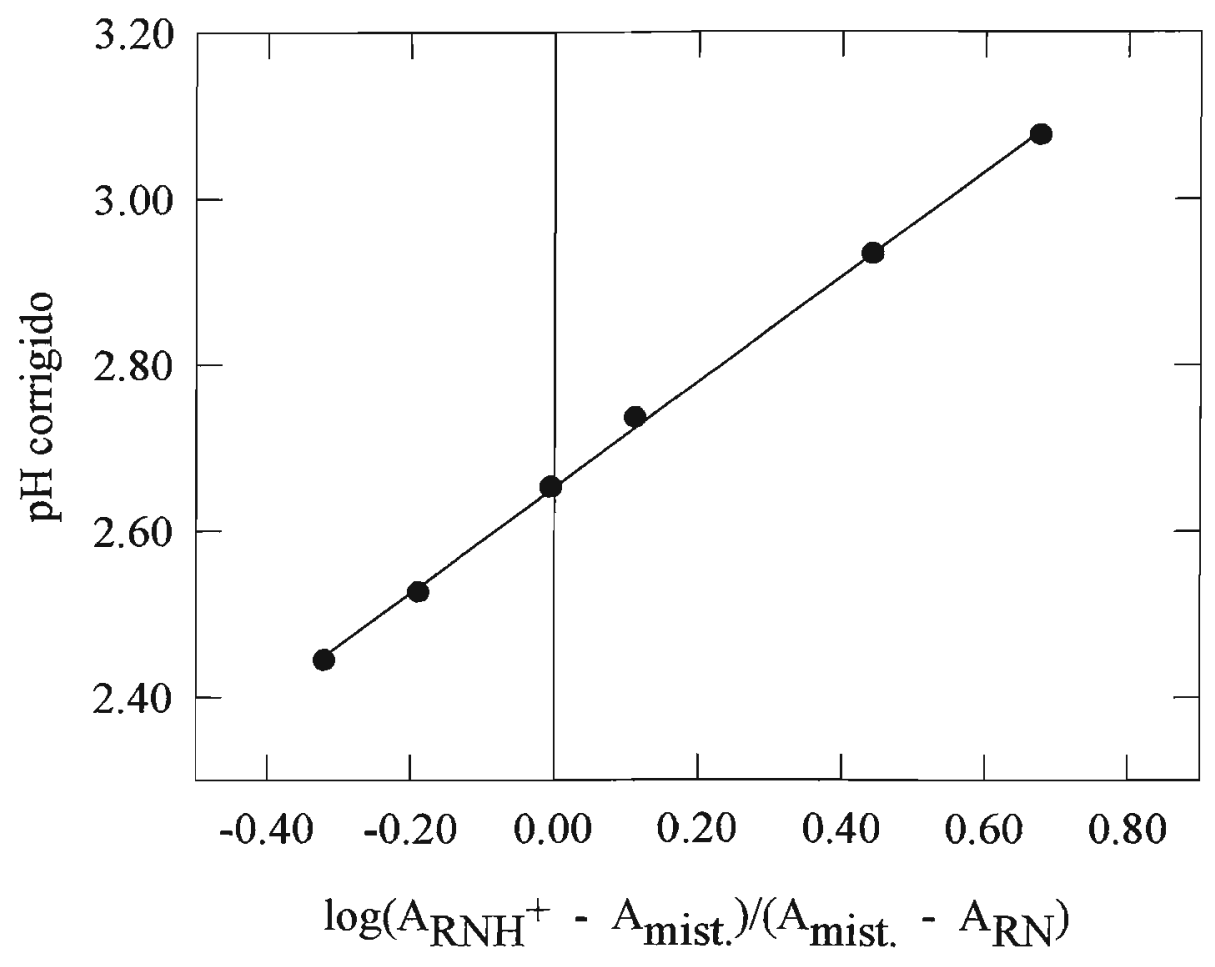

Figura $27-\mathrm{pH}$ corrigido versus logarítmo das absorbâncias das espécies envolvidas no equilíbrio de dissociação em $48 \%$ de etanol a $(25,000 \pm 0,005)^{\circ} \mathrm{C}$. 
Tabela XXVI - Valores de $\mathrm{pK}_{1}$ e $\mathrm{K}_{1}$ do DPKBH em 10 e $48 \%$ de etanol.

\begin{tabular}{ccc}
\hline \hline \% etanol & $\mathrm{pK}_{1}$ & $\mathrm{~K}_{1}\left(\mathrm{~mol}^{-1}\right)$ \\
\hline 10 & 3,257 & $5,53 \cdot 10^{-4}$ \\
48 & 2,654 & $2,21.10^{-3}$ \\
\hline \hline
\end{tabular}

Quando compara-se os valores de $\mathrm{pK}_{1}$ em $48 \%$ de etanol da Tabela XXVI com o da Tabela XXIV, obtido petenciometricamente, observa-se uma discrepância nos valores. Acredita-se que isto seja devido ao fato de que em valor de $\mathrm{pH}$ igual a 0,22 já ocorra talvez a presença da espécie $\mathrm{RH}_{2}{ }^{2+}$. Sendo assim, da mesma forma como fez-se com relação ao valor de $A_{R O}-$ e $\mathrm{K}_{2}$ resolveu-se desenvolver uma equação que possibitasse obter os valores de $\mathrm{ARNH}_{\mathrm{RH}^{+}}$e $\mathrm{K}_{1}$. A partir da equação (52), através de rearranjos matemáticos tem-se:

$$
\mathrm{A}_{\text {mist. }}=\mathrm{A}_{\mathrm{RNH}^{+}}+\mathrm{K}_{1} \frac{\mathrm{A}_{\mathrm{RN}}-\mathrm{A}_{\text {mist. }}}{\left[\mathrm{H}^{+}\right]}
$$

Valores de $A_{\text {mistura, em }} 319 \mathrm{~nm}$ que representa o 
máximo de absorbância da espécie neutra conforme observa-se na Figura 23, e da $\left[\mathrm{H}^{+}\right]$obtidos experimentalmente foram utilizados para construir um gráfico de $\mathrm{A}_{\text {mistura }}$ versus $\frac{\mathrm{A}_{\mathrm{RN}}-\mathrm{A}_{\text {mist. }}}{\left[\mathrm{H}^{+}\right]}$. $\mathrm{O}$ coeficiente angular da reta indica o valor do $\mathrm{K}_{1}$ e o linear a absorbância do DPKBH totalmente na forma protonada $\left(\mathrm{ARNH}_{\mathrm{RN}^{+}}\right)$, estes dados estão representados na Figura 28.

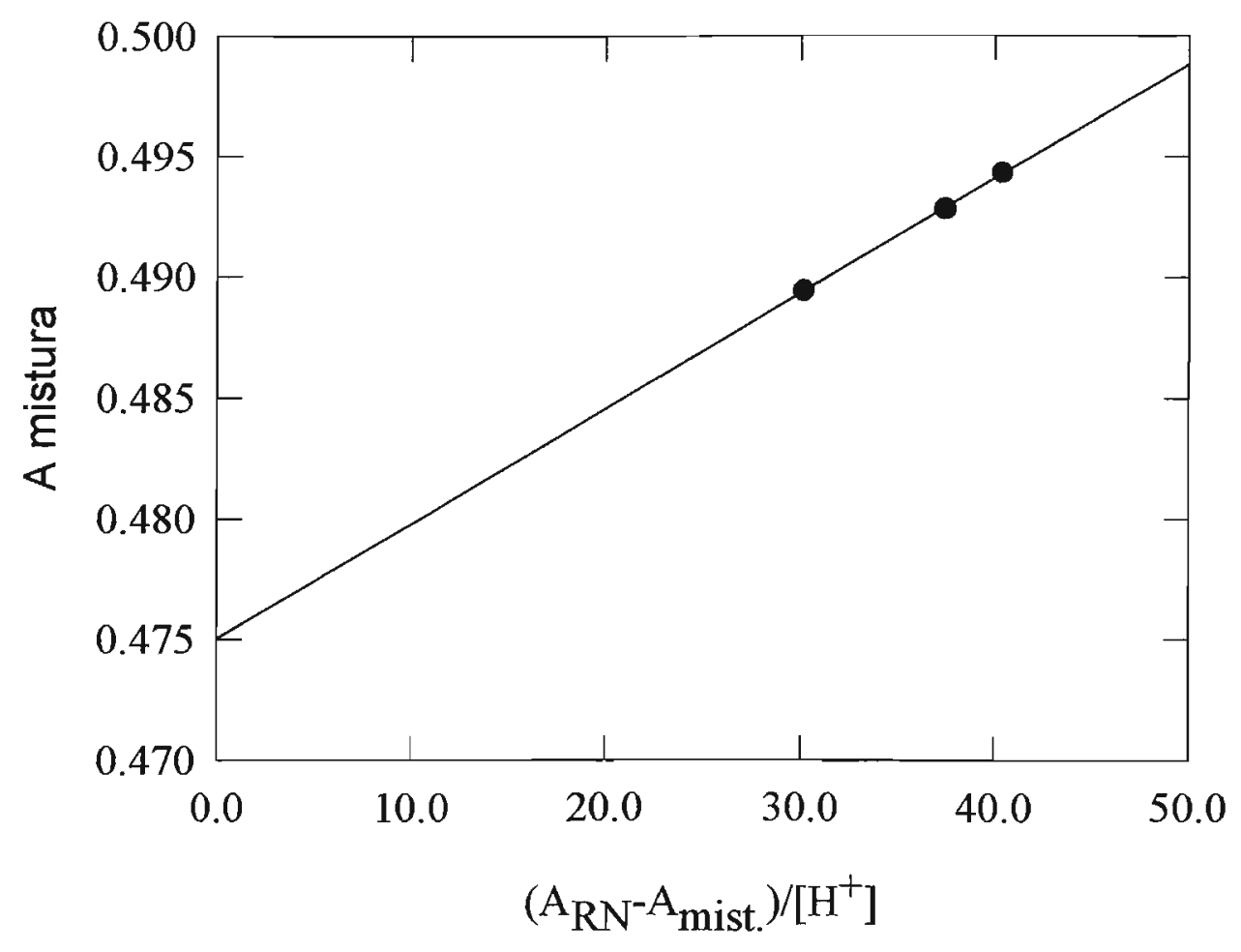

Figura 28 - Absorbância das misturas $\left(\mathrm{RNH}+\mathrm{RNH}^{+}\right)$em diferentes valores de $\mathrm{pH}$ versus $\left(\mathrm{A}_{\mathrm{RN}}-\mathrm{A}_{\text {mistura }}\right) /\left[\mathrm{H}^{+}\right]$em $48 \%$ de etanol. 
A Tabela XXVII apresenta os valores de $\mathrm{A}_{\mathrm{RNH}^{+}}$e $\mathrm{K}_{1}$ e $\mathrm{pK}_{1}$ obtidos pelo método da estimativa.

Tabela XXVII - Valores de absorbância máxima da forma protonada, $\mathrm{K}_{1}$ em $48 \%$ de etanol, obtidos pelo método da estimativa.

\begin{tabular}{cccc}
\hline \hline \% de etanol & $\mathrm{A}_{\mathrm{RNH}^{+}}$ & $\mathrm{pK}_{1}$ & $\mathrm{~K}_{1}\left(\mathrm{~mol} \mathrm{~L}^{-1}\right)$ \\
\hline 48 & 0,475 & 3,322 & $4,76.10^{-4}$ \\
\hline \hline
\end{tabular}

A Tabela XXVIII apresenta os valores de $\mathrm{pK}$ e $\mathrm{K}$ do DPKBH em 10 e $48 \%$ de etanol determinados utilizando-se medidas espectrofotométricas.

Tabela XXVIII - Valores de pK e K do DPKBH em 10 e $48 \%$ de etanol.

\begin{tabular}{ccccc}
\hline$\%$ Etanol & $\mathrm{pK}_{1}$ & $\mathrm{~K}_{1}\left(\mathrm{~mol} \cdot \mathrm{L}^{-1}\right)$ & $\mathrm{pK}_{2}$ & $\mathrm{~K}_{2}\left(\mathrm{~mol}^{-1} \mathrm{~L}^{-1}\right)$ \\
\hline 10 & 3,257 & $5,53.10^{-4}$ & 10,880 & $1,31.10^{-11}$ \\
48 & 3,322 & $4,76.10^{-4}$ & 11,820 & $1,51.10^{-12}$ \\
\hline \hline
\end{tabular}




\section{VII.4 - Estudos Referentes à Protonação do DPKBH}

A molécula do DPKBH, apresentada anteriormente, contém duas piridinas que podem, a princípio, participar da reação de protonação. Titulações condutométricas em $10 \%$ de etanol foram realizadas visando determinar se as duas piridinas ou somente uma delas é protonada quando adiciona-se solução de $\mathrm{HClO}_{4}$.

Conhecendo-se a concentração das espécies durante a titulação condutométrica constrói-se um gráfico de condutância corrigida versus razão [DPKBH]/[HClO 4$]$, Figura 29. Observa-se a definição de dois segmentos de reta, ocorrendo uma mudança de inclinação por volta de $1: 1$ indicando a razão [DPKBH]/[HClO $\left.{ }_{4}\right]$, ou seja evidenciando que somente uma das piridinas do DPKBH é protonada. 


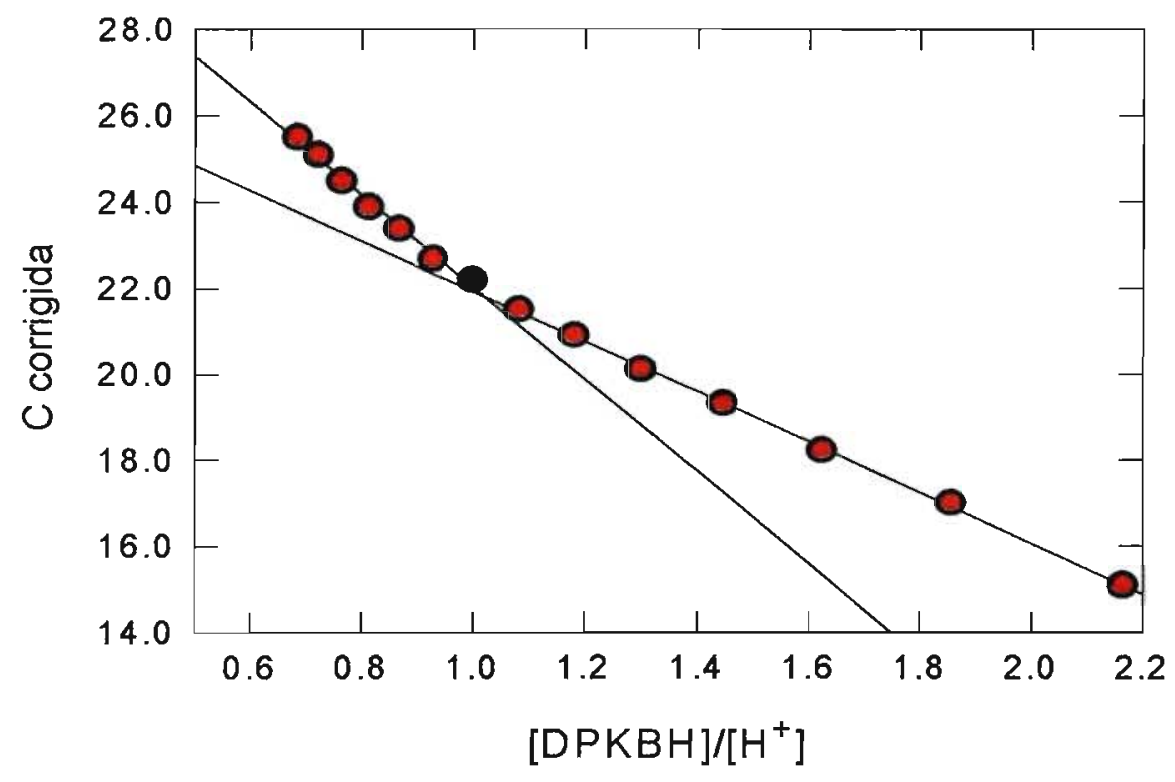

Figura 29 - Valores de condutância corrigida versus razão $[D P K B H] /\left[\mathrm{H}^{+}\right]$obtidos para uma titulação de DPKBH $1,01.10^{-3}$ mol. $\mathrm{L}^{-1}$ com $\mathrm{HClO}_{4} 3,03 \cdot 10^{-3}$ mol. $\mathrm{L}^{-1}$ em etanol $10 \%$ a $(25,000 \pm 0,005)^{\circ} \mathrm{C}$. 
VIII-DISCUSSÕES E CONCLUSÕES 


\section{VIII - DISCUSSÕES e CONCLUSÕES}

Os valores de $\mathrm{K}_{1}$ e $\mathrm{K}_{2}$ determinado pelo método potenciométrico para 10,19 e $29 \%$ de etanol foram calculados a partir de medidas de $\mathrm{pH}$ obtidas com o mesmo eletrodo de vidro combinado. Os valores de "slope" encontrados nas porcentagens de etanol acima indicadas são, 54,56 $\pm 0,07 ; \quad 53,88 \pm 0,05$ e $51,14 \pm 0,04 \mathrm{mV}$, respectivamente. O decréscimo desses valores evidencia uma perda de sensibilidade do eletrodo em função do aumento da fração de etanol no meio de estudo. Este comportamento vem confirmar uma das observações feitas por Lahiri e Aditya $^{(64)}$ sobre as correções de $\mathrm{pH}$ em misturas de solventes (capítulo V.3).

Cabe salientar que o comportamento do eletrodo se manteve praticamente inalterado após um ano de uso em diferentes porcentagens de etanol. Este fato pode ser observado comparandose o valor inicial de "slope" $10 \%$ de etanol igual a $54,56 \pm$ 0,07mV (página 84 desta dissertação) e o valor obtido quando da aplicação do método espectrofotométrico, que resultou em 54,96 \pm $0,07 \mathrm{mV}$ (página 102 desta dissertação). Apresenta-se uma diferença de $0,4 \mathrm{mV}$ entre ambos que corresponde a um erro de \pm 0,007 unidades de $\mathrm{pH}$, bastante menor que a diferença 
encontrada $(0,05)$ entre os dois valores de $\mathrm{pK}_{1}$ para $10 \%$ de etanol: 3,257 (espectrofotométrico) e 3,210 (potenciométrico).

Com relação à faixa de $\mathrm{pH}$ útil para a obtenção do "slope" do eletrodo de vidro observa-se a princípio o mesmo comportamento que em solução aquosa ${ }^{(63)}$. A resposta não linear do eletrodo em regiões de $\mathrm{pH}$ maiores e principalmente próximos de 7 foi amplamente discutida por May et $\mathrm{al}^{(57)}$. Entretanto, é interessante salientar que os mesmos autores mostram haver uma variação linear na faixa de 10,8 a 11,3 .

No presente trabalho, considera-se que o mesmo valor de "slope" encontrado na região ácida se mantém na região alcalina. Tal premissa teve como base o trabalho desenvolvido por Hedwing e Powell( ${ }^{(85)}$ que obtiveram a mesma correlação entre E medido versus $\mathrm{pH}$ calculado para 3 diferentes faixas de $\mathrm{pH}$, em força iônica constante.

Devido à falta de estabilidade do eletrodo em uso, para o estudo em $48 \%$ de etanol, efetuou-se a compra de outro eletrodo cujo comportamento mostrou-se diferenciado do primeiro. Encontrou-se valor de "slope" igual a $56,93 \mathrm{mV}$.

Em todos os casos a determinação do "slope" exige a medição dos valores de $\mathrm{E}(\mathrm{mV})$ e o cálculo do $\mathrm{pH}$ teórico. A princípio resolveu-se considerar que em qualquer porcentagem de 
etanol na faixa de 0 a $48 \%$, a dissociação do $\mathrm{HCl}$ e do $\mathrm{NaOH}$ é completa. Assim, suas concentrações analíticas aplicadas aos balanços de massa permitem calcular o valor de $\mathrm{pH}$ teórico. Se, entretanto, esta consideração não for verdadeira e os valores de $\mathrm{pH}$ calculados estiverem afetados de um fator proporcional à porcentagem de etanol, haverá apenas um deslocamento da reta no sentido paralelo a ela em todos os pontos, mantendo-se assim a mesma inclinação. Seria assim obtido um coeficiente linear diferente correspondendo a um outro valor de $\left(E^{0}+E_{j}\right)$, este entretanto não é utilizado nos demais cálculos e correções.

Além da avaliação da resposta de um eletrodo de vidro, sua aplicação exige a calibração do sistema com solução de pH conhecido. Entretanto, apesar de em muitos campos da indústria (alimentos, fármacos) e da pesquisa científica tornar-se necessário medir o $\mathrm{pH}$ em solventes mistos, pouco se encontra na literatura a respeito do assunto. No presente trabalho adotou-se o uso do sal ácido fraco hidrogenoftalato de potássio como solução de calibração. Os respectivos valores de $\mathrm{pH} 4,086 ; 4,442 ; 4,694$ e 5,172 obtidos para $10 ; 19 ; 25$ e $48 \%$ de etanol (Tabela XIII, página 84) evidenciam a influência do meio. Verifica-se que com o aumento da fração de etanol ocorre uma diminuição na concentração de íons hidrogênio livres. Tal comportamento pode 
estar diretamente relacionado à variação da constante dielétrica do meio que diminui com o aumento da fração de etanol conforme evidenciada na Tabela XXVII ${ }^{(86)}$.

Tabela XXVII - Valores das Constantes Dielétrica em diferentes porcentagens e etanol.

\begin{tabular}{cc}
\hline \hline \% Etanol & Constante Dielétrica \\
\hline 10 & 76,7 \\
19 & 74,6 \\
29 & 72,1 \\
48 & 65,6 \\
\hline \hline
\end{tabular}

Comportamento semelhante foi encontrado por Gorina e Seregina ${ }^{(87)}$ ao trabalhar com soluções tampão em diferentes porcentagens de solvente orgânico, e eletrodo de hidrogênio, compondo a célula:

$\mathrm{Pt}, \mathrm{H}_{2} \mid$ solução tampão, etanol + água, $\mathrm{Cl}^{-}$(m) $|\mathrm{AgCl}, \mathrm{Ag}| \mathrm{Pt}$ (III)

Medidas de potencial foram efetuadas para soluções tampão de citrato, fosfato e bórax em diferentes porcentagens (10, 
30 e 50) de etanol-água e concentrações de cloreto. Valores de pH $\left(p w H^{*}\right)$ foram calculados a partir da expressão:

$$
\mathrm{pwH}^{*}=-\log \left(\mathrm{m}_{\mathrm{H}^{+}} \gamma^{*}{ }_{\mathrm{H}^{+}} \gamma^{*} \mathrm{Cl}^{-}\right)=\frac{\left(\mathrm{E}-\mathrm{E}^{0}\right) \mathrm{F}}{\mathrm{RT} \ln 10}+\log \mathrm{m}_{\mathrm{Cl}^{-}}
$$

onde $\gamma^{*}{ }_{\mathrm{H}^{+}}$e $\gamma^{*} \mathrm{Cl}^{-}$são os coeficientes de atividade do $\mathrm{H}^{+}$e $\mathrm{Cl}^{-}$, respectivamente, no meio etanol-água.

A extrapolação de $\mathrm{pwH}^{*}$ versus $\mathrm{m}_{\mathrm{Cl}}{ }^{-}$fornece $\mathrm{pwH}^{\circ}$, independente do meio iônico. Desta forma, para cada composição do solvente, um valor de $\mathrm{pH}\left(\mathrm{pa}_{\mathrm{H}}{ }^{*}\right)$ foi obtido com base na equação:

$$
\mathrm{pa}_{\mathrm{H}}{ }^{*}=-\log \mathrm{m}_{\mathrm{H}}{ }^{+} \gamma_{\mathrm{H}}^{*}=\mathrm{pwH}^{\mathrm{o}}+\log \gamma^{*} \mathrm{Cl}^{-}
$$

Calculando o termo $\log \gamma^{*} \mathrm{Cl}^{-}$através de uma equação de Debye-Hückel ${ }^{(41)}$, Gorina e Seregina ${ }^{(87)}$, chegaram a expressões gerais (equações de segundo grau) que relacionam, para cada tampão, os valores de $\mathrm{pa}_{\mathrm{H}}$ * e de porcentagem de etanol.

No presente trabalho, fez-se uso de eletrodo de vidro e não de hidrogênio. Neste caso, os valores de $\mathrm{pH}$ foram obtidos diretamente para o hidrogenoftalato em diferentes porcentagens 
de etanol, após calibração do sistema com solução de ácido clorídrico aquosa. Corrigindo os valores de $\mathrm{pH}$ experimentais com a equação (25), e usando-se o "Software" Sigma Plot, procurou-se o melhor ajuste dos valores de pHcorrigido versus porcentagen de etanol. Os valores utilizados encontram-se na Tabela XXVIII.

Tabela XXVIII - Valores de $\mathrm{pH}$ corrigidos, utilizando-se a equação (25), das soluções de hidrogenoftalato de potássio.

\begin{tabular}{ccc}
\hline \hline \% etanol $\left(\mathrm{P}_{\text {EtOH }}\right)$ & $\mathrm{pH}_{\text {biftalato }}$ & $\mathrm{pH}$ corrigido \\
\hline 10 & 4,086 & 4,262 \\
19 & 4,442 & 4,681 \\
29 & 4,694 & 5,116 \\
48 & 5,172 & 5,296 \\
\hline
\end{tabular}

O melhor ajuste deu-se com os 3 primeiros valores e uma equação de reta foi ajustada levando à expressão geral: 


$$
\mathrm{pH}=3,818+0,0450 * \mathrm{P}_{\mathrm{EtOH}}
$$

onde $\mathrm{P}_{\mathrm{EtOH}}$ representa a porcentagem de etanol no meio.

Construiu-se um gráfico utilizando-se os valores de pHcorrigido da solução de hidrogenoftalato de potássio e as \% de etanol do estudo que está apresentado na Figura 31.

Conforme já descrito anteriormente, os valores de $\mathrm{pK}$ foram obtidos, então, pelos métodos potencio e espectrofotométrico. Os resultados obtidos encontram-se na Tabela XXIX.

A utilização dos dois métodos, potencio e espectrofotométrico, mostrou-se viável para a determinação das constantes. O método espectrofotométrico apresentou uma pequena dificuldade quanto à determinação da absorbância das espécies $\mathrm{RO}^{-}$em 10 e $48 \%$ de etanol e $\mathrm{RNH}^{+}$em $48 \%$ de etanol. Esta foi amplamente solucionada com o desenvolvimento de equações (56 e 57) que possibilitaram a determinação destes valores, bem como as respectivas constantes de dissociação/ionização nestas porcentagens de etanol. 


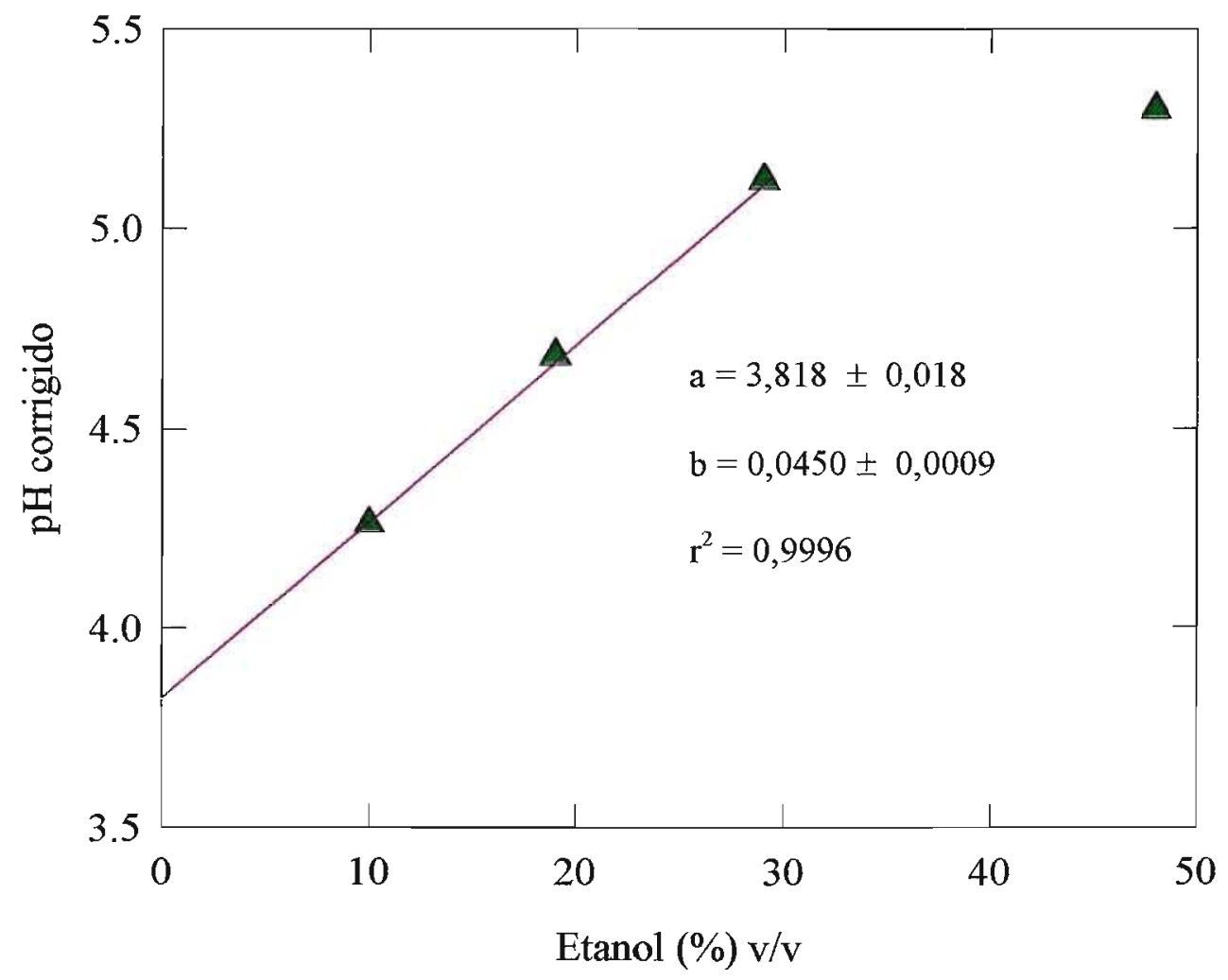

Figura 30 - Relação existente entre os valores experimentais de pHcorrigido do hidrogenoftalato de potássio e diferentes porcentagens de etanol-água, bem como os devios padrão dos parâmetros a e b. Curva teórica calculada com a equação (60). 
Conforme se verifica na Tabela XXIX com o aumento da porcentagem de etanol, até $29 \%$ em relação à água, há um aumento nos valores de pKs e consequente diminuição das constantes de dissociação/ionização, determinados potenciometricamente. Isto pode estar relacionado à diminuição da fração de água e da constante dielétrica do meio, conforme observa-se na Tabela XXVII.

Tabela XXIX - Valores dos pKs obtidos nas duas técnicas utilizadas, nas respectivas porcentagens de etanol.

\begin{tabular}{ccccc}
\hline \hline & \multicolumn{2}{c}{ potenciométrica } & \multicolumn{2}{c}{ espectrofotométrica } \\
\hline \% etanol & $\mathrm{pK}_{1}$ & $\mathrm{pK}_{2}$ & $\mathrm{pK}_{1}$ & $\mathrm{pK}_{2}$ \\
10 & 3,210 & 10,834 & 3,257 & 10,880 \\
19 & 3,342 & 11,013 & - & - \\
29 & 3,400 & 11,793 & - & - \\
48 & 3,362 & 11,382 & 3,322 & 11,820 \\
\hline \hline
\end{tabular}


As relações existentes entre as constantes de dissociação/ionização $\left(\begin{array}{lllllll}K_{1} & \mathrm{e} & \mathrm{K}_{2}\end{array}\right)$ e $\quad$ inverso da constante dielétrica do solvente estão apresentadas nas Figuras 31 e 32, respectivamente.

Sabe-se que o efeito eletrostático resultante da mudança da constante dielétrica do meio atua no coeficiente de atividade das espécies carregadas $\left(\mathrm{RNH}^{+}, \mathrm{RO}^{-} \text {e } \mathrm{H}^{+}\right)^{(88)}$. A magnitude deste efeito é inversamente proporcional ao raio das espécies iônicas consideradas, consequentemente o próton sofre influência maior, excedendo aquela das formas $\mathrm{RNH}^{+}$e $\mathrm{RO}^{-}$. Assim os valores das constantes de ionização/dissociação tendem a diminuir com o aumento da proporção do solvente orgânico no meio ${ }^{(89)}$. Esta tendência é apresentada nas Figuras 33 e 34 para o $\mathrm{K}_{1}$ e $\mathrm{K}_{2}$, respectivamente, até $29 \%$ de etanol, onde a fração molar $\left(\mathrm{X}_{\mathrm{EtOH}}\right)$ do etanol é dada por:

$$
\mathbf{x}_{\mathrm{EtOH}}=\frac{\mathbf{n}_{\mathrm{EtOH}}}{\mathbf{n}_{\mathrm{EtOH}}+\mathbf{n}_{\mathrm{H}_{2} \mathrm{O}}}
$$




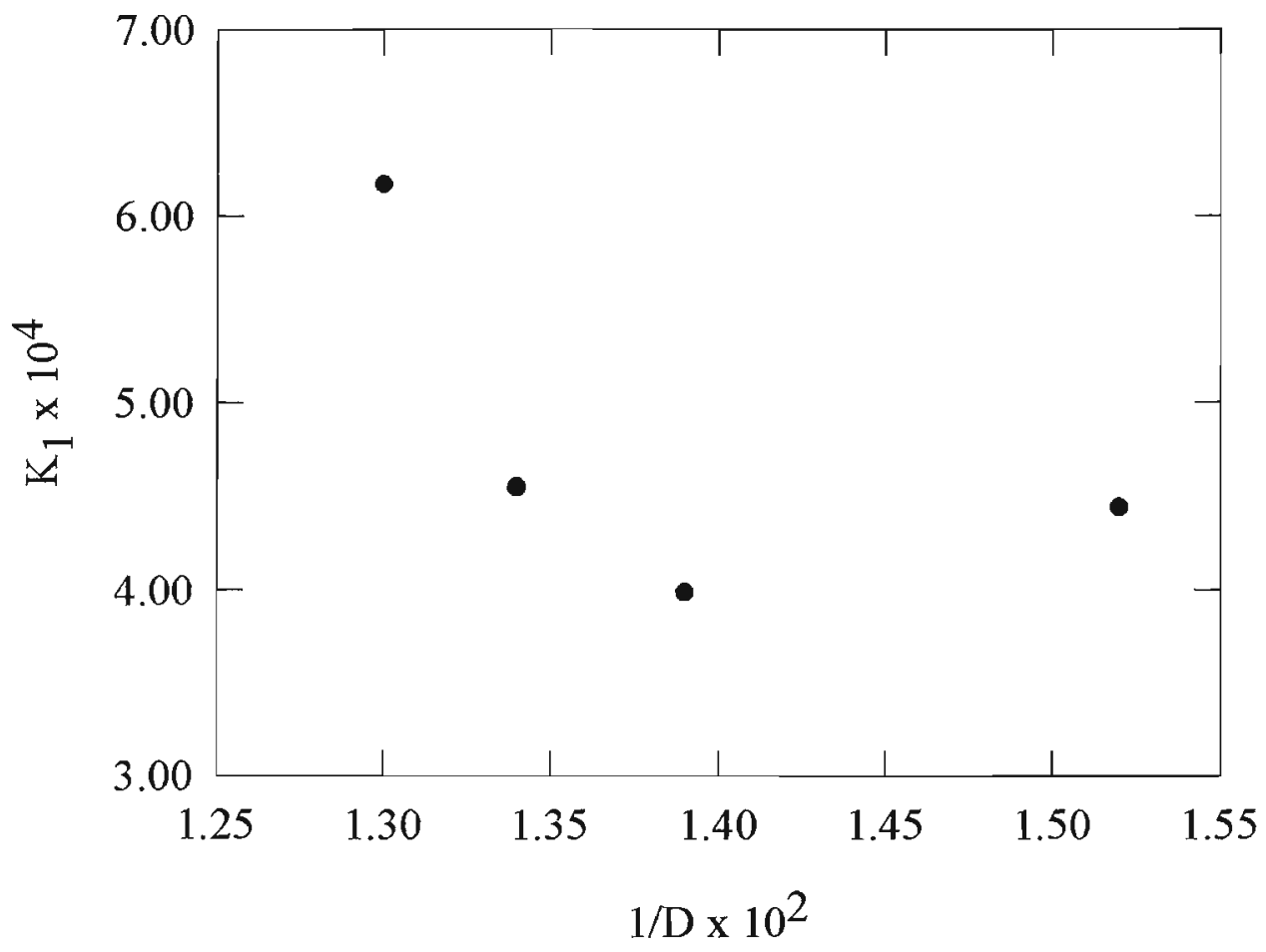

Figura 31 - Variação de $\mathrm{K}_{1}$, obtido potenciometricamente para o DPKBH, em função do inverso da Constante Dielétrica do meio etanol-água. 


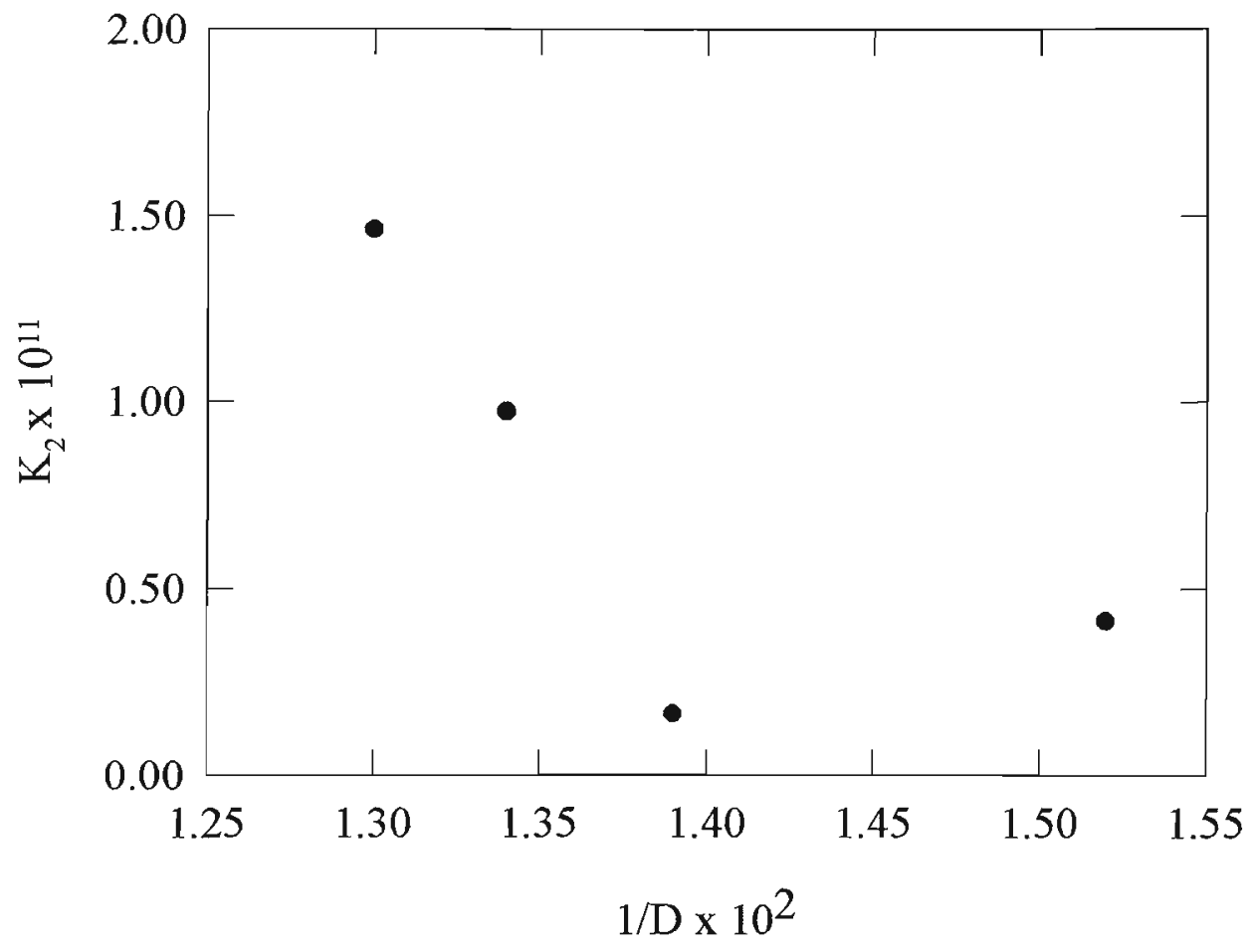

Figura 32 - Variação de $\mathrm{K}_{2}$, obtido potenciometricamente para o DPKBH, em função do inverso da Constante Dielétrica do meio etanol-água. 


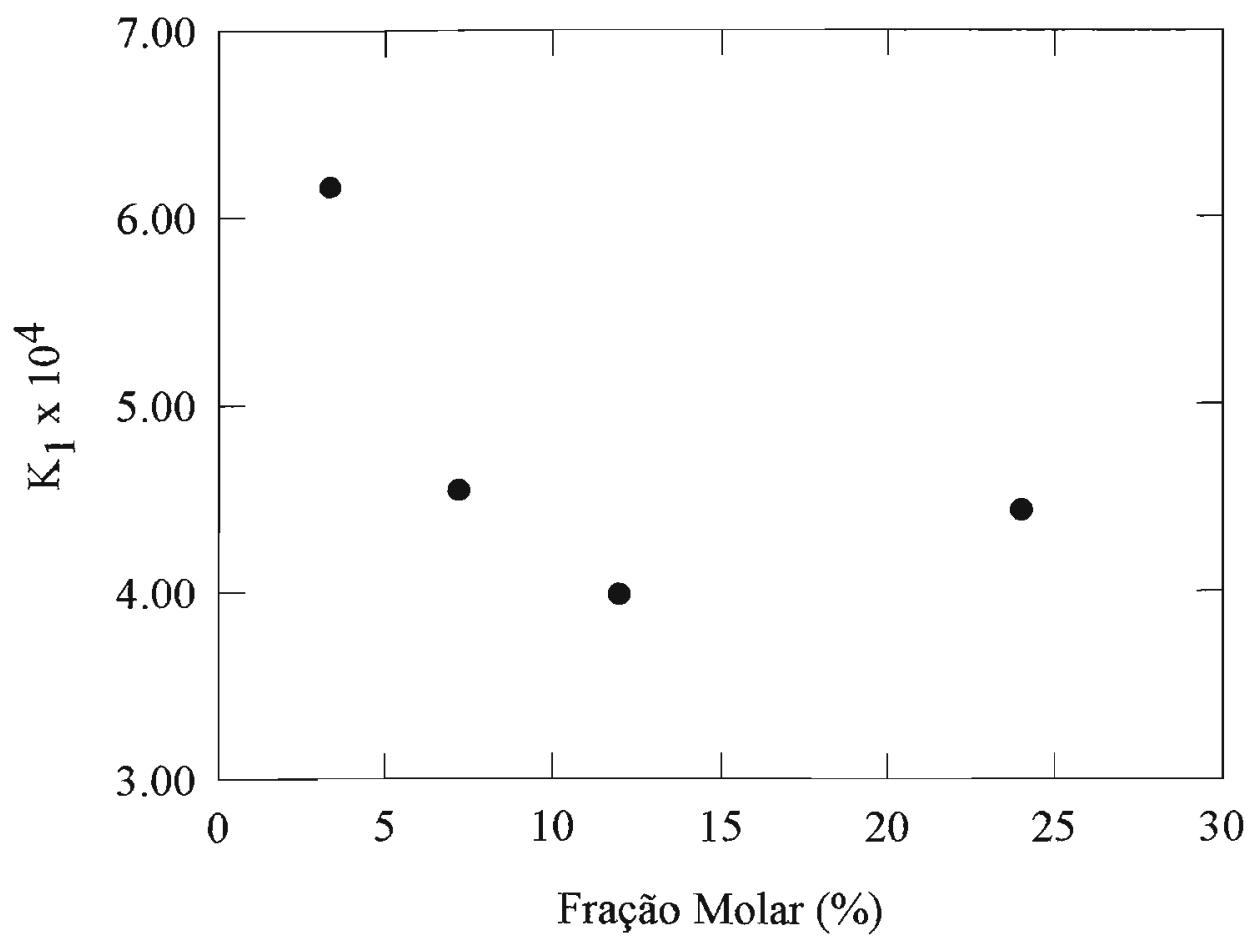

Figura 33 - Variação dos valores de $K_{1}$ para o DPKBH, obtidos por método potenciométrico em diferentes porcentagens de etanolágua, em função da Fração Molar do solvente orgânico. 


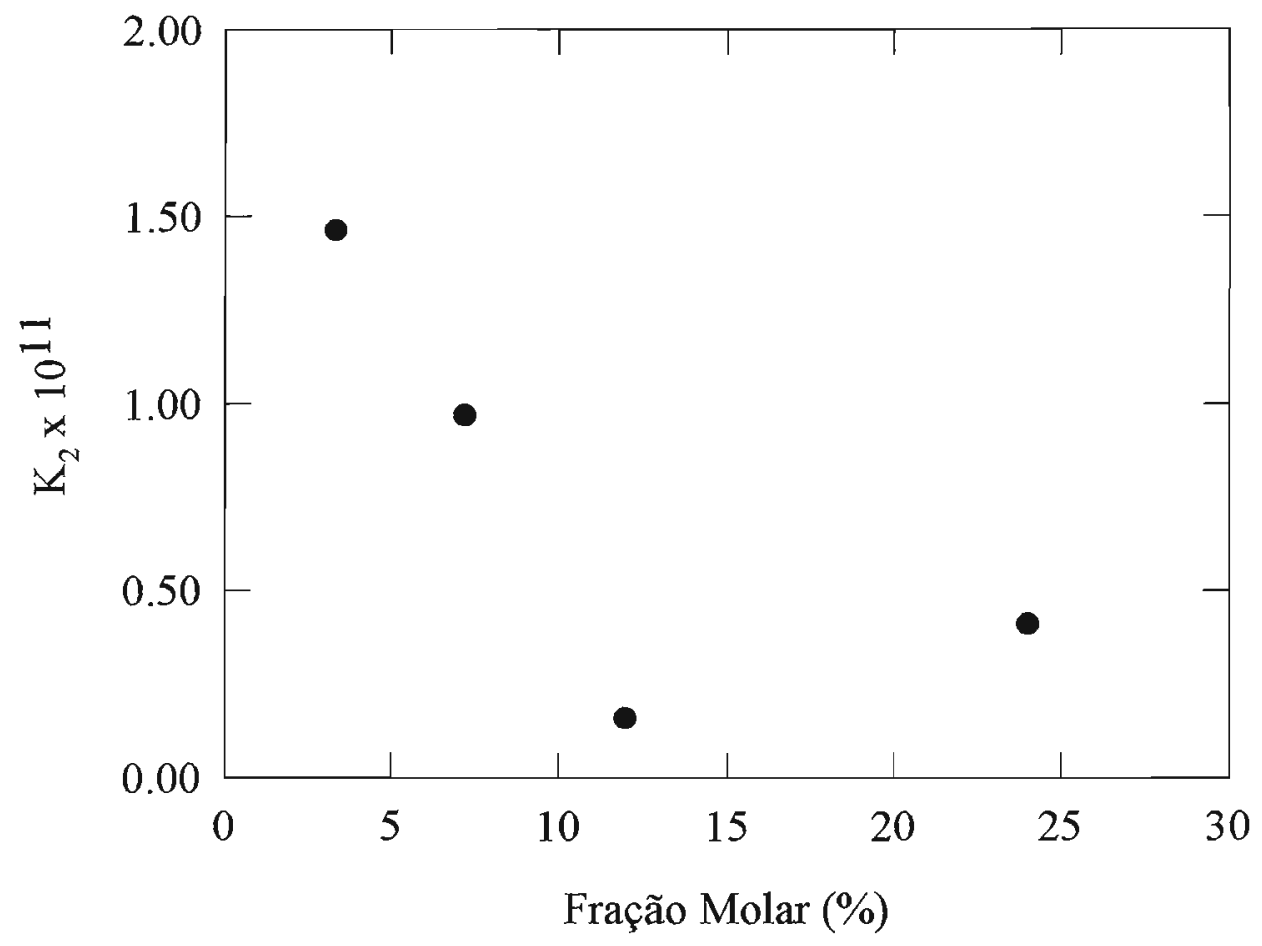

Figura 34 -Variação dos valores de $\mathrm{K}_{2}$ para o DPKBH, obtidos por método potenciométrico em diferentes porcentagens de etanolágua, em função da Fração Molar do solvente orgânico.

Porém as variações comentadas até o momento ocorrem somente até $29 \%$ de etanol. Em $48 \%$ desse solvente tem-se o 
aumento da constante de dissociação/ionização. Acredita-se que isto seja devido a outros fatores além do efeito eletrostático que atuam também no processo de dissociação/ionização.

$$
\text { Bates et } \mathrm{al}^{(73-75,90,91)} \text { e Chattopadhyay e Lahiri }{ }^{(92)}
$$

estudaram o efeito da mudança da composição do solvente nas constantes de dissociação e as energias de Gibbs em misturas de solventes. Nestas publicações indica-se que os efeitos da mudança eletrostática resultante da mudança da constante dielétrica com a composição do solvente são de menor importância na interpretação dos efeitos do solvente. Além desses autores muitos outros utilizam esta mesma afirmação para justificar o comportamento das constantes de dissociação/ionização em misturas de solventes como água-solventes orgânicos ${ }^{(66,77,93-95)}$.

Outro fator fundamental na determinação das constantes de equilíbrio é a influência da força iônica, já que interfere diretamente nos coeficientes de atividade das espécies iônicas presentes em equilíbrio. Estudo bastante aprofundado desta influência foi elaborado por Bertotti ${ }^{(62)}$ ao trabalhar em forças iônicas elevadas.

Uma avaliação sobre a força iônica foi feita no presente trabalho e considerada no uso tanto do método potenciómetrico quanto no espectrofotométrico, pois apesar de 
estar diretamente relacionada à coerência das medidas potenciométricas obtidas por processo de titulação não pode deixar de ser considerada no estudo espectrofotométrico, devido às interações que dela são dependentes.

Para efeito de cálculo da força iônica, considera-se que a mesma, em titulações envolvendo o $\mathrm{HClO}_{4}$ e $\mathrm{DPKBH}$, é representada a partir da soma das concentrações das espécies $\mathrm{RNH}^{+}$e $\mathrm{H}^{+}$no equilíbrio. Esta soma resulta igual à concentração de $\mathrm{ClO}_{4}^{-}$e consequentemente nos valores de $\mathrm{I}$, que são apresentados na Tabela XXX em 10 e $48 \%$ de etanol.

Para titulações envolvendo $\mathrm{NaOH}$ e $\mathrm{DPKBH}$ a força iônica é representada pela soma das concentrações das espécies $\mathrm{RO}^{-}$e $\mathrm{H}^{+}$no equilíbrio. Esta soma resulta na concentração de $\mathrm{Na}^{+}$ e consequentemente nos valores de I, que são apresentados na Tabela XXXI.

Observa-se nas Tabelas XXX e XXXI que a força iônica tanto em 10 como em $48 \%$ de etanol é baixa, na ordem de $10^{-4}$ a $10^{-3}$, sendo assim pode-se considerar que o coeficiente de atividade das espécies iônicas é próximo a unidade e que a concentração é igual à atividade das espécies participantes dos equilíbrios. Além disso pode-se considerar termodinâmicas as constantes de dissociação/ionização obtidas. 
Tabela XXX - Valores de força iônica em diferentes etapas da "titulação" DPKBH com $\mathrm{HClO}_{4}$, em 10 e $48 \%$ de etanol. As concentrações de $\mathrm{HClO}_{4}$ e DPKBH são $4,18.10^{-3}$ e $1,01.10^{-3}$ mol. $L^{-1}$ em $10 \%$ de etanol e $3,02.10^{-3}$ e $1,00.10^{-3}$ mol. $L^{-1}$ em $48 \%$ de etanol, respectivamente.

\begin{tabular}{cccccc}
\hline \hline \% Etanol & $\begin{array}{c}\text { Volume de } \\
\text { HClO }\end{array}$ & {$\left[\mathrm{RNH}^{+}\right]$} & {$\left[\mathrm{ClO}_{4}{ }^{-}\right]$} & {$\left[\mathrm{H}^{+}\right]$} & $\mathrm{I}$ \\
\hline 10 & 0,500 & $1,55 \mathrm{E}-04$ & $3,77 \mathrm{E}-04$ & $2,22 \mathrm{E}-04$ & $3,77 \mathrm{E}-04$ \\
10 & 1,00 & $2,58 \mathrm{E}-04$ & $6,91 \mathrm{E}-04$ & $4,33 \mathrm{E}-04$ & $6,91 \mathrm{E}-04$ \\
10 & 1,50 & $3,69 \mathrm{E}-04$ & $9,57 \mathrm{E}-04$ & $5,88 \mathrm{E}-04$ & $9,57 \mathrm{E}-04$ \\
10 & 2,00 & $4,23 \mathrm{E}-04$ & $1,19 \mathrm{E}-03$ & $7,63 \mathrm{E}-04$ & $1,19 \mathrm{E}-03$ \\
48 & 0,500 & $1,33 \mathrm{E}-04$ & $2,72 \mathrm{E}-04$ & $1,39 \mathrm{E}-04$ & $2,72 \mathrm{E}-04$ \\
48 & 1,00 & $2,58 \mathrm{E}-04$ & $4,99 \mathrm{E}-04$ & $2,41 \mathrm{E}-04$ & $4,99 \mathrm{E}-04$ \\
48 & 1,50 & $3,24 \mathrm{E}-04$ & $6,92 \mathrm{E}-04$ & $3,68 \mathrm{E}-04$ & $6,92 \mathrm{E}-04$ \\
48 & 2,00 & $3,88 \mathrm{E}-04$ & $8,57 \mathrm{E}-04$ & $4,69 \mathrm{E}-04$ & $8,57 \mathrm{E}-04$ \\
\hline
\end{tabular}

Os valores dos pKs obtidos no presente estudo em $10 \%$ de etanol podem ser comparados com dados da literatura $^{(2)}$, a Tabela XXXII reune esses valores dos pKs. Podese observar que os valores de $\mathrm{pK}_{1}$ e $\mathrm{pK}_{2}$ encontrados 
espectrofotometricamente por Nakanishi e Otomo ${ }^{(2)}$ e os obtidos no presente estudo apresentaram-se bastante concordantes, nas duas técnicas utilizadas.

Tabela XXXI - Valores de força iônica em diferentes etapas da "titulação" DPKBH com NaOH, em 10 e $48 \%$ de etanol. As concentrações de $\mathrm{NaOH}$ e DPKBH são $9,49.10^{-3}$ e $5,24.10^{-3}$ mol. $L^{-1}$ em $10 \%$ de etanol e $1,00.10^{-3}$ e $3,00.10^{-3}$ mol. $L^{-1}$ em $48 \%$ de etanol, respectivamente.

\begin{tabular}{cccccc}
\hline \hline \% Etanol & $\begin{array}{c}\text { Volume } \\
\text { de NaOH }\end{array}$ & {$\left[\mathrm{RO}^{-}\right]$} & {$\left[\mathrm{Na}^{+}\right]$} & {$\left[\mathrm{H}^{+}\right]$} & $\mathrm{I}$ \\
\hline 10 & 1,30 & $1,94 \mathrm{E}-04$ & $1,94 \mathrm{E}-04$ & $1,60 \mathrm{E}-11$ & $1,94 \mathrm{E}-04$ \\
10 & 1,35 & $2,00 \mathrm{E}-04$ & $2,00 \mathrm{E}-04$ & $1,50 \mathrm{E}-11$ & $2,00 \mathrm{E}-04$ \\
10 & 1,40 & $2,06 \mathrm{E}-04$ & $2,06 \mathrm{E}-04$ & $1,40 \mathrm{E}-11$ & $2,06 \mathrm{E}-04$ \\
10 & 1,60 & $2,28 \mathrm{E}-04$ & $2,28 \mathrm{E}-04$ & $1,16 \mathrm{E}-11$ & $2,28 \mathrm{E}-04$ \\
48 & 0,750 & $3,88 \mathrm{E}-04$ & $3,88 \mathrm{E}-04$ & $4,31 \mathrm{E}-12$ & $3,88 \mathrm{E}-04$ \\
48 & 0,800 & $4,11 \mathrm{E}-04$ & $4,11 \mathrm{E}-04$ & $4,11 \mathrm{E}-12$ & $4,11 \mathrm{E}-04$ \\
48 & 0,900 & $4,54 \mathrm{E}-04$ & $4,54 \mathrm{E}-04$ & $3,82 \mathrm{E}-12$ & $4,54 \mathrm{E}-04$ \\
48 & 1,00 & $4,96 \mathrm{E}-04$ & $4,96 \mathrm{E}-04$ & $3,55 \mathrm{E}-12$ & $4,96 \mathrm{E}-04$
\end{tabular}


Tabela XXXII - Valores dos pKs do presente trabalho e da literatura ${ }^{(1)}$ em $10 \%$ de etanol.

\begin{tabular}{ccc}
\hline \hline Métodos & $\mathrm{pK}_{1}$ & $\mathrm{pK}_{2}$ \\
\hline espectrofotométrica $^{*}$ & 3,257 & 10,880 \\
potenciométrica $^{*}$ & 3,210 & 10,834 \\
espectrofotométrica $^{* *}$ & 3,180 & 10,870
\end{tabular}

* Presente Trabalho

${ }^{* *}$ Nakanishi e Otomo ${ }^{(1)}$

Finalmente, uma comparação mais efetiva com os dados da literatura torna-se prejudicada pela falta de detalhes sobre o método espectrofotométrico empregado, calibração de eletrodo, medidas de $\mathrm{pH}$, e outros. 


\section{IX - PERSPECTIVAS FUTURAS}




\section{IX - PERSPECTIVAS FUTURAS}

Muitas perguntas persistem e há muitos caminhos a seguir.

Como se comporta o hidrogenoftalato de potássio nas porcentagens de etanol mais próximas de $50 \%$ ? Haverá alguma alteração na sua dissociação ou até solubilização ? Assim, a utilização de outros tampões (diferentes pKs e solubilidades) para a calibração do sistema potenciométrico deve ser explorada. Regiões de $\mathrm{pH}$ mais próximas às do presente estudo devem ser atingidas, por exemplo: $\mathrm{pH}=10-11$. Além disso seria bastante esclarecedor determinar o "slope" do eletrodo de vidro nas faixas de $\mathrm{pH}$ maiores.

Investigação da probabilidade da formação da espécie $\mathrm{RH}_{2}{ }^{2+}$. Utilização do método espectrofotométrico para a determinação da constante dessa espécie principalmente em $48 \%$ de etanol.

Para finalizar, diversos esclarecimentos poderiam ser alcançados ao se comparar o processo de correção de $\mathrm{pH}$ utilizado no presente trabalho com os demais encontrados na literatura, principalmente o de Bates et al. ${ }^{(74)}$, Van Uitert e Hass ${ }^{(65)}$ e Lahiri 
e Aditya ${ }^{(64)}$. Para isso, os mesmos sistemas e condições (compostos, temperatura e porcentagens do solvente) poderiam ser utilizados associados às medidas de $\mathrm{pH}$ obtidas e corrigidas com a sistemática apresentada nesta dissertação. 


\section{X-REFERÊNCIAS BIBLIOGRÁFICAS}




\section{X - REFERÊNCIAS BIBLIOGRÁFICAS}

1. Nakanishi e M. Otomo, Microchemical Journal, 33, 172 (1986).

2. M. Garcia-Vargas, M. Belizón, M.P. Hernãndez - Artigo, C. Martinez e J.A. Perez-Bustamante, Applied Spectroscopy, 40, $1058(1986)$.

3. S.O. Pehkonen, Y. Erel e M.R. Hoffmann, Environm. Eng. Science, 26, 1731 (1992).

4. Y.Erel, S.O. Pehkonem e M.R. Hoffmann, J. Geophys. Res., 98D, 18423 (1993).

5. M.E.V. Suárez-Iha, S.O. Pehkonen e M.R. Hoffmann, Environ. Scien. Technol., 28, 2080 (1994).

6. M. Katyal e Y. Dutt, Talanta, 22, 151 (1975).

7. R.B. Singh, P. Join e R.P. Singh, Talanta, 29, 77 (1982).

8. M. Mohan, M.P. Gupta, L. Chang e N.K. Jha, Inorg. Chim. Acta., 61, $151(1988)$.

9. Zh.V. Molodykh, B.I. Buzykin, N.N. Bystrykh e Yu.P. Kitaev, Khim. Farm. Zh., 11, 37 (1978). Apud: Chem. Abstr., 88, $989280 y$.

10.B. Budesinsky, Chem. Listy, 54, 916 (1960).

11.V.A. Terentév e R.K. Andreeva, Zh. Anal. Khim., 23, 1089 (1968). 
12.R.E. Peterson e M.E. Bollier, Anal. Chem., 27, 1195 (1955).

13. E. Somers e J.L. Garraway, Chem. Ind., 395, 1957.

14. K.R. Middleton, Analyst, 90, 234 (1965).

15.L.J.A. Haywood e P. Sutcliff, Analyst, 81, 651 (1956).

16. G. Brown e R.K. Rohde, Anal. Chem., 38, 911 (1966).

17.F.C. Frouty, Anal. Chim. Acta, 47, 511 (1969).

18.A.J. Comeron e N.A. Gibson, Anal. Chim. Acta, 51, 249 (1970).

19.idem, ibidem, 51, 257 (1970).

20.K.T. Lee, Y.F. Chang e S.F. Tan, Mikrochimica Acta, 2, 505 (1976).

21.T.H. Kowimtzis, C. Apostolopoulos e I. Staphilakis, Anal. Chim. Acta, 113, $185(1980)$.

22.J.E. Going e R.T. Pflaum, Anal. Chem., 42, 1098 (1970).

23.F. Grases e F. Garcia-Sanchez, Anal. Chim. Acta, 119, 359 (1980).

24.M.A. Al-Nuri, M. Abu-Eid, N.A. Zatar, S. khalofi e M. Hannoun, Anal. Chim. Acta, 259, 175 (1992).

25.W. Hirsch, Analyst, 73, 160 (1948).

26.E.K. Libergott, C.L.S. Roquette-Pinto e P.L.A. Aguiar Neto, Anal. Chim. Acta, 101, 229 (1978). 
27.R.W. Green, P.S. Hallman e F. Lions, Inorg. Chem., 3, 1541 (1964).

28.R.W. Green, P.S. Hallman e F. Lions, Inorg. Chem., 3, 376 (1967).

29.P. Umapathy e N.A. Roju, Indian J. Chem.,1, 272 (1963).

30.N.A. Zatar, A.Z. Abu-Zuhri, M.A. Al-Nuri, F.M. Mahmoud e A.A. Abu-Obaid, Spectroscopy Letters, 22, 1203 (1989).

31.T. Nakanishi e M. Otomo, Analytical Sciences, 1, 161(1985).

32.N.A. Zatar, M.A. Al-Nuri, M. Abu-Eid, M. Hannoun, A.Z. Abu-Zuhri, S. Khalaf e M. Khamis, Spectroscopy Letters, 24, $1145(1991)$.

33.M.V.Rossi, M.E.V. Suárez-Iha e M.R.Hoffmann, Spectroscopy Letters, 28, 1153 (1995).

34.L.H.S.A. Terra e M.E.V. Suárez-Iha, Spectroscopy Letters, no prelo.

35.M.M Kamal, A.Z. Abu Zuhri e M.M. Hannoun, Fresenius J. Anal Chem., 344, 275 (1992).

36.A.L. Lehninger - "Biochemistry", Worth Publishers, Inc., 4ed., p.48 (1977).

37.G.N. Lewis e M. Randall, J.Am. Chem. Soc., 43, 436 (1921).

38.P.Debye e E. Hückel, Phys. Z., 24, 185 (1923). 
39.B.Damanskin e O.Petri, "Fundamentos da Eletroquímica Teórica", Mir, Moscou (1978).

40.A.I.Vogel, “Análise Química Quantitativa", $5^{\text {a }}$ ed, editora Guanabara Koogan, Rio de Janeiro, p.451 (1992).

41.M.T.Beck, "Chemistry of Complex Equilíbria", Van Nostrand, London (1970).

42.A. Albert e E.P. Sargent; "Ionization Constants of Acids and Bases", Methven \& Coltd, $1^{\text {a }}$. ed., London, p.16 (1962).

43.O. Redlich e G. C. Hood, Disc. Farad. Soc., 24, 87 (1957).

44.J.F.J. Dippy, Chem. Rev., 25, 151 (1939).

45.I. Giolito, "Métodos Eletrométricos e Eletroanalíticos". Multitec, 2 ed., p. 41, 118 (1980).

46.K.A. Rubinson, "Chemical Analysis", Little Brown and Company, Canada, p.390 (1986).

47.H.H.Willard, L.L.Merritt Jr., J.A.Dean e F.A. Settle Jr., "Instrumental Methods of Analysis", p.390, 7ªed., Wadsworth Publishing Company, California, p.390 (1988).

48.H.S. Harned e R.W. Ehlers, J. Amer. Chem. Soc., 54, 1350 (1932).

49.J. Inczedy, "Analytical Application of Complex Equilibria", Ellis Horwood Ltd, England, p.89 (1976). 
50.H.Rossotti, "The study of ionic equilibria", Longman Inc., New York (1978).

51.L.W.Potts, "Quantitative Analysis, Theory and Practice", Harper \& Row Publishers, New York, p.478 (1987).

52.M. Kil Patrick, J. Amer. Chem. Soc., 56, 2048 (1934).

53.E. Eisemman (Eds.), "Glass Electrode for Hydrogen and Other Cation", Marcel Dekker, New York (1967).

54.F. Haber, Z.Z. Klemensiewicz, Physik. Chem., 67, 385 (1909). 55.R.C. Pereira, "Construção, Avaliação e Aplicação Analítica de Eletrodos Seletivos Sensíveis a Salicilato", Dissertação de Mestrado, Instituto de Química - UNICAMP, São Paulo (1987). 56.B.H. Vassos, G.W. Ewing, "Eletroanalytical Chemistry", John Willey, New York (1983).

57.P.M. May, D.R. Williams, P.W. Linder e R.G. Torrington, Talanta, 29, 249 (1982).

58.C.F.F. Lopes, "Determinação das Constantes de Estabilidade para os Sistemas Lantânio (III) com Formiato, Acetato e Propionato", Dissertação de Mestrado, Instituto de Química, USP, São Paulo (1994).

59.H.M. Irving, M.G. Miles, L.D. Pettit,Anal. Chim. Acta, 38, 475 (1967). 
60.L.Angnes - "Estudos Potenciométricos e Espectrofotométricos dos Sistemas $\mathrm{UO}_{2}{ }^{++} / \mathrm{SCN}^{-}, \mathrm{H}^{+}$e $\mathrm{HNCS} / \mathrm{SCN}^{-}$.", IQ - USP, São Paulo (1986).

61.W.A.E. Mc Bryde, The Analyst, 94, 337 (1969).

62.M. Bertotti - "Estudos Potenciométricas sobre a Formação de Complexos entre Indio(III) e Azoteto, em meio aquoso.", Dissertação de Mestrado, IQ - USP, São Paulo (1986).

63.T.V. Silva e E.A. Neves, Anais do IV Simp. Bras. Eletroq. e Eletroan., USP/UFSCar, São Paulo, p. 63 (1984).

64.S.C. Lahiri e S. Aditya, J. Indian Chem. Soc., 51, 319 (1974).

65.L.G. Van Uitert, C.G. Haas, W.C. Fernalius e B.E. Douglas, J. Am. Chem. Soc., 75, 455 (1953).

66.D.K. Hazra e S.C. Lahiri, J. Indian Chem. Soc., 53, 787 (1976).

67.idem, Anal. Chim. Acta, 79, 335 (1975).

68.idem, J. Indian Chem. Soc., 53, 567 (1976).

69.S.K. Maity e S.C. Lahiri, Z. Phys. Chemie, 263, 183 (1982).

70.A. K. Bhottacharyya, D. Sengupta e S.C. Lahiri, Z. Phys. Chemie, 265, 372 (1984).

71.C.C. Deb, D.K. Hazra e S.C. Lahiri, Z. Phys. Chemie, 266, 158 (1985) 
72.H.S. Harned e B.B.Owen, "Physical Chemistry of Electrolytic Solutions", 2nd ed., Reinhold Pub. Corp., New York, N.Y., p. $548(1950)$.

73.R.G. Bates, "Determination of $\mathrm{pH}$, Theory and Practice", Wiley, New York, 2nd ed., p.211 (1973).

74.R.G. Bates, M. Paabo e R.A. Robinson, J.Phys.Chem., 67, $1833(1963)$.

75.R.G. Bates, Crit. Rev. Anal. Chem., 10, 248 (1981).

76.G.Douhéret, Bull. Soc. Chim. Fr., 8, 3122 (1968).

77.A.A.A. Boraei e I.T. Ahmed, J. Chem. Eng. Data, 41, 787 (1996).

78.H.M.N.H. Irving e U.S. Manhot, J. Inorg. Noclear Chem., 30, $1215(1968)$.

79.H. Siegel, A. Zuberbühler e O. Yamaushi, Anal. Chim. Acta, $63,255(1991)$.

80.W. Strenstrom, N. Goldsmith, J. Phys. Chem., 20, 1683 (1926).

81.A.G. Asuero, M.J. Navas, J.L. Jimenez-Trillo, Talanta, 33, 195 (1986).

82.A.K. Lunn e R.A. Morton, Analyst, 77, 718 (1952).

83.L. Sacconi, J. Phys. Coll. Chem., 54, 829 (1950).

84.F. Ingman, Talanta, 20, 993 (1973).

85.G.R. Hedwing e H.K.J. Powell, Anal.Chem., 43. 1206 (1971). 
86.G. Alkerlof, J. Amer. Chem. Soc., 54, 4125 (1932).

87.M.Yu.Gorina e L.N. Seregina,Soviet Electrochemistry, 8, 804 (1972)

88.J.F. Coetzee e C.D. Ritchie, "Solute-Solvent Interactions", Dekker, New York, p. 68,75, 221, 229 (1969).

89.S.A. El-Gyar, M.M.A. Hamedm, E.M. Abdalla e M.R. Mahmoud, Monatshefte für Chemie, 124, 127 (1993).

90.M. Paabo, R.G. Bates e R.A. Robinson, J. Phys. Chem., 70, $247(1965)$.

91.R.G. Bates, J. Electroanal. Chem., 29, 1 (1971).

92.A.K.Cgattopadhyay e S.C. Lahiri, Electrochim. Acta, 27, 269 (1982).

93.M.S.K. Niazi e J. Mollin, Bull. Chem. Soc. Japan., 60, 2605 (1987).

94.C.C. Panichajakul e E.M. Woolley, Anal. Chem., 47, 1880 (1975).

95.E. Kiliç, F. Koseoglu e O. Basgut, Anal. Chim. Acta, 294, 215 (1994). 
GLOSSÁRIO 


\section{GLOSSÁRIO}

$\{a\}$

A

que

$\mathrm{A}_{\mathrm{HL}}$

$\mathrm{A}_{\mathrm{L}}$

A mist.

$\phi$

$\mathrm{A}_{\mathrm{RN}}, \mathrm{A}_{\mathrm{ROH}}$

$\mathrm{A}_{\mathrm{RNH}+}$

ARO-

B

$B^{\prime}$ e $C^{\prime}$ atividade das espécies

absorbância ou constante (eq. de Debye-Hückel)

em solução aquosa e a $25^{\circ} \mathrm{C}$ é igual a 0,509

absorbância da espécie protonada

absorbância da espécie desprotonada

absorbância da mistura

anel benzênico

absorbância da di-2-piridil cetona benzoil-

hidrazona totalmente na forma neutra

absorbância da di-2-piridil cetona benzoil-

hidrazona totalmente na forma protonada

absorbância da di-2-piridil cetona benzoil-

hidrazona totalmente na forma aniônica

símbolo para escala de $\mathrm{pH}$ em soluções não

aquosas ou constante (eq. de Debye-Hückel) que

depende da constante dielétrica do solvente e da

temperatura

parâmetros empíricos utilizados nas equações de aproximações da teoria de Debye-Hückel. 


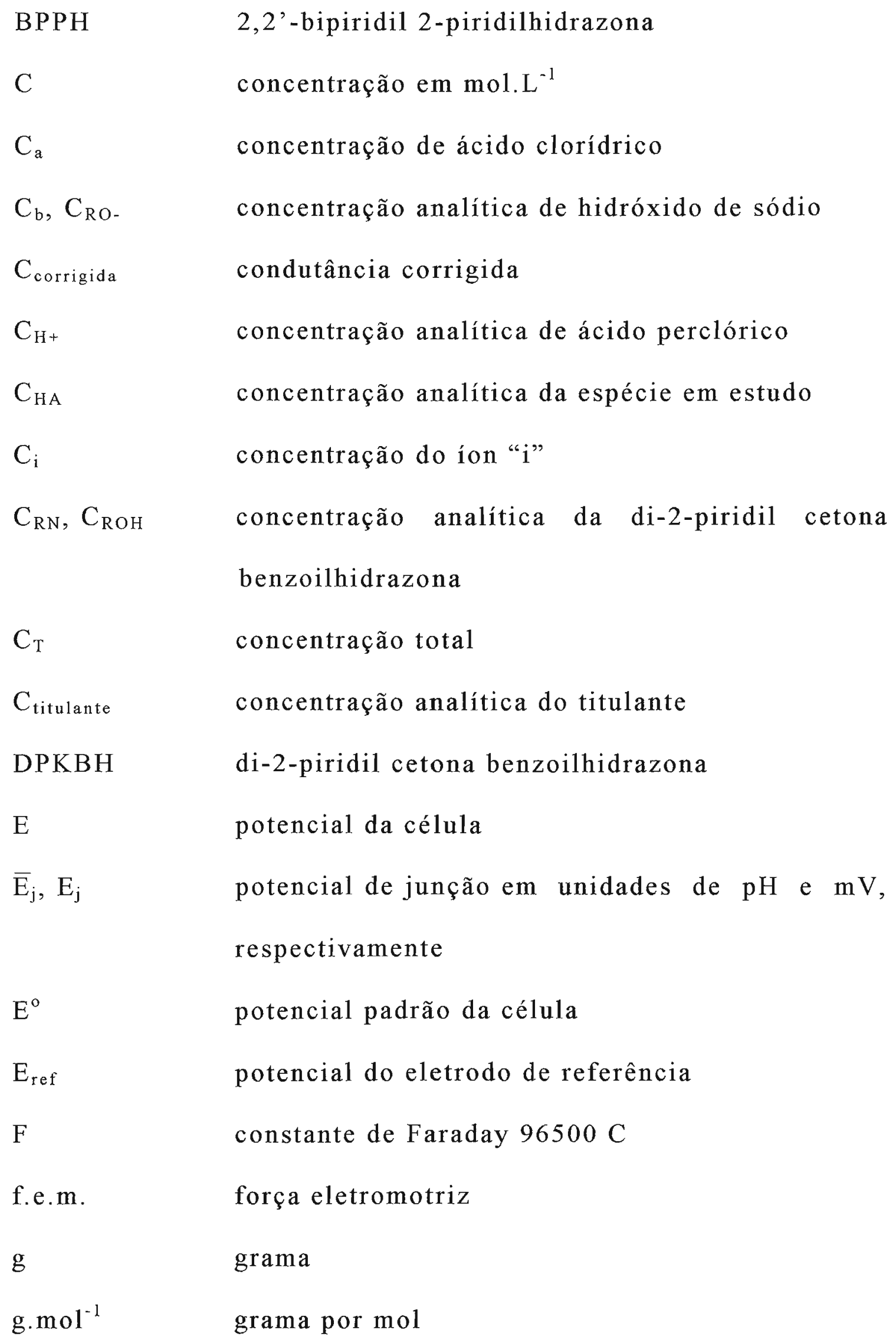




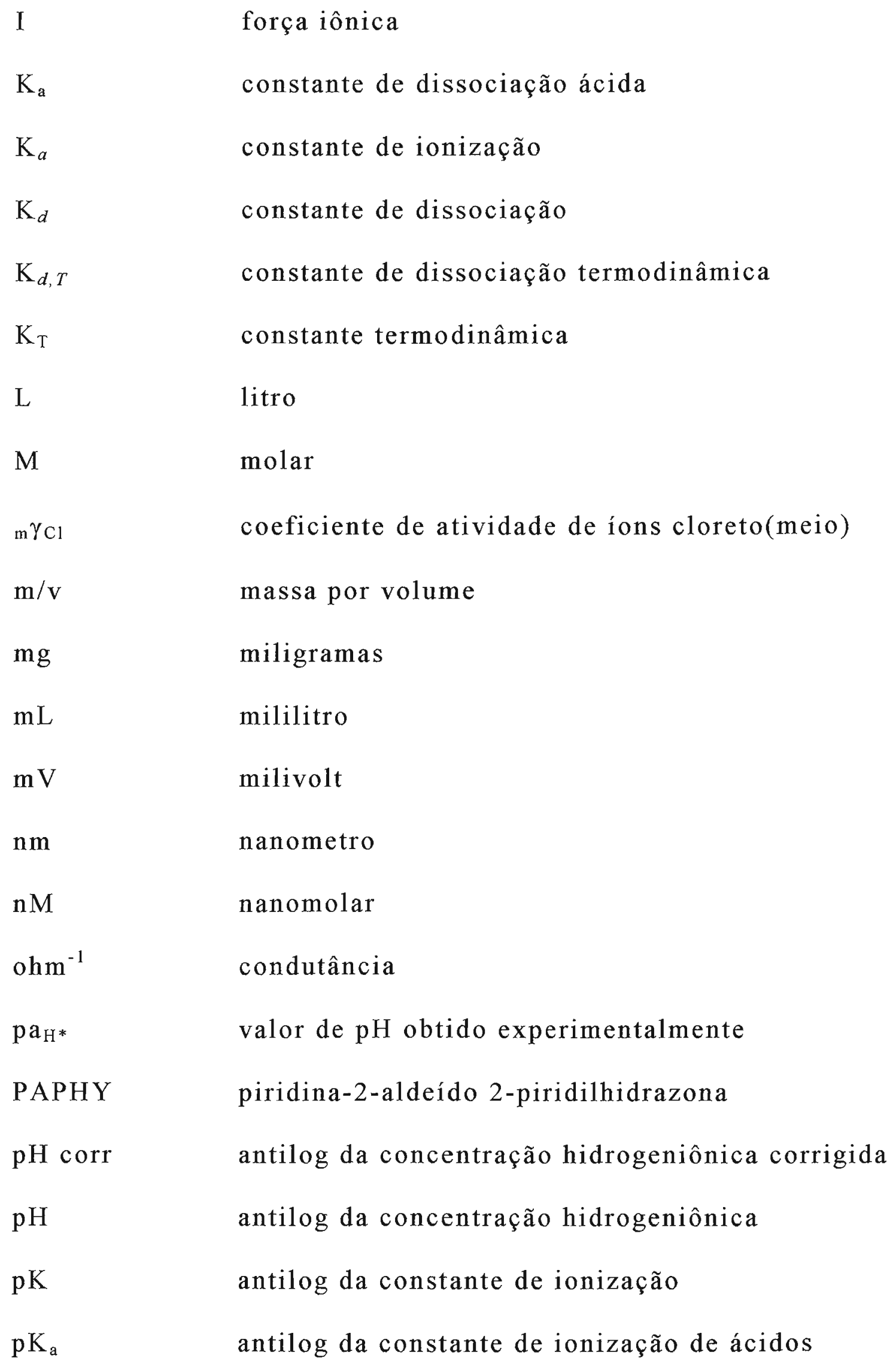




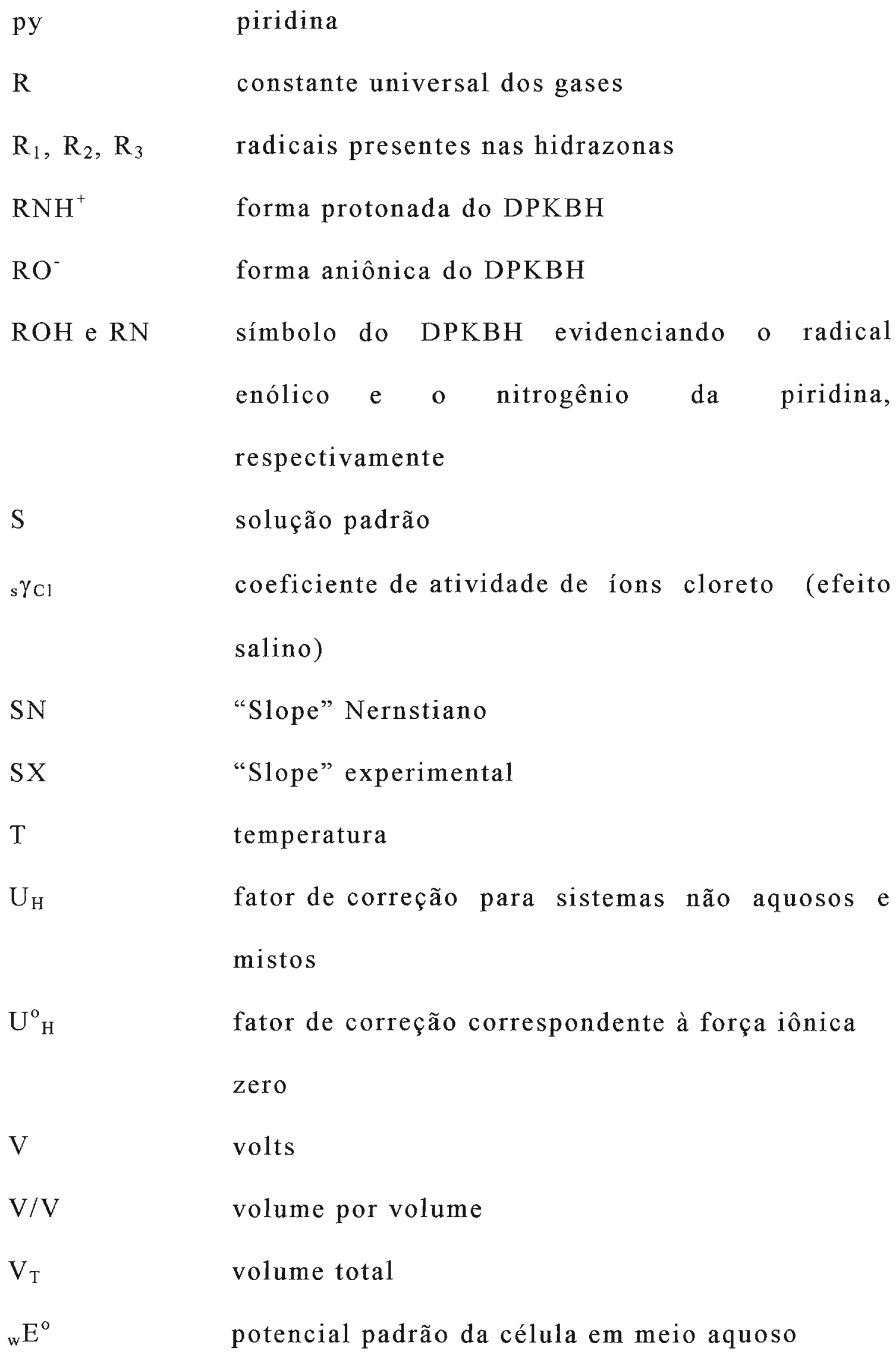




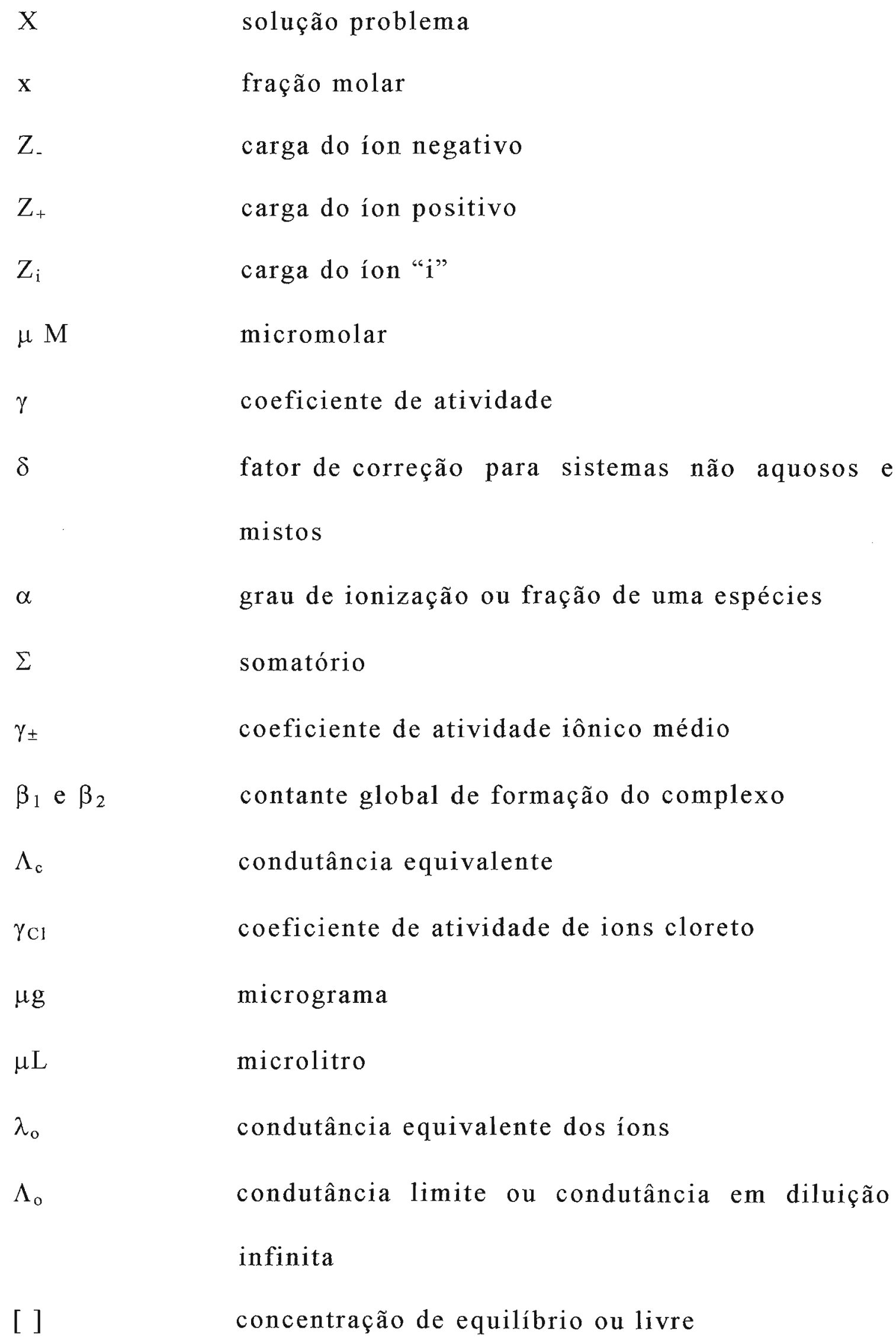

